\title{
DEMONSTRATION OF AN INTEGRATED APPROACH TO MERCURY CONTROL AT LEE STATION
}

Final Report

\author{
Prepared by: \\ Vitali Lissianski and Pete Maly,
}

U.S. DOE Contract No. DE-FC26-05NT42310

U.S. DOE Project Officer Lynn Brickett

September 8, 2007

Submitted by:

GE Energy

Energy and Environmental Research Corporation (GE EER)

1831 E. Carnegie Ave, Santa Ana, CA 92705 


\section{$\underline{\text { Disclaimer }}$}

This report was prepared as an account of work sponsored by an agency of the United States Government. Neither the United States nor any agency thereof, nor any of their employees, makes any warranty, express or implied, or assumes any legal liability or responsibility for the accuracy, completeness, or usefulness of any information, apparatus, product, or process disclosed, or represents that its use would not infringe privately owned rights. Reference herein to any specific commercial product, process, or service by trade name, trademark, manufacturer, or otherwise does not necessarily constitute or imply its endorsement, recommendation, or favoring by the United States Government or any agency thereof. The views and opinions of authors expressed herein do not necessarily state or reflect those of the United States Government or any agency thereof. 


\section{Table of Contents}

\section{Section}

Table of Contents .................................................................................................................................................. ii

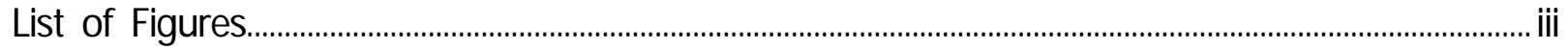

List of Tables....................................................................................................................................................... iv

Revision History ..................................................................................................................................... iv

Executive Summary ................................................................................................................................

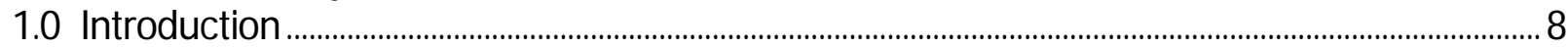

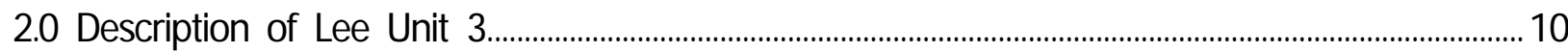

3.0 Combustion Optimization.................................................................................................................11

3.1 Baseline Mercury Testing..............................................................................................................

3.2 Riffle Boxes.........................................................................................................................................13

3.3 Coal Balancing................................................................................................................................. 14

3.4 Air Flow Balancing..................................................................................................................... 15

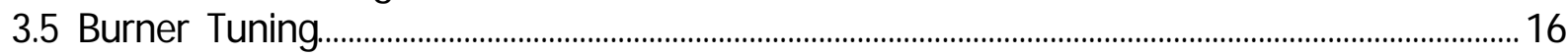

3.6 Mercury Emissions at Optimized Combustion Conditions..........................................................17

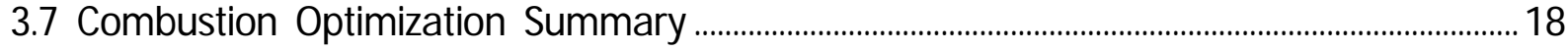

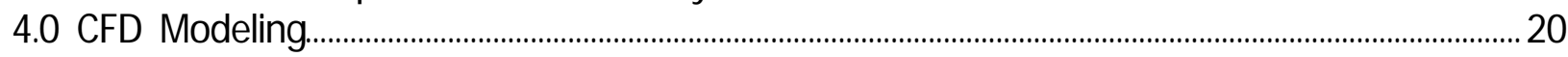

4.1 CFD Model Setup.......................................................................................................................2

4.2 CFD Modeling Approach and Boundary Conditions.................................................................2

4.3 Baseline Study..................................................................................................................................25

4.4 Humidification Study.................................................................................................................2 26

4.4 Sorbent Injection Study........................................................................................................... 28

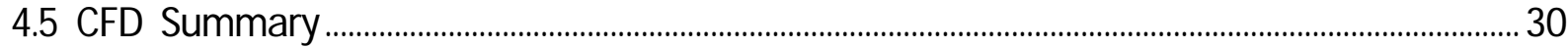

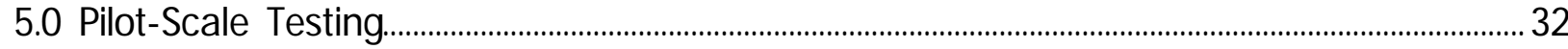

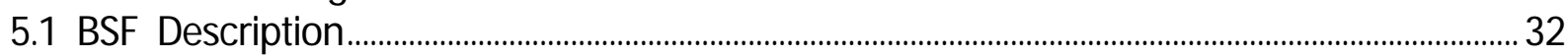

5.2 Sorbent Performance Data ...................................................................................................................

5.3 Pilot-Scale Summary .................................................................................................................... 34

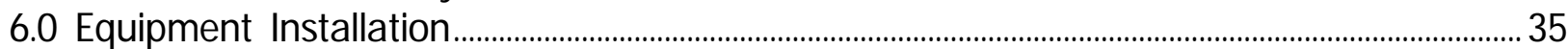

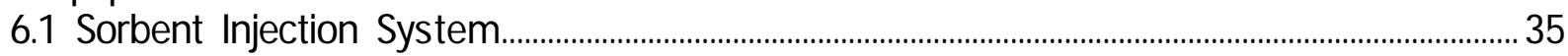

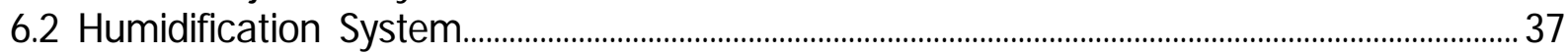

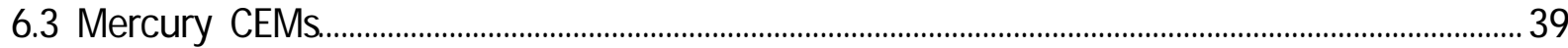

7. 0 Optimization of Humidification and Sorbent Injection Systems................................................ 41

7.1 Optimization of Humidification System .................................................................................... 41

7.2 Baseline and Sorbent Optimization Tests.......................................................................................4 43

7.3 System Optimization Summary ......................................................................................................... 45

8.0 Continuous Sorbent Injection......................................................................................................4

8.1 Ontario Hydro Measurements....................................................................................................4

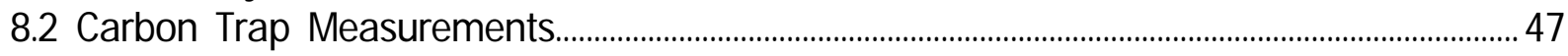

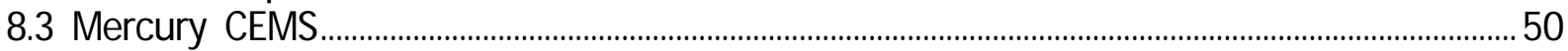

8.3.1 Mercury CEMS Data....................................................................................................................50 
8.3.2 Mercury Reduction........................................................................................................................52

8.4 Sorbent Injection Summary ...................................................................................................................53

9.0 Effect of $\mathrm{SO}_{3}$ on Sorbent Performance..............................................................................................5

9.1 DARCO ${ }^{\circledR} \mathrm{Hg}$ and DARCO ${ }^{\circledR} \mathrm{HgE25C}$ Performance...................................................................54

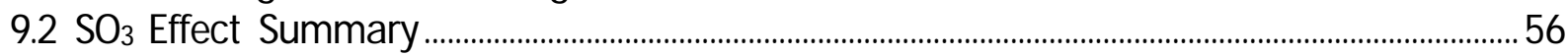

10.0 Economics of Mercury Control..........................................................................................................5

11.0 Effect of Sorbent Injection on ESP.............................................................................................6

Attachment A. Mercury CEM Data..................................................................................................................61

\section{List of Figures}

Figure 1. Lee station Unit 3...................................................................................................................10

Figure 2. Riffle boxes..................................................................................................................................13

Figure 3. Carbon and mercury content in ash measured in samples taken at ESP inlet ducts.

Figure 4. Riffle box layout with damper positions...............................................................................15

Figure 5. Coal flow deviations before and after balancing ................................................................

Figure 6. Duct geometry for CFD modeling ......................................................................................21

Figure 7. Temperature distribution across ESP inlet duct......................................................................22

Figure 8. Lance layout for the humidification system.........................................................................23

Figure 9. Water droplet size distribution ..................................................................................................23

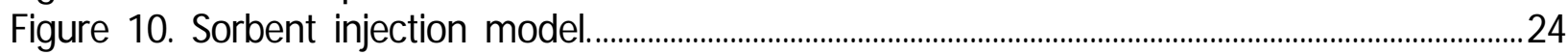

Figure 11. Sorbent particle size distribution..........................................................................................24

Figure 12. Baseline velocity profiles in the duct.................................................................................25

Figure 13. Temperature profiles in the duct....................................................................................26

Figure 14. Water droplets trajectories colored by residence time.........................................................27

Figure 15. Water droplet concentration. .............................................................................................27

Figure 16. Temperature profiles in the duct...........................................................................................28

Figure 17. Sorbent injection lances ........................................................................................................29

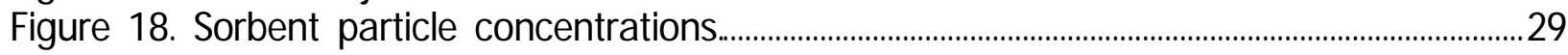

Figure 19. Temperature distribution ........................................................................................................30

Figure 20. Sorbent trajectories colored by residence time..................................................................30

Figure 21. Boiler Simulator Facility (BSF)........................................................................................32

Figure 22. Effect of sorbent injection on mercury removal................................................................34

Figure 23. Sorbent injection system .....................................................................................................36

Figure 24. Arrangement for sorbent injection..................................................................................36

Figure 25. Installed sorbent injection system at Lee station...............................................................37

Figure 26. Lances for water injection.............................................................................................38

Figure 27. Pump skid and valve assembly............................................................................................39

Figure 28. Arrangement for mercury sampling .......................................................................................40

Figure 29. Arrangement of lances for water injection.........................................................................41

Figure 30. Temperature traversing at the location of humidification lances...................................42

Figure 31. Mercury concentrations with and without duct humidification......................................42 
Figure 32. Concentration of mercury at Side B outlet (symbols), unit 3 load (solid line) and results of Ontario Hydro measurements (red line).

Figure 33. Unit 3 LOI....

Figure 34. Comparison of sorbent injection data...............................................................................4

Figure 35. Mercury concentrations upstream and downstream of Side B ESP..............................51

Figure 36. Total and elemental mercury concentrations at ESP inlet measured on August 3, 2006.

Figure 37. Mercury reduction on ESP sides A and B........................................................................5

Figure 38. Mercury removal as function of DARCO ${ }^{8} \mathrm{Hg}$ injection rate with and without $\mathrm{SO}_{3}$ injection.

Figure 39. Comparison of $\mathrm{DARCO}^{\circledR} \mathrm{Hg}$ and $\mathrm{DARCO}^{\circledR}$ E25C performance with (a) and without $\mathrm{SO}_{3}(\mathrm{~b})$ injection.

Figure 40. Sorbent performance in the presence of $\mathrm{SO}_{3}$.

Figure 41. Mercury reductions at baseline and optimized combustion conditions......................57

Figure 42. Sorbent injection rates at baseline and optimized combustion conditions................58

Figure 43. Incremental cost of electricity................................................................................................58

Figure 44. Variable annual O\&M costs............................................................................................59

Figure 45. Data on Unit 3 opacity..............................................................................................................60

\section{List of Tables}

Table 1. Results of baseline sampling using Ontario Hydro method.................................................12

Table 2. Fuel composition during baseline tests.....................................................................................12

Table 3. Summary of mercury testing......................................................................................................13

Table 4. Initial point-to-point measurements...................................................................................16

Table 5. Optimum point-to-point measurements. .....................................................................................16

Table 6. Unit 3 emissions before and after tuning ..............................................................................17

Table 7. Coal composition................................................................................................................17

Table 8. Results of sampling using Ontario Hydro method............................................................18

Table 9. CFD model inputs.........................................................................................................................22

Table 10. Results of sampling using Ontario Hydro method.........................................................48

Table 11. Summary of carbon traps measurements.........................................................................49

Table 12. Composition of coal samples............................................................................................51

\section{Revision History}

\begin{tabular}{|c|l|l|l|l|}
\hline Revision & \multicolumn{1}{|c|}{ Date } & Author(s) & \multicolumn{1}{|c|}{ Approver } & \multicolumn{1}{c|}{$\begin{array}{c}\text { Description of } \\
\text { Changes }\end{array}$} \\
\hline 02 & September 8, 2007 & $\begin{array}{l}\text { Vitali Lissianski } \\
\text { Pete Maly }\end{array}$ & Randy Seeker & $\begin{array}{l}\text { Added section on } \\
\text { economics of mercury } \\
\text { control }\end{array}$ \\
\hline
\end{tabular}




\section{Executive Summary}

General Electric (GE) has developed an approach whereby native mercury reduction on fly ash can be improved by optimizing the combustion system. This approach eliminates carbon-rich areas in the combustion zone, making the combustion process more uniform, and allows increasing carbon content in fly ash without significant increase in $\mathrm{CO}$ emissions. Since boiler excess $\mathrm{O}_{2}$ can be also reduced as a result of optimized combustion, this process reduces $\mathrm{NO}_{\mathrm{x}}$ emissions. Because combustion optimization improves native mercury reduction on fly ash, it can reduce requirements for activated carbon injection $(\mathrm{ACl})$ when integrated with sorbent injection for more efficient mercury control. The approach can be tailored to specific unit configurations and coal types for optimal performance.

This report describes results of a U.S. DOE sponsored project designed to evaluate the effect of combustion conditions on "native" mercury capture on fly ash and integrate combustion optimization for improved mercury and $\mathrm{NO}_{\mathrm{x}}$ reduction with $\mathrm{ACl}$. The technology evaluation took place in Lee Station Unit 3 located in Goldsboro, NC and operated by Progress Energy. Unit 3 burns a low-sulfur Eastern bituminous coal and is a $250 \mathrm{MW}$ opposed-wall fired unit equipped with an ESP with a specific collection area of $249 \mathrm{ft} 2 / \mathrm{kacfm}$. Unit 3 is equipped with $\mathrm{SO}_{3}$ injection for ESP conditioning. The technical goal of the project was to evaluate the technology's ability to achieve $70 \%$ mercury reduction below the baseline emission value of $2.9 \mathrm{lb} /$ TBtu, which was equivalent to $80 \%$ mercury reduction relative to the mercury concentration in the coal. The strategy to achieve the $70 \%$ incremental improvement in mercury removal in Unit 3 was (1) to enhance "naturally" occurring fly ash mercury capture by optimizing the combustion process and using duct humidification to reduce flue gas temperatures at the ESP inlet, and (2) to use $\mathrm{ACl}$ in front of the ESP to further reduce mercury emissions. The program was comprised of field and pilot-scale tests, engineering studies and consisted of eight tasks. As part of the program, GE conducted pilot-scale evaluation of sorbent effect on mercury reduction, supplied and installed adjustable riffle boxes to assist in combustion optimization, performed combustion optimization, supplied mobile sorbent injection and flue gas humidification systems, conducted CFD modeling of sorbent injection and flue gas humidification, and performed mercury testing including a continuous 30-day sorbent injection trial.

Combustion optimization was the first step in reduction of mercury emissions. Goals of combustion optimization activities were to improve "native" mercury capture on fly ash and reduce $\mathrm{NO}_{\mathrm{x}}$. Combustion optimization included balancing of coal flow through individual burners to eliminate zones of carbon-rich combustion, air flow balancing, and burner adjustments. As part of the project, the original riffle boxes were replaced with FosterWheeler's adjustable riffle boxes to allow for biasing the coal flow between the coal pipes. A 10-point $\mathrm{CO} / \mathrm{O}_{2} / \mathrm{NO}_{x}$ grid was installed in the primary superheater region of the back pass to assist in these activities. Testing of mercury emissions before and after combustion optimization demonstrated that mercury emissions were reduced from $2.9 \mathrm{lb} / \mathrm{TBtu}$ to 1.8 $\mathrm{lb} / \mathrm{TBtu}$ due to boiler operation differences in conjunction with combustion optimization, a $38 \%$ improvement in "native" mercury capture on fly ash. Native mercury reduction from coal was $\sim 42 \%$ at baseline conditions and $64 \%$ at optimized combustion conditions. As a result of combustion optimization $\mathrm{NO}_{x}$ emissions were reduced by $18 \%$.

A three-dimensional CFD model was developed to study the flow distribution and sorbent 
injection in the post air heater duct in Lee Station Unit 3. Modeling of the flow pattern exiting the air pre-heater demonstrated that because of the duct transition from a circular opening at the exit of air-pre-heater to a rectangular ESP inlet duct, flow separation occurred at the corners after the transition. Modeling also demonstrated that the flow was severely biased from the South side to the North side due to the bend of the duct. Results of CFD modeling were used to design lances for better sorbent distribution across the ESP inlet duct.

Modeling of water injection demonstrated that because of flue gas temperature biasing, the droplet evaporation rate was slower on the North side than that on the South side of the duct. Modeling suggested that an improvement of water droplet evaporation could be achieved by closing the lance on the North side where flue gas temperatures were lower.

Preliminary evaluation of the effect of carbon-based sorbents on mercury reduction took place in a $1 \mathrm{MBtu} / \mathrm{hr}(300 \mathrm{~kW})$ Boiler Simulator Facility using the same coal as fired at Lee Station. Testing had demonstrated that DARCO ${ }^{\circledR} \mathrm{Hg}$ (basic activated carbon) and DARCO ${ }^{\circledR}$ $\mathrm{Hg}$-LH (brominated activated carbon) showed similar performances in the absence of $\mathrm{SO}_{3}$ injection. Based on results of pilot-scale testing, it was suggested that DARCO ${ }^{\circledR} \mathrm{Hg}$ be selected for field testing. Sorbent injection rate required to achieve the $70 \%$ incremental improvement in mercury reduction was estimated at $10 \mathrm{lb} / \mathrm{MMACF}$.

The following equipment was installed at Lee station in preparation for testing: sorbent injection and duct humidification systems, and mercury CEMs. The sorbent injection system was designed to inject up to $1,000 \mathrm{lbs}$ of sorbent per hour. It could accept sorbent from a pneumatic bulk trailer with $40,000 \mathrm{lb}$ sorbent capacity or from 900-pound bulk bags. The humidification system used a dual fluid nozzle system (compressed air and water) and was designed to cool flue gas by $30^{\circ} \mathrm{F}$ without water droplet carryover into the precipitator. Mercury measurements during sorbent injection were performed by Apogee Scientific, Inc. (Apogee) using two Apogee Semi-Continuous Emissions Monitor systems with three extraction systems.

Temperature traversing at the location of water injection ports was done prior to the humidification system shakedown to ensure that water injection would not lower local flue gas temperatures below 260 of - the acid dewpoint temperature estimated for Lee coal. Measurements showed that flue gas temperatures in some locations were close to or even below 260 oF. Therefore the decision was made to use only 4 out of 8 lances to avoid water injection in the lower temperature areas of the duct. A 2-hour test was conducted in which 4 $\mathrm{G} / \mathrm{min}$ of water were injected through each lance. The $\mathrm{SO}_{3}$ conditioning system was not operational during the test. No noticeable improvement in "native" mercury capture on fly ash was observed. Although mercury removal on fly ash improves with reduction of ESP temperature, it is possible that the 12 of decrease in temperature of flue gas measured in the test was not significant enough to result in noticeable improvement in mercury capture. Further decrease in flue gas temperature could not be achieved because of concerns about acid condensation and duct corrosion.

One week of sorbent optimization tests was conducted in Unit 3 to evaluate and select sorbent and define sorbent injection rate for long-term testing. These tests were guided by results of pilot-scale sorbent evaluation. Sorbent optimization tests showed that DARCO ${ }^{\circledR} \mathrm{Hg}$ and DARCO ${ }^{\circledR} \mathrm{Hg}$-LH performances were about the same in the absence of $\mathrm{SO}_{3}$ injection. Based on results of sorbent optimization tests, DARCO ${ }^{\circledR} \mathrm{Hg}$ was selected for the 30 -day trial. 
Recommended sorbent injection rate without $\mathrm{SO}_{3}$ conditioning was $10 \mathrm{lb} / \mathrm{MMACF}$ and with $\mathrm{SO}_{3}$ conditioning $20 \mathrm{lb} / \mathrm{MMACF}$.

Mercury data during the 30-day test were collected using mercury CEMS, Ontario Hydro, and carbon trap methods. Comparison of Ontario Hydro, sorbent trap and mercury CEMS data at ESP outlet shows reasonable agreement. Mercury content in coal samples collected during testing compared well with measured mercury concentrations at ESP inlet. Combined mercury removal due to sorbent injection and fly ash during the 30-day tests without $\mathrm{SO}_{3}$ injection was in $70-90 \%$ range while with $\mathrm{SO}_{3}$ injection it was in the range of $50-80 \%$. Thus, program objective of achieving $70 \%$ improvement in mercury reduction from the baseline emissions or $80 \%$ mercury reduction from coal has been achieved, although ability to achieve target mercury removal with $\mathrm{SO}_{3}$ injection was marginal.

Test results showed that $\mathrm{SO}_{3}$ reduced the ability of DARCO ${ }^{\circledR} \mathrm{Hg}$ to remove mercury by 50 $70 \%$. A novel $\mathrm{SO}_{3}$ resistant sorbent DARCO ${ }^{\circledR} \mathrm{Hg}$ E25C from Norit Americas, Inc. was tested during the last week of sorbent injection. Two DARCO ${ }^{\circledR} \mathrm{HgE25C}$ products with $30 \%$ and $100 \%$ strength were tested. Data demonstrated that DARCO ${ }^{\circledR}$ E25C performance was similar to that of $\mathrm{DARCO}^{\circledR} \mathrm{Hg}$ with and without $\mathrm{SO}_{3}$ injection.

Economic analysis of mercury control at Lee station suggests that the cost of mercury control using the integrated approach is about $40 \%$ lower than that of activated carbon injection alone and pay back time on capital investment required for combustion optimization is less than one year. Cost of mercury control is about $40 \%$ higher when $\mathrm{SO}_{3}$ injection is used for ESP conditioning.

Tests also demonstrated that with $\mathrm{SO}_{3}$ conditioning sorbent injection did not have noticeable effect on stack opacity. 


\subsection{Introduction}

Many utilities are actively seeking efficient, cost-effective technologies for controlling multiple pollutants including mercury $(\mathrm{Hg})$ emitted from power plants. Activated carbon injection $(\mathrm{ACl})$ is currently one of the most mature technologies for mercury control. Cost of mercury control using ACl in ESP applications is dominated 1,2 by the sorbent cost and may exceed several million dollars per year in sorbent cost for a $500 \mathrm{MW}$ unit.

Due to a number of reasons coal combustion in boilers is never complete, resulting in formation of unburned carbon in ash or LOI (Loss on Ignition). Although this carbon is not as reactive towards mercury as is activated carbon, the overall amount of unburned carbon in ash can be significant resulting in some mercury reduction on fly ash (natural mercury removal). Since unburned carbon in ash results in loss of unit heat efficiency, typically coalfired units are operated in a way that minimizes LOI. It is known ${ }^{3}$ that efficiency of natural mercury removal on fly ash increases with increasing LOI. Thus, one way to increase natural mercury reduction on fly ash is to increase LOI which can be achieved, for example, by deturning the combustion process. This approach, however, is not optimum since it may result in increase in $\mathrm{CO}$ emissions.

General Electric (GE) has developed an approach whereby native mercury reduction on fly ash is improved by optimizing the combustion system. This approach eliminates carbon- rich areas in the combustion zone, making the combustion process more uniform, and allows increasing carbon content in fly ash without significant increase in $\mathrm{CO}$ emissions. Since boiler excess $\mathrm{O}_{2}$ can be also reduced in the optimized combustion, this $\mathrm{O}_{2}$ decrease reduces $\mathrm{NO}_{x}$ emissions and may offset decrease in boiler heat efficiency as a result of LOI increase. Another benefit of combustion optimization is more uniform distribution of high carbon fly ash across inlet duct of a particulate control device. Because of biases in coal flows to individual burners in a typical boiler, high carbon fly ash formation is dominated by burners with higher coal flows (fuel-rich burners) while remaining burners are fuel-lean and form low carbon fly ash. This non-uniform space distribution of high carbon fly ash in flue gas continues as flue gas flows into the particulate control device resulting in non-optimum mercury reduction. Because combustion optimization makes the combustion process more uniform, distribution of high carbon fly ash across the inlet to the particulate control device is also more uniform. Combustion optimization allows maintaining a narrow range of combustion conditions and LOI to maximize mercury removal, minimize the negative effect of high-carbon fly ash on boiler operation and avoid high $\mathrm{CO}$ emissions. Other benefits of combustion optimization include reduced $\mathrm{NO}_{x}$ emissions and improved boiler performance. Because combustion optimization improves native mercury reduction on fly ash, it can reduce requirements for $\mathrm{ACl}$ when integrated with sorbent injection for more efficient mercury control. The approach can be tailored to specific unit configurations and coal types

1. Hoffmann, J., and Brown, J.R. "Preliminary Cost Estimate of Activated Carbon Injection for Controlling Mercury Emissions from an Un-Scrubbed 500 MW Coal-Fired Power Plant", Final Report, U.S. DOE, November 2003.

2. J ones, A.P.; Hoffmann, J.W.; Smith, D.N.; Feeley, T.J. III; and Murphy, J.T. "Preliminary Economic Analysis of Activated Carbon Injection", DOE/NETL's Phase II Mercury Control Technology Field Testing Program, Report, April 2006.

3. Senior, C.L. and Johnson, S.A. Impact of Carbon-in-Ash on Mercury Removal Across Particulate Control Devices in Coal-Fired Power Plants", Presented at 95 AWMA meeting, Paper \#42730, Baltimore, 2002. 
for optimal performance.

In 2003-2005 GE conducted a preliminary evaluation of $\mathrm{Hg}$ and $\mathrm{NO}_{x}$ control using coal reburning at Western Kentucky Energy Green Station under joint sponsorship of U.S. DOE National Energy Technology Laboratory (NETL) and GE. The project approach included enhancing the "naturally occurring" mercury capture by fly ash through coal reburning, combustion optimization, and lowering ESP temperature. The project demonstrated that natural mercury reduction on fly ash could be as high as $80 \%$ at optimized combustion conditions.

This report describes results of a U.S. DOE NETL sponsored program designed to evaluate the effect of combustion conditions on "native" mercury capture on fly ash and integrate combustion optimization for improved mercury and $\mathrm{NO}_{x}$ reduction with $\mathrm{ACl}$. The technology evaluation was performed in 2005-2006 and took place in Lee Station Unit 3 located in Goldsboro, NC and operated by Progress Energy. Unit 3 burns a low-sulfur Eastern bituminous coal and is a $250 \mathrm{MW}$ opposed-wall fired unit equipped with an ESP with a specific collection area (SCA) of $249 \mathrm{ft} 2 / \mathrm{kacfm}$. The technical goal of the project was to evaluate the technology's ability to achieve $70 \%$ mercury reduction below the baseline emission value of $2.9 \mathrm{lb} / \mathrm{TBtu}$, which is equivalent of $80 \%$ mercury reduction from coal. The strategy to achieve the $70 \%$ incremental improvement in mercury removal in Unit 3 was (1) to enhance "naturally" occurring fly ash mercury capture by optimizing the combustion process and using duct humidification to reduce flue gas temperatures at the ESP inlet, and (2) to use ACl in front of the ESP as a mercury removal step. The program was comprised of field and pilot-scale tests, engineering studies and consisted of eight tasks. As part of the program, GE conducted pilot-scale evaluation of sorbent effect on mercury reduction, supplied and installed adjustable riffle boxes to assist in combustion optimization, performed combustion optimization, supplied mobile sorbent injection and flue gas humidification systems, conducted CFD modeling of sorbent injection and duct humidification, and performed mercury testing including a continuous 30-day sorbent injection. The following sections describe project activities. 


\subsection{Description of Lee Unit 3}

Progress Energy's Lee Station Unit 3 (Figure 1) is a 250 MW opposed wall fired boiler furnished by DB Riley in 1978. The unit has a total of 20 burners arranged in 5 columns by 2 rows on the front and rear walls. In 1997, the original burners were replaced with B\&W DRBXCL low-NOx burners along with an overfire air system (OFA) to minimize NOx emissions. Lee Station's Unit 3 has five double-sided horizontal hammer mills that have riffle boxes located on each outlet. Each riffle box also has two outlets. Unit 3 has a split ESP with two inlet ducts designated as A and B. Unit 3 burns a low-sulfur Eastern bituminous coal and is equipped with an ESP with a specific collection area (SCA) of $249 \mathrm{ft} 2 / \mathrm{kacfm}$ with $\mathrm{SO}_{3}$ injection for ESP conditioning. The $\mathrm{SO}_{3}$ is injected immediately after airheater. According to the plant, $\mathrm{SO}_{3}$ concentration in the flue gas is $\sim 15 \mathrm{ppm}$ when the injection system is operational.

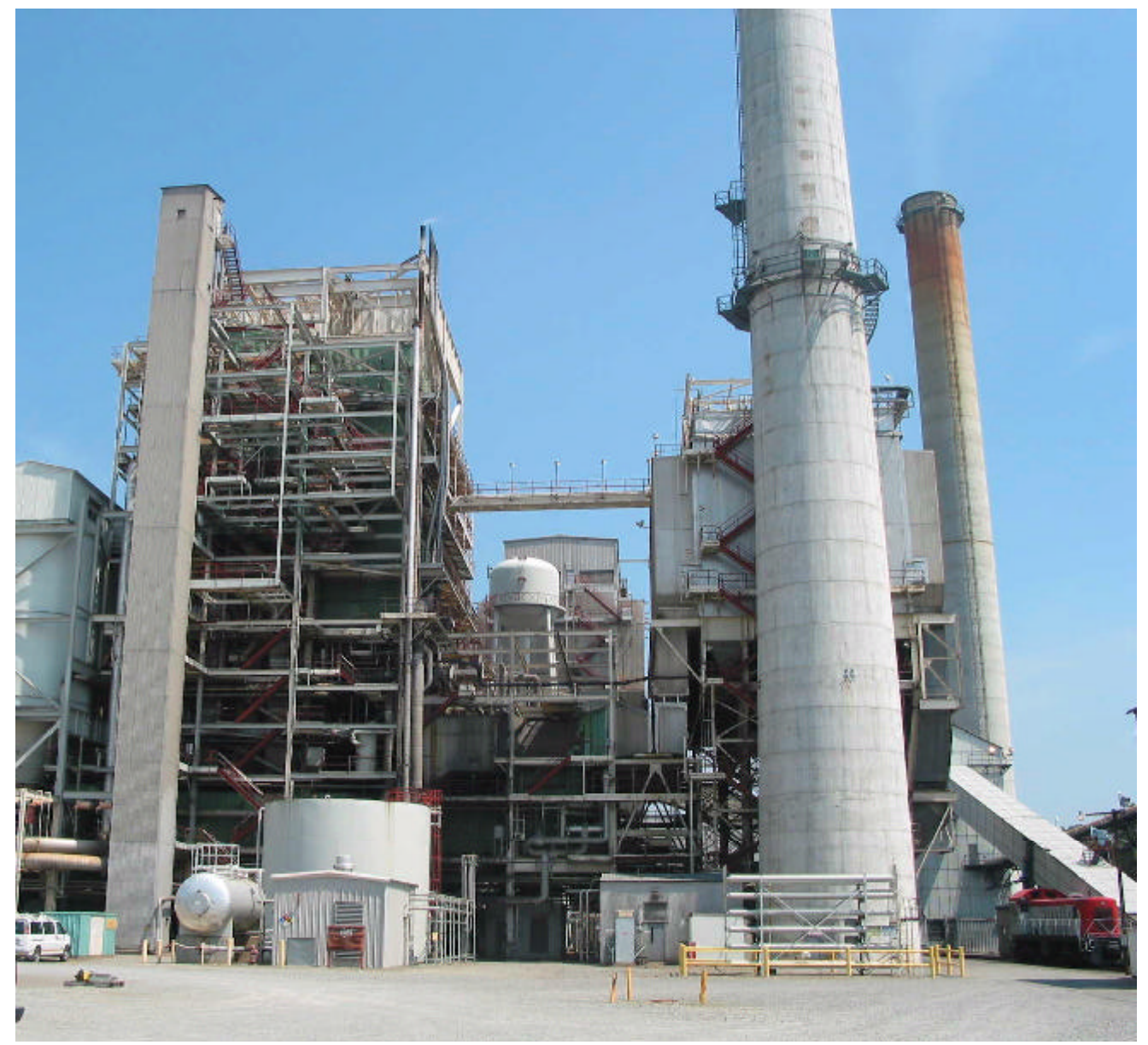

Figure 1. Lee station Unit 3. 


\subsection{Combustion Optimization}

Combustion optimization was an important element of the project strategy to enhance "naturally" occurring fly ash mercury capture. It was expected that combustion optimization would (1) result in more uniform carbon in ash distribution between Unit 3's two exhaust ducts and within each duct and (2) improve combustion process and reduce $\mathrm{CO}$ emissions allowing deeper staging of the combustion process (more air is diverted from the main combustion zone to OFA) than at current combustion conditions thus decreasing $\mathrm{NO}_{\mathrm{x}}$ emissions and improving fly ash reactivity towards mercury. Fly ash reactivity was expected to be further improved by lowering ESP temperature using a duct humidification system.

Combustion optimization included: (1) balancing of coal flow through individual burners to eliminate zones of carbon-rich combustion, (2) air flow balancing, and (3) burner tuning. These steps are critical in improving "native" mercury capture since non-uniformity of coal and air flows to burners also resulted in flue gas stratification. Previous experience suggested that in boilers with unbalanced combustion systems LOI could vary by $50-100 \%$ within cross section of the exhaust duct. Mercury oxidation and absorption on fly ash in such non-optimized systems is not as effective as in units with uniform LOI distribution.

Coal balancing typically reduces $\mathrm{LOI}$ and $\mathrm{CO}$ and allows unit operation at reduced excess $\mathrm{O}_{2}$. Reduction in excess $\mathrm{O}_{2}$ decreases $\mathrm{NO}_{x}$ emissions and typically increases LOI thus offsetting LOI decrease as a result of coal balancing. Thus, the overall result of combustion optimization was expected to be improved "native" mercury capture due to more uniform distribution of high carbon fly ash and increased LOI. Improvement in "native" mercury capture was expected even if LOI stayed the same as a result of combined effects of coal balancing and reduction in excess $\mathrm{O}_{2}$.

\subsection{Baseline Mercury Testing}

The first project activity was to characterize Unit 3 baseline mercury emissions. On J une 9 , 2005 mercury emissions were measured at the Lee Station Unit 3 stack. A total of three Ontario Hydro measurements were performed at normal unit operation conditions by GE Management Services, Inc. At each sampling condition a sample of coal was taken from coal mills. These samples were analyzed for mercury and $\mathrm{HCl}$ content, and coal ultimate analysis was also performed.

Table 1 shows results of baseline mercury emissions measurements. Mercury concentration in the flue gas ranged from $3.11 \mu \mathrm{g} / \mathrm{dscm}$ to $3.84 \mu \mathrm{g} / \mathrm{dscm}$ with an average $\mathrm{Hg}$ concentration of $3.53 \mu \mathrm{g} / \mathrm{dscm}$. Measurements also showed that about $80 \%$ of total mercury at the stack was present in the oxidized form. Since most particulate matter is removed in the ESP, it is not surprising that very little mercury was associated with particulate matter.

Table 2 shows fuel ultimate analysis as well as $\mathrm{Cl}$ and mercury content for each test. Ultimate coal analysis was performed by Commercial Testing \& Engineering Co. Fuel samples were analyzed for chlorine and mercury continent by Consol Energy laboratory. Fuel analysis shows that the fuel fired in Lee Station Unit 3 is a low sulfur coal with relatively high $\mathrm{Cl}$ content. High $\mathrm{Cl}$ content in coal is consistent with the high fraction of oxidized 
mercury from the total mercury measured at the stack. Analysis also suggests significant variability in mercury in coal content.

Table 1. Results of baseline sampling using Ontario Hydro method.

\begin{tabular}{|c|c|c|c|c|}
\hline Test Run Number & 1 & 2 & 3 & Average \\
\hline Source Condition & Normal & Normal & Normal & \\
\hline Date & $6 / 9 / 2005$ & $6 / 9 / 2005$ & $6 / 9 / 2005$ & \\
\hline Start Time & $11: 50$ & $14: 35$ & $16: 55$ & \\
\hline End Time & $13: 45$ & $16: 23$ & 18:50 & \\
\hline \multicolumn{5}{|c|}{ Particle Bound Mercury Emissions } \\
\hline net $\mu \mathrm{g}$ detected: & 0.047 & 0.100 & 0.084 & \\
\hline$\mu \mathrm{g} / \mathrm{dscm}:$ & 0.020 & 0.045 & 0.037 & 0.03 \\
\hline lb/hr: & 0.000045 & 0.000096 & 0.000080 & 0.00 \\
\hline \multicolumn{5}{|c|}{ Oxidized $\left(\mathrm{Hg}^{2+}\right)$ Mercury Emissions } \\
\hline net $\mu_{\mathrm{g}}$ detected: & 6.7 & 6.9 & 5.5 & \\
\hline$\mu_{\mathrm{g} / \mathrm{dscm}:}$ & 2.914 & 3.106 & 2.411 & 2.81 \\
\hline $\mathrm{lb} / \mathrm{hr}:$ & 0.0064 & 0.0066 & 0.0053 & 0.0061 \\
\hline \multicolumn{5}{|c|}{ Elemental $\left(\mathbf{H g}^{0}\right)$ Mercury Emissions } \\
\hline net $\mu \mathrm{g}$ detected: & 1.602 & 1.524 & 1.521 & \\
\hline$\mu \mathrm{g} / \mathrm{dscm}:$ & 0.697 & 0.686 & 0.667 & 0.68 \\
\hline lb/hr: & 0.0015 & 0.0015 & 0.0015 & 0.0015 \\
\hline \multicolumn{5}{|c|}{ Total Mercury Emissions } \\
\hline net $\mu \mathrm{g}$ detected: & 8.349 & 8.524 & 7.105 & \\
\hline$\mu \mathrm{g} / \mathrm{dscm}:$ & 3.631 & 3.837 & 3.115 & 3.53 \\
\hline $\mathrm{lb} / \mathrm{hr}:$ & 0.00801 & 0.00816 & 0.00678 & 0.00765 \\
\hline
\end{tabular}

Table 2. Fuel composition during baseline tests.

\begin{tabular}{|c|c|c|c|c|}
\hline Test No & Units & Test 1 & Test 2 & Test 3 \\
\hline Ult. Analysis: & wt \% & & & \\
\hline C & & 70.71 & 68.07 & 70.33 \\
\hline $\mathrm{H}$ & & 4.70 & 4.72 & 4.74 \\
\hline$N$ & & 1.37 & 1.36 & 1.37 \\
\hline S & & 0.83 & 0.82 & 0.82 \\
\hline Ash & & 9.54 & 10.01 & 9.84 \\
\hline 0 & & 6.84 & 8.71 & 6.77 \\
\hline $\mathrm{H} 2 \mathrm{O}$ & & 6.01 & 6.31 & 6.13 \\
\hline Wet HV & Btu/lb & 12549 & 12383 & 12429 \\
\hline Dry Analysis & wt \% & & & \\
\hline C & & 75.23 & 72.65 & 74.92 \\
\hline $\mathrm{H}$ & & 5.00 & 5.04 & 5.05 \\
\hline$N$ & & 1.46 & 1.45 & 1.46 \\
\hline S & & 0.88 & 0.88 & 0.87 \\
\hline Ash & & 10.15 & 10.68 & 10.48 \\
\hline 0 & & 7.28 & 9.30 & 7.21 \\
\hline Dry HV & Btu/lb & 13351 & 13217 & 13241 \\
\hline $\mathrm{Cl}$ in coal & wt\%dry & 1560 & 1600 & 1460 \\
\hline $\mathrm{Hg}$ in coal & ppb dry & 70 & 56 & 80 \\
\hline $\mathrm{Hg}$ in coal & ppb wet & 66 & 52 & 75 \\
\hline
\end{tabular}

Table 3 compares the theoretical concentrations of $\mathrm{Hg}$ in the flue gas (calculated based on 
coal composition and mercury content) and measured mercury concentrations. Table 3 shows that mercury reduction from coal at the stack varied from $27 \%$ to $54 \%$ with average mercury reduction of $42 \%$. Average mercury emissions during testing were $2.9 \mathrm{lb} / \mathrm{TBtu}$. Analysis of fly ash collected from the ESP showed that average LOl during testing was $16.2 \%$.

Table 3. Summary of mercury testing.

\begin{tabular}{|c|c|c|c|c|c|c|c|c|}
\hline \multirow{2}{*}{ Test No } & $\begin{array}{c}\text { Mercury in Coal, } \\
\mathrm{lb} / \mathrm{Tbtu}\end{array}$ & $\begin{array}{c}\text { Stack } \mathrm{O}_{2}, \\
\mathrm{dry} \%\end{array}$ & $\begin{array}{c}\mathrm{Hg}^{\mathrm{p}} \\
\mu \mathrm{g} / \mathrm{dm}^{3}\end{array}$ & $\begin{array}{c}\mathrm{Hg}^{0} \\
\mu \mathrm{g} / \mathrm{dm}^{3}\end{array}$ & $\begin{array}{c}\mathrm{Hg}^{+2} \\
\mu \mathrm{g} / \mathrm{dm}^{3}\end{array}$ & $\begin{array}{c}\mathrm{Hg} \text { total, } \\
\mu \mathrm{g} / \mathrm{dm}^{3}\end{array}$ & $\begin{array}{c}\mathrm{Hg} \text { total, } \\
\mathrm{Ib} / \mathrm{TBtu}\end{array}$ & $\begin{array}{c}\text { Meduction, } \\
\%\end{array}$ \\
\hline 1 & 5.2 & 5 & 0.02 & 0.7 & 2.91 & 3.63 & 2.9 & 45 \\
2 & 4.2 & 5 & 0.05 & 0.69 & 3.11 & 3.85 & 3.1 & 27 \\
3 & 5.7 & 5.5 & 0.04 & 0.67 & 2.41 & 3.12 & 2.6 & 54 \\
\hline
\end{tabular}

\subsection{Riffle Boxes}

Lee Station's Unit 3 has five double-sided mills that have riffle boxes located on each outlet (two riffle boxes per mill). Each riffle box also has two outlets and supplies coal to two burners. Original riffle boxes did not allow adjustments in coal flows to individual burners. As part of this project, the original riffle boxes were replaced with Foster-Wheeler's adjustable riffle boxes to allow for biasing the coal flow between the two outlets. Unlike original riffle boxes (Figure 2), adjustable riffle boxes are equipped with vanes that allow coal biasing. Ten original Unit 3 riffle boxes were replaced with adjustable during fall of 2005 prior to the beginning of combustion optimization activities.

Riffle Box

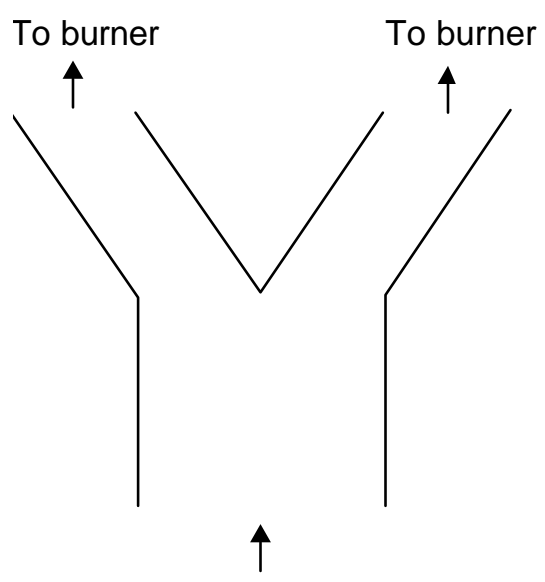

From mill
Adjustable Riffle Box

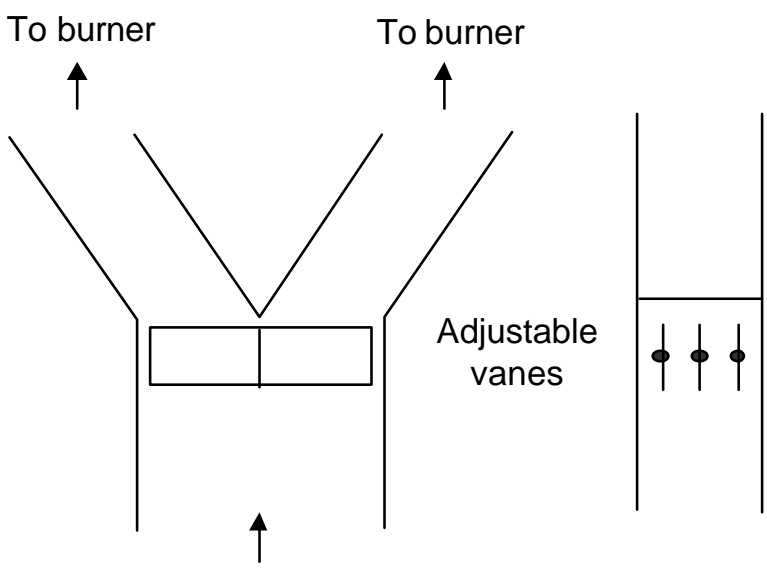

From mill

Figure 2. Riffle boxes. 


\subsection{Coal Balancing}

This section describes coal balancing activities that were conducted in December 2005. Prior to the beginning of the coal balancing program, fly ash samples were taken from ESP inlet ducts and analyzed for LOI and mercury content. Unit 3 has a split ESP with two inlet ducts designated as $A$ and $B$. Each duct has 11 sampling ports upstream of ESP. Fly ash samples were collected from ports 3 and 7 of each duct. Figure 3 shows distributions of $\mathrm{LOI}$ and $\mathrm{Hg}$ content in fly ash at the ESP inlet. It demonstrates that significant non-uniformities in carbon and mercury in ash distribution existed prior to the beginning of combustion optimization. It also demonstrates that higher LOI is associated with higher mercury content in fly ash. Coal balancing and combustion optimization were expected to result in more uniform distribution of carbon and mercury in ash and higher overall mercury removal.
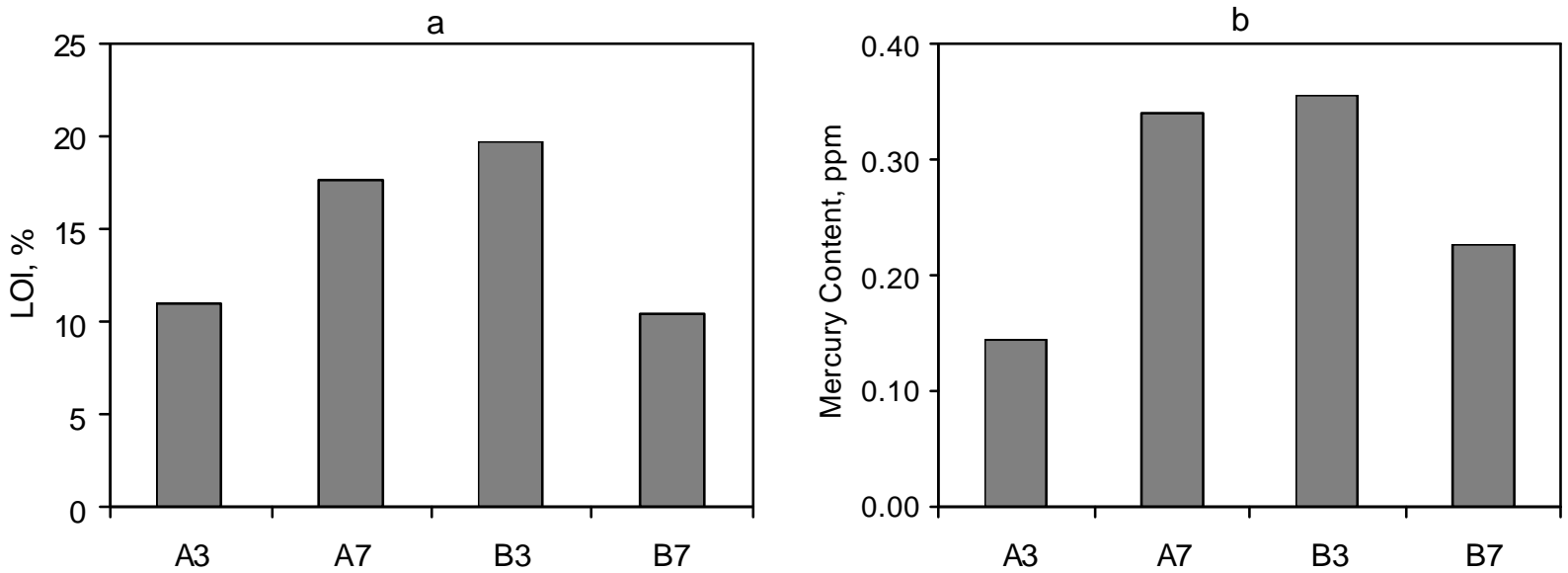

Figure 3. Carbon and mercury content in ash measured in samples taken at ESP inlet ducts.

Upon completion of installation of adjustable riffle boxes coal flow measurements in each coal pipe were made with the RotorProbe ${ }^{\mathrm{TM}}$ (GE trademark) measurement system and primary air was measured with the dirty air pitot probe. The RotorProbe ${ }^{\mathrm{TM}}$ pulverized coal sampling system implements International Standard Organization (ISO) Method 9931 and samples the coal-air mixture at 64 points representing equal cross-sectional areas of the coal pipe. As each mill was tested, it was operated in manual control at $100 \%$ output, while the other four mills remained in normal operation. The initial tests were carried out to detect the initial deviation in the coal and air flows in each of the pipes. If necessary, recommendations were made to adjust the dampers on the riffle boxes to improve the distribution of coal flow between the pipes in a mill group. Following those adjustments, coal and air flow measurements were repeated to verify that the flows were balanced. The criterion was to achieve a $\pm 10 \%$ coal mass flow deviation between all pipes in a mill group.

Figure 4 shows the damper positions available on the riffle boxes. The $\mathrm{F}$ and $\mathrm{R}$ designation signify the front side or rear side of the riffle box. The $\mathrm{N}$ position is the neutral position and the position of the initial riffle box setting. During coal balancing process the position of the damper was adjusted as necessary to bias the coal flow. 


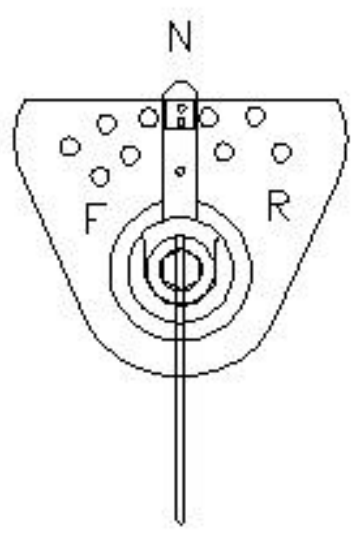

Figure 4. Riffle box layout with damper positions.

Figure 5 shows maximum deviation in each coal pipe relative to the mean coal flow between all four pipes coming out of the mill before and after coal flow balancing. Figure 5 shows that only mills $B$ and $D$ required coal flow balancing while mills $A, C$, and $E$ were within the criterion of a $\pm 10 \%$ coal mass flow deviation between all pipes in a mill group.

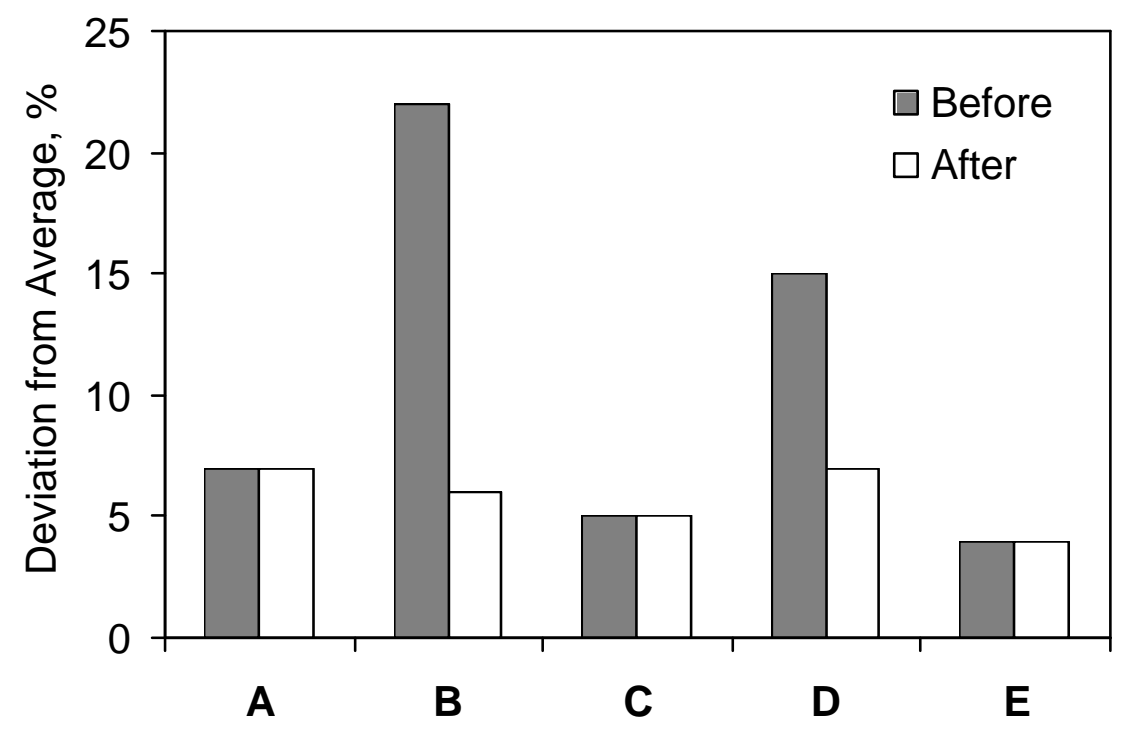

Figure 5. Coal flow deviations before and after balancing.

Figure 5 demonstrates that before coal balancing maximum deviation in coal flow from average flow was $22 \%$. After coal flow balancing all mills were within the $\pm 10 \%$ criterion. As a result of coal flow balancing, $\mathrm{NO}_{\mathrm{x}}$ emissions were reduced by $10 \%$.

\subsection{Air Flow Balancing}

The next steps in combustion optimization process were balancing burner air flow and 
optimizing burners. These activities were conducted in J anuary 2006. A 10-point sensor grid was installed in the primary superheater region of the back pass to assist in these activities. The grid provided information on spatial distributions of $\mathrm{O}_{2}, \mathrm{NO}_{x}$, and $\mathrm{CO}$ in the back pass. This information was used in burner tuning and air flow balancing. The target of combustion optimization was to achieve a variation in point-to-point $\mathrm{O}_{2}$ measurements of less than $15 \%$.

Results of the initial point-to-point grid measurements are shown in Table 4. The overall variation in $\mathrm{O}_{2}$ measurements for this initial test was $23 \%$. These measurements were consistent with the plant $\mathrm{O}_{2}$ probes. Through a series of adjustments to the burner air register disks, the variation in the point-to-point $\mathrm{O}_{2}$ measurements was lowered to $15 \%$ as shown in Table 5. This variation was on the target set prior to the beginning of combustion optimization activities. Table 5 shows that as a result of air flow balancing $\mathrm{NO}_{\mathrm{x}}$ and $\mathrm{CO}$ emissions were reduced by $7.4 \%$ and $30 \%$, respectively.

Table 4. Initial point-to-point measurements.

\begin{tabular}{|l|c|c|c|}
\hline & $\mathrm{O}_{2}, \%$ & $\mathrm{NO}_{\mathrm{x}}, \mathrm{ppm}$ & $\mathrm{CO}, \mathrm{ppm}$ \\
\hline Average & 3.04 & 311 & 38.5 \\
\hline St Dev & 0.7 & 25 & 39.2 \\
\hline Variation & $23 \%$ & $8 \%$ & $102 \%$ \\
\hline
\end{tabular}

Table 5. Optimum point-to-point measurements.

\begin{tabular}{|l|c|c|c|}
\hline & $\mathrm{O}_{2}, \%$ & $\mathrm{NO}_{x}, \mathrm{ppm}$ & $\mathrm{CO}, \mathrm{ppm}$ \\
\hline Average & 3.17 & 288 & 26.7 \\
\hline St Dev & 0.48 & 31 & 16.6 \\
\hline Variation & $15 \%$ & $11 \%$ & $62 \%$ \\
\hline
\end{tabular}

\subsection{Burner Tuning}

The final task in combustion optimization was to explore how adjustments to the burner inner and outer vane settings could improve the combustion process, reduce $\mathrm{NO}_{x}$ emissions, increase flame stability, and improve mercury capture on fly ash.

Table 6 shows $\mathrm{NO}_{x}$ and $\mathrm{CO}$ emissions before and after tuning. Table 6 demonstrates that as a result of burner tuning, $\mathrm{NO}_{x}$ emissions were reduced by $\sim 16 \%$. Although $\mathrm{CO}$ emissions increased, they remained significantly below the limit of 200 ppm set for the plant operation. 
Table 6. Unit 3 emissions before and after tuning.

\begin{tabular}{|c|c|c|}
\hline & $\begin{array}{c}\mathrm{NO}_{x}, \\
\mathrm{lb} / \mathrm{Mbtu}\end{array}$ & $\mathrm{CO}, \mathrm{ppm}$ \\
\hline Before tuning & 0.43 & 39 \\
\hline After tuning & 0.36 & 60 \\
\hline
\end{tabular}

\subsection{Mercury Emissions at Optimized Combustion Conditions}

Testing of mercury emissions in Unit 3 was conducted after completion of combustion optimization activities. A total of 4 Ontario Hydro measurements were performed at full unit load by GE Management Services, Inc.: two on J une 12 and two on J une 16. A sample of coal was taken from the coal mills at the first three test conditions. These samples were analyzed for mercury content. A coal ultimate analysis was also performed. These data were then compared with results of mercury testing at baseline conditions (see Section 3.1) conducted in J une 2005 prior to the installation of riffle boxes, coal balancing, and Unit 3 combustion optimization.

Table 7 compares compositions of fuel in baseline and combustion optimization tests. Table 7 demonstrates that although there are some differences in coal compositions between two sets of tests, these differences are not significant. Progress Energy confirmed that for the year over which the tests were conducted, the Lee station coal supply was from the same source.

Table 7. Coal composition.

\begin{tabular}{|c|c|c|c|c|c|c|c|c|c|}
\cline { 3 - 10 } \multicolumn{2}{c|}{} & \multicolumn{4}{c|}{ Optimized Conditions } & \multicolumn{4}{c|}{ Baseline } \\
\hline Ult. Analysis: & Units & Test 1 & Test 2 & Test 3 & Average & Test 1 & Test 2 & Test 3 & Average \\
\hline C & wt\% & 67.20 & 66.36 & 67.62 & 67.06 & 70.71 & 68.07 & 70.33 & 69.70 \\
$\mathrm{H}$ & $\mathrm{wt} \%$ & 4.52 & 4.61 & 4.57 & 4.57 & 4.70 & 4.72 & 4.74 & 4.72 \\
$\mathrm{~N}$ & $\mathrm{wt} \%$ & 1.29 & 1.28 & 1.30 & 1.29 & 1.37 & 1.36 & 1.37 & 1.37 \\
$\mathrm{~S}$ & $\mathrm{wt} \%$ & 0.76 & 0.72 & 0.74 & 0.74 & 0.83 & 0.82 & 0.82 & 0.82 \\
$\mathrm{Ash}$ & $\mathrm{wt} \%$ & 9.03 & 7.87 & 9.15 & 8.68 & 9.54 & 10.01 & 9.84 & 9.80 \\
$\mathrm{O}$ & $\mathrm{wt} \%$ & 7.94 & 10.41 & 7.34 & 8.56 & 6.84 & 8.71 & 6.77 & 7.44 \\
$\mathrm{H} 2 \mathrm{O}$ & $\mathrm{wt} \%$ & 9.26 & 8.75 & 9.28 & 9.10 & 6.01 & 6.31 & 6.13 & 6.15 \\
$\mathrm{Wet} \mathrm{HV}$ & Btu/lb & 12,035 & 12,321 & 12,084 & 12,147 & 12,549 & 12,383 & 12,429 & 12,454 \\
\hline $\mathrm{Hg}$ & $\mathrm{ppb}, \mathrm{dry}$ & 69 & 61 & 69 & 66 & 70 & 56 & 75 & 67 \\
\hline $\mathrm{Hg}$ & $\mathrm{lb} / \mathrm{Tbtu}$ & 5.20 & 4.52 & 5.18 & 4.96 & 5.24 & 4.24 & 5.66 & 5.05 \\
\hline
\end{tabular}

Table 8 shows results of mercury emissions measurements at optimized conditions and mercury content in coal. Mercury concentration in the flue gas was in the range from 0.86 $\mu \mathrm{g} / \mathrm{dscm}$ to $2.33 \mu \mathrm{g} / \mathrm{dscm}$. Comparison of results of 4 measurements shows that total mercury concentration in Test No 1 was significantly lower than that in Tests No 2-4. Since Unit 3 was firing the same coal during all tests and changes in combustion conditions were not significant enough to explain differences in mercury concentrations, it was decided that only Tests No 2-4 would be used in data analysis. The average mercury concentration in Tests $2-4$ was $2.9 \mu \mathrm{g} / \mathrm{dscm}$ at $0 \% \mathrm{O}_{2}$ or $1.8 \mathrm{lb} / \mathrm{TBtu}$. Table 8 also shows theoretical mercury 
concentration in flue gas calculated using coal composition and coal mercury content. Since a coal sample was not collected during Test \#4, mercury content in coal in Test \#4 was assumed to be equal to the average mercury content in Tests \#1-3. Average "native" mercury reduction from coal measured at optimized combustion conditions was $64 \%$.

Table 8. Results of sampling using Ontario Hydro method.

\begin{tabular}{|c|c|c|c|c|c|c|c|c|c|}
\hline \multirow[b]{2}{*}{$\begin{array}{l}\text { Test } \\
\text { No }\end{array}$} & \multirow[b]{2}{*}{$\begin{array}{c}\text { Mercury in } \\
\text { Coal, lb/TBtu }\end{array}$} & \multirow[b]{2}{*}{$\begin{array}{c}\text { Stack O2, dry } \\
\%\end{array}$} & \multicolumn{6}{|c|}{ Mercury Concentration in Stack Gas } & \multirow{2}{*}{$\begin{array}{c}\text { Mercury } \\
\text { Reduction } \\
\text { from Coal, } \\
\%\end{array}$} \\
\hline & & & $\begin{array}{c}\mathrm{Hg}^{\mathrm{p}} \\
\mu \mathrm{g} / \mathrm{dm}^{3}\end{array}$ & $\begin{array}{c}\mathrm{Hg}^{0} \\
\mu \mathrm{g} / \mathrm{dm}^{3}\end{array}$ & $\begin{array}{c}\mathrm{Hg}^{+2} \\
\mu \mathrm{g} / \mathrm{dm}^{3}\end{array}$ & $\begin{array}{l}\text { Total } \mathrm{Hg} \\
\mu \mathrm{g} / \mathrm{dm}^{3}\end{array}$ & $\begin{array}{c}\text { Total } \mathrm{Hg} \\
\left(@ 0 \% \mathrm{O}_{2}\right) \\
\mu \mathrm{g} / \mathrm{dm}^{3}\end{array}$ & $\mathrm{Hg}$ total, Ib/TBtu & \\
\hline 1 & 5.2 & 5.0 & 0.44 & 0.25 & 0.17 & 0.86 & 1.13 & 0.7 & 87 \\
\hline 2 & 4.5 & 5.0 & 1.49 & 0.23 & 0.35 & 2.07 & 2.72 & 1.7 & 63 \\
\hline 3 & 5.2 & 5.0 & 1.38 & 0.77 & 0.18 & 2.33 & 3.06 & 1.9 & 64 \\
\hline 4 & 5.0 & 5.0 & 1.72 & 0.38 & 0.17 & 2.27 & 2.98 & 1.8 & 63 \\
\hline
\end{tabular}

Note: mercury content in coal in Test \#4 was assumed to be average of that in Tests \#1-3

Stack mercury emissions were reduced from $2.9 \mathrm{lb} /$ TBtu to $1.8 \mathrm{lb} /$ TBtu due to boiler operation differences in conjunction with combustion optimization, a $38 \%$ improvement in "native" mercury capture on fly ash. Average "native" mercury reduction from coal was $\sim 42 \%$ at baseline conditions (Section 3.1) and 64\% at optimized combustion conditions. Average LOl during mercury testing at optimized conditions was $16 \%$.

It should be noted that opacity increase during combustion optimization did not allow longterm operation at optimized conditions and full load. It is not clear if this opacity increase was due to the change in boiler operation conditions or due to other reasons. As discussed at the end of Section 10, historically Unit 3 opacity increased when unit operated at full load. All combustion optimization activities were conducted at full load.

\subsection{Combustion Optimization Summary}

Goals of combustion optimization activities were to improve "native" mercury capture on fly ash and reduce $\mathrm{NO}_{x}$. Combustion optimization included balancing of coal flow through individual burners to eliminate zones of carbon-rich combustion, air flow balancing, and burner adjustments. As part of the project, the original riffle boxes were replaced with Foster-Wheeler's adjustable riffle boxes to allow for biasing the coal flow between the two outlets. A 10-point sensor grid was installed in the primary superheater region of the back pass to assist in these activities. The grid provided information on spatial distributions of $\mathrm{O}_{2}$, $\mathrm{NO}_{x}$, and $\mathrm{CO}$ in the back pass. Before coal balancing the maximum deviation in coal flow from the average flow was $22 \%$. After coal flow balancing all mills were within the $\pm 10 \%$ criterion. As a result of coal flow balancing $\mathrm{NO}_{x}$ emissions were reduced by $10 \%$. Through a series of adjustments to the burner air register disks, the variation in the point-to-point grid $\mathrm{O}_{2}$ measurements was lowered to $15 \%$. As a result of air flow balancing $\mathrm{NO}_{x}$ emissions were reduced by additional $7 \%$, bringing overall $\mathrm{NO}_{x}$ reduction due to combustion optimization to 
$16 \%$.

Testing of mercury emissions before and after combustion optimization has demonstrated that mercury emissions were reduced from $2.9 \mathrm{lb} /$ TBtu to $1.8 \mathrm{lb} /$ TBtu due to boiler operation differences in conjunction with combustion optimization, a 38\% improvement in "native" mercury capture on fly ash. Native mercury reduction from coal was $\sim 42 \%$ at baseline conditions and $64 \%$ at optimized combustion conditions. 


\subsection{CFD Modeling}

Effective mercury removal using sorbent injection is possible only when sorbent is uniformly distributed across the duct cross-section, allowing better utilization of mercury removal capacity of the sorbent. Recent results ${ }^{4}$ of Computational Fluid Dynamics (CFD) modeling of sorbent injection suggest that relatively low mercury removal efficiencies due to sorbent injection observed at least in some full-scale tests were due to poor sorbent mixing with flue gas. Poor mixing may be the result of improper design of sorbent injection lances or due to flue gas flow distribution.

The following sections describe CFD model setup and modeling results of water and sorbent injection upstream of the ESP.

\subsection{CFD Model Setup}

A three-dimensional CFD model was developed to study the flow distribution and sorbent injection in the post air heater duct in Lee Station Unit 3. There are two ducts exiting out of the air heater and entering the ESP. The two ducts are independent and geometrically symmetrical and therefore, the CFD model was developed for the one side of the duct where sorbent would be injected. The CFD model geometry is shown in Figure 6. The model inlet is at the outlet of the air heater. A set of turning vanes sits in the 90-degree elbow to help distribute the flow and minimize the flow separation. Thirteen baffles are located at the 90 degrees turn before the ESP, along with the perforated plate to eliminate the reverse flow from the ESP.

Fluent solves transport equations, such as continuity, momentum and energy equations, to simulate the flow and temperature distributions in the duct. Physical models such as turbulence model, discrete phase model, and droplet-evaporation model are applied to account for sorbent particle mixing and water droplet evaporation processes in the turbulent duct flow.

Appropriate boundary conditions are required for enclosure of the transport equations. The boundary conditions include the flow rates at model inlets, initial particle/droplet size and droplet distribution and pressure resistance of the perforated plate. The outputs from the CFD model are velocity vectors, temperature information and particle/droplet concentration at the center of each computational cell. The information can be used to plot the velocity, temperature and particle/droplet concentration profiles in the three-dimensional domain.

4. J. Madsen; T. J . O'Brien; Wi A. Rogers; and A. Diamant "CFD Modeling of Full-Scale Sorbent Injection for Mercury Control - LessonsLearned from DOE/NETL Field Test Program". Presented at 9th EUEC Conference, J anuary 2007. 


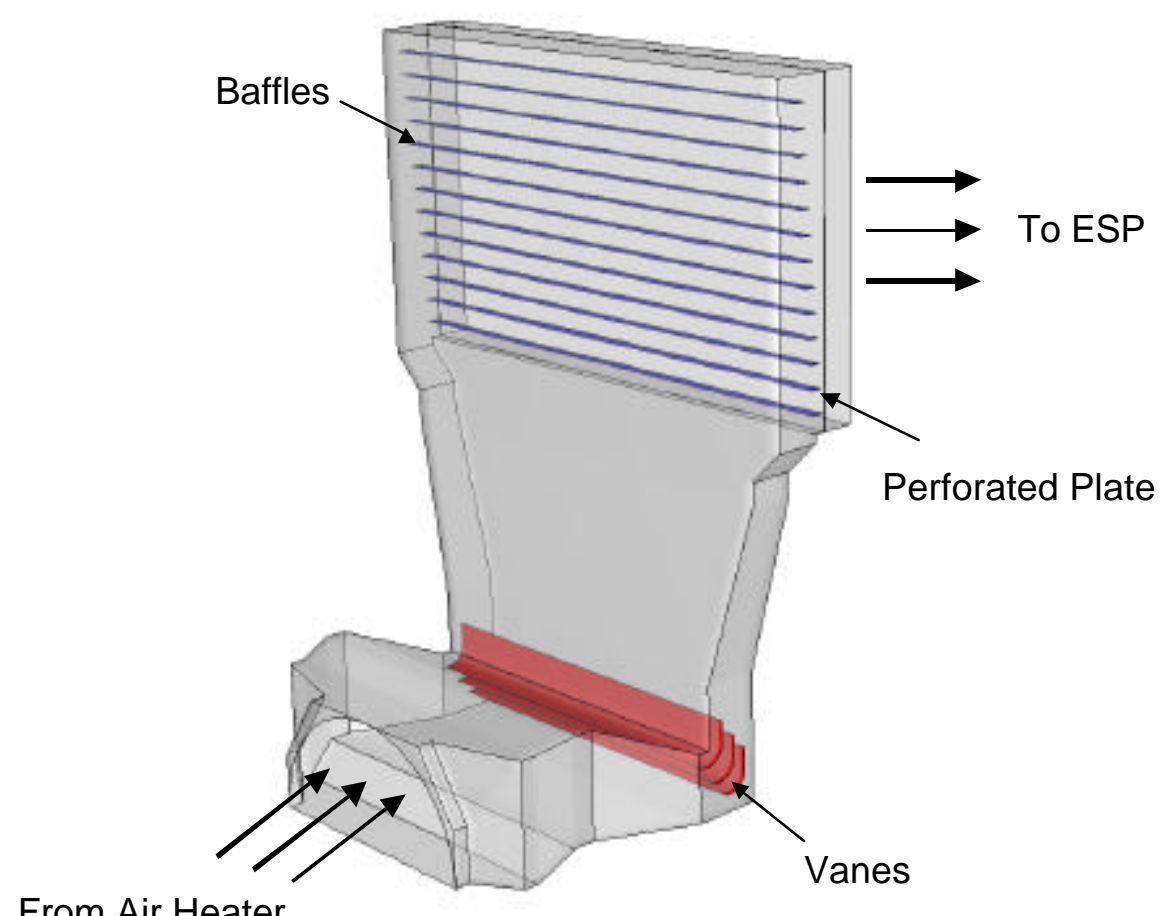

From Air Heater

Figure 6. Duct geometry for CFD modeling.

\subsection{CFD Modeling Approach and Boundary Conditions}

The CFD modeling studies followed three steps: 1) baseline study, 2) humidification system study, and 3) sorbent injection study. The baseline study provided an understanding on the flow and temperature distributions without water and sorbent injection. The humidification system study evaluated the completeness and uniformity of water droplet evaporation before the ESP. Finally, the sorbent injection study was performed to predict the sorbent particle trajectories and the mixing performance of the sorbent injection system. The discrete phase model was applied to the last two studies to simulate the particle or droplet trajectories and the mass and heat transfer between the continuous phase and the discrete phase.

The boundary conditions for the three studied cases are summarized in Table 9. The flow rates in Table 9 are for the single duct at $250 \mathrm{MW}$ load condition. Flue gas temperature at the model inlet is around $300 \mathrm{oF}$ and is biased from side to side as shown in Figure 7 . The biased temperature profile is extracted from field measurements taken by the plant downstream of the turning vanes. 
Table 9. CFD model inputs.

\begin{tabular}{llc}
\hline One Duct & Unit & Values \\
\hline Flue Gas Flow Rate & lb/hr & $1,410,815$ \\
Flue Gas Temperature & degrees F & 300 \\
Sorbent Injection & & \\
$\quad$ Transport Air Flow Rate & lb/hr & 6,550 \\
$\quad$ Sorbent Flow Rate & lb/hr & 400 \\
Transport Air Temperature & degrees F & 120 \\
Humidification & & \\
$\quad$ Water & GPM & 12 \\
$\quad$ Water Temperature & degrees F & 80 \\
Transport Air & SCFM & 325 \\
Injection Full Angle & degrees F & 25 \\
\hline
\end{tabular}

The humidification system was designed to have four lances per duct. The spacing of the lances is shown in Figure 8. The baseline design for humidification lances included three nozzles of $5.5 \mathrm{~mm}$ diameter in each lance. The water droplet injections were modeled as point injections without transport air to simplify the model geometry. The droplets were injected upward in a conical shape from the specified injection locations at a full angle of $25^{\circ}$, which corresponded to the nozzle design as specified by the vendor. It was assumed that the droplet size followed Rosin-Rammler distribution as shown in Figure 9. When the droplets impinge on the baffles, it is assumed that the droplets are dispersed and are trapped onto the baffles.

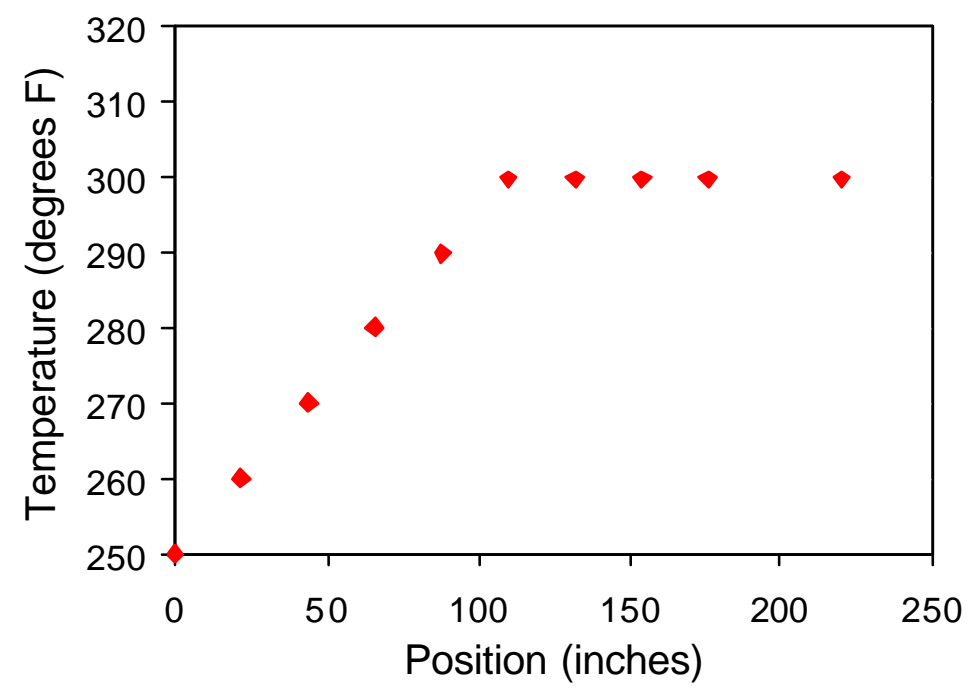

Figure 7. Temperature distribution across ESP inlet duct. 


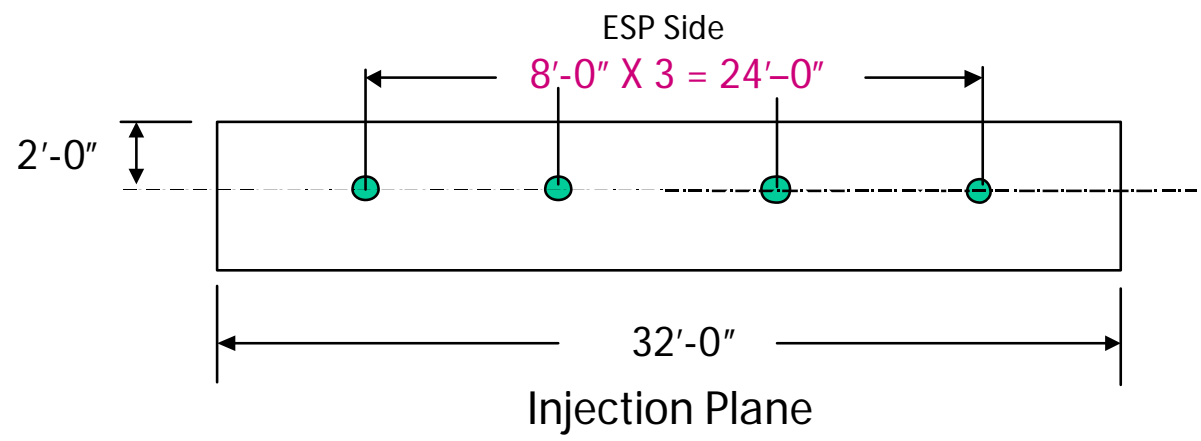

Figure 8. Lance layout for the humidification system

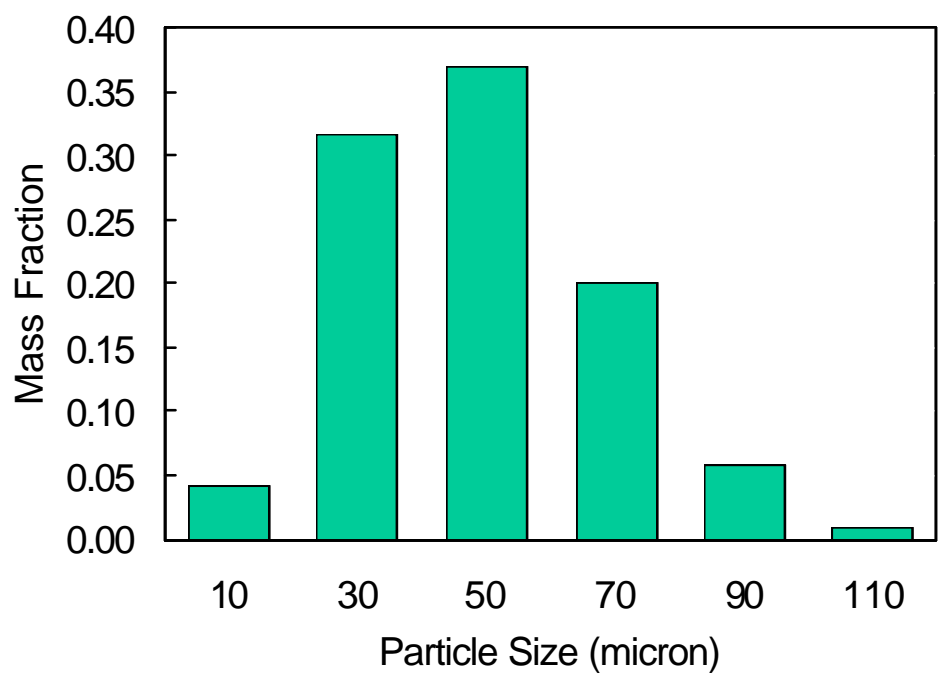

Figure 9. Water droplet size distribution.

The initial (baseline) design of the sorbent injection system consisted of four lances, each of which had eight (8) holes as shown in Figure 10. To resolve the flow field surrounding the small holes, a fine mesh was created near the lances and therefore, the model was truncated after the turning vanes to reduce the number of cells and computational time. The transport air and the sorbent flow rates are listed in Table 9. Cumulative sorbent mass fraction as a function of the particle size shown in Figure 11. It was assumed that the distribution followed a Rosin-Rammler distribution and was derived based on the mean particle size $(18 \mu \mathrm{m})$ and $95 \%$ particles less than $45 \mu \mathrm{m}$ size as specified in the DARCO ${ }^{\circledR} \mathrm{Hg}$ MSDS. 


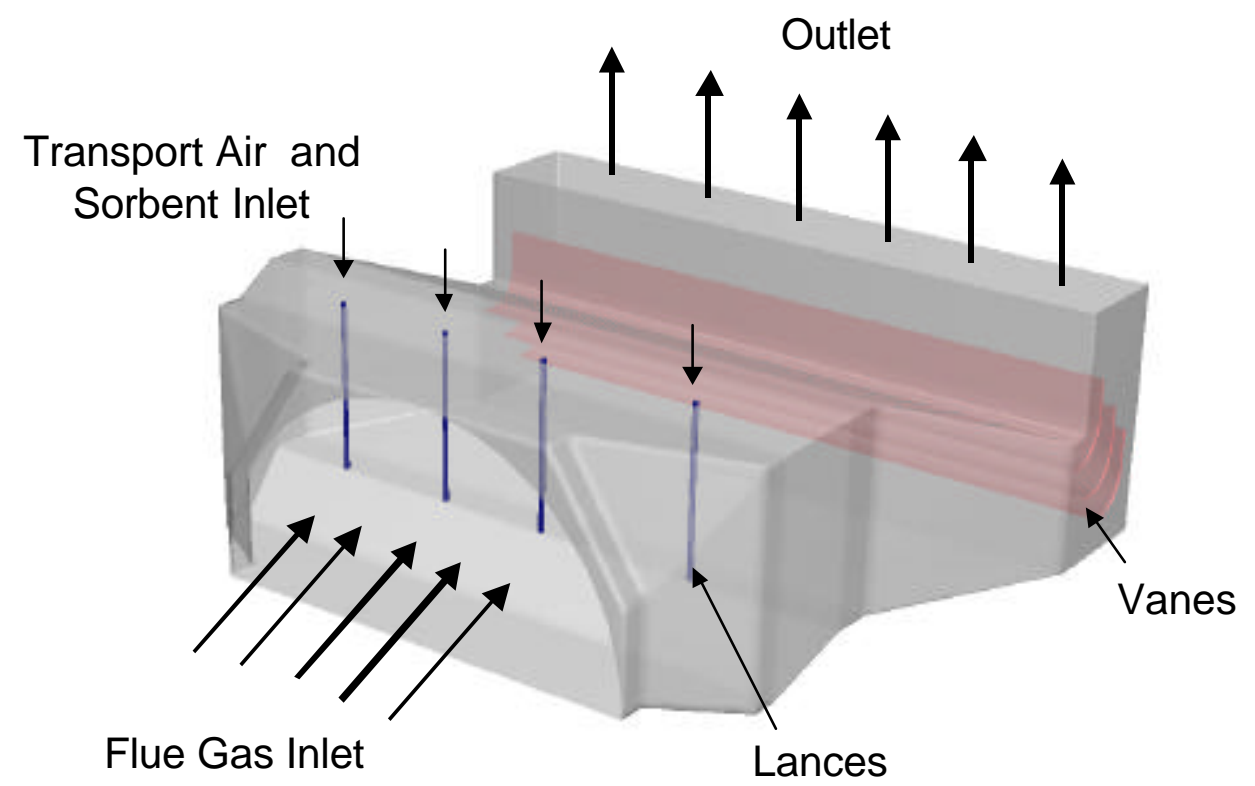

Figure 10. Sorbent injection model.

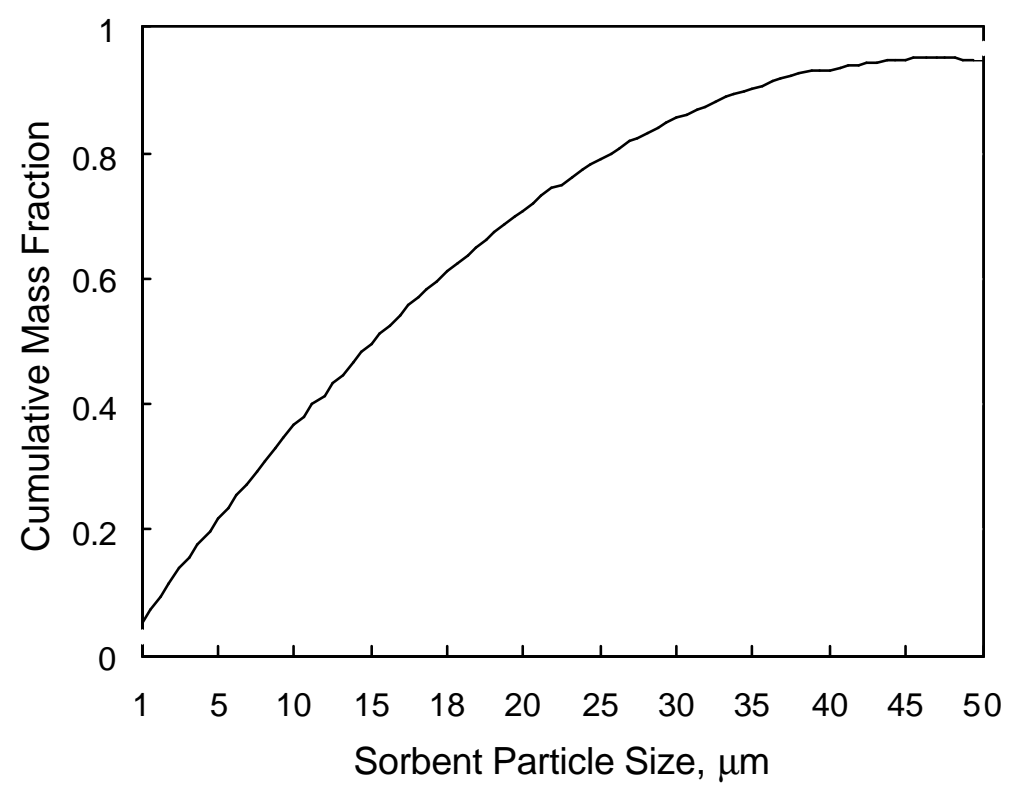

Figure 11. Sorbent particle size distribution.

The CFD results for baseline, humidification and sorbent injection studies are presented and discussed below. 


\subsection{Baseline Study}

The baseline case represents duct conditions before injection of sorbent and water droplets to lower flue gas temperature. The flow distribution at the model inlet was assumed to be uniform coming out of the air heater. The temperature profile at the model inlet, however, is biased and is specified based on the distribution shown in Figure 7.

Figure 12 shows the velocity profiles at the cross sectional planes along the duct. Since the duct transits from a circular opening to a rectangular one, flow separation occurs at the corners after the transition, which results in reverse flow in the local area. Before the elbow, the flow is severely biased from the South side to the North side due to the bend of the duct. The biased flow distribution hints that the sorbent flow distribution amongst the four lances should be biased as well to follow the flue gas flow distribution. The turning vanes at the elbow have helped to distribute the flow from front to back. However, the flow is still biased slightly in this direction.
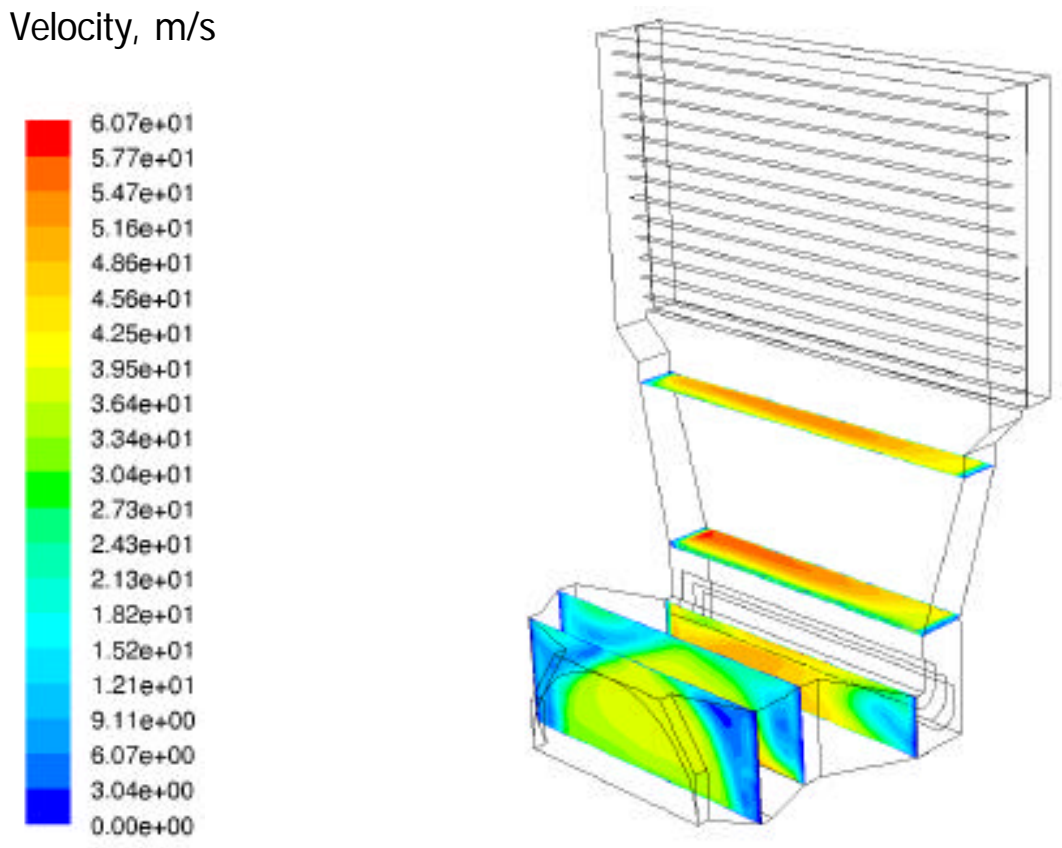

Figure 12. Baseline velocity profiles in the duct.

Temperature profiles in the duct are shown in Figure 13. The temperature varies from $250 \mathrm{oF}$ to $300{ }^{\circ} \mathrm{F}$ at inlet based on the measurements. The biased distribution is carried out through the duct with the degree of biasing being reduced by thermal diffusion and convection. Average temperature of each cross sectional plane along the duct is $287.5{ }^{\circ} \mathrm{F}$. 

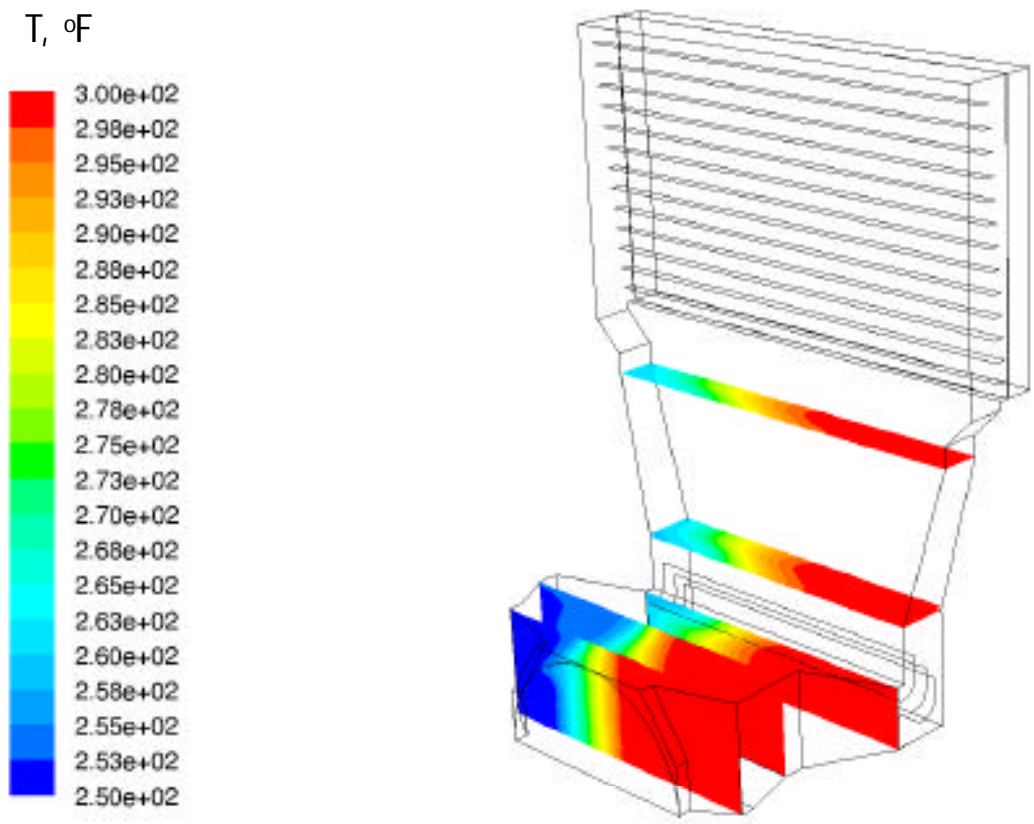

Figure 13. Temperature profiles in the duct.

\subsection{Humidification Study}

As shown in Figure 14, water droplets are sprayed upward from four lances that are spaced out evenly. Each lance has three small nozzles with 25 degrees spray angle. The trajectories of the water droplets in Figure 14 are colored by residence time. It takes about 500 milliseconds for the droplets to travel from the nozzles to the front of the baffles.

Figure 15 shows the water droplet concentrations. The concentrations of water droplets have a discrete distribution and the discrete distribution is carried out through the rest of the duct. At the model exit, i.e., the entrance of ESP, more than $80 \%$ (mass weighted) of droplets are evaporated and less than $20 \%$ of droplets escape to the ESP, most of which escape from the North side of the duct as shown in Figure 15. The biased water-droplet escaping rate is due to the imbalanced temperature distribution in the duct. The flue gas temperature in the duct is lower on the North side as shown in Figure 16. As a result, the droplet evaporation rate is slower on the North side than that on the South side.

To reduce the amount of water droplets escaping to ESP, the water flow rate to lances can be adjusted. A study was done to evaluate the improvement of water droplet evaporation by closing the lance on the Northmost side. The result indicates that the amount of evaporated droplets increases from $80 \%$ to $85 \%$. 
Time, $\mathrm{s}$
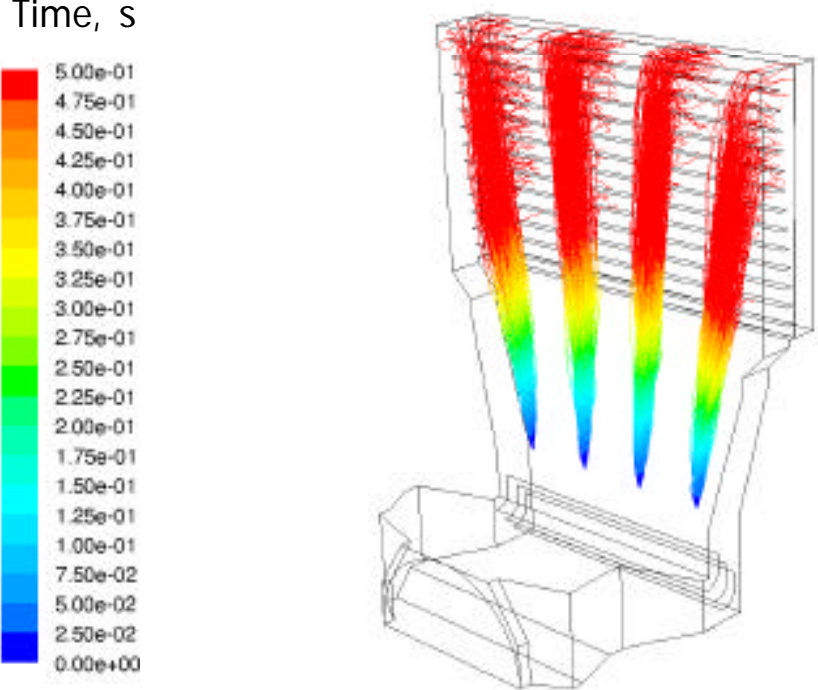

Figure 14. Water droplets trajectories colored by residence time.
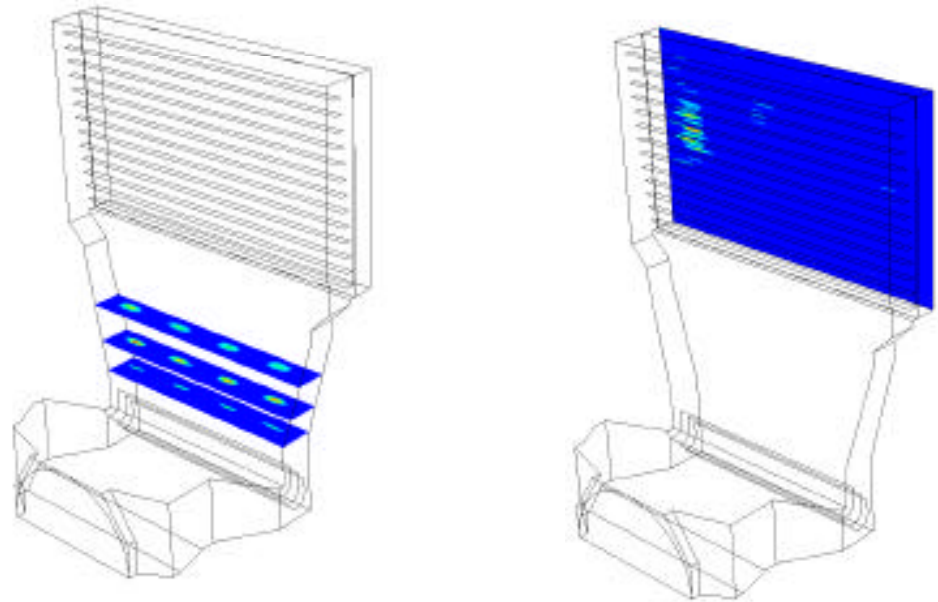

Figure 15. Water droplet concentration. 

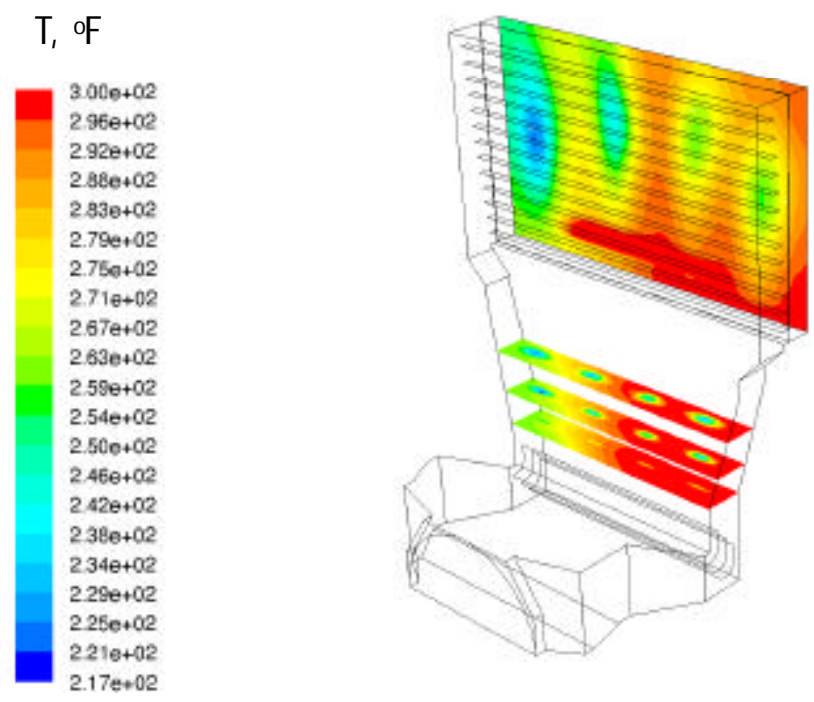

Figure 16. Temperature profiles in the duct.

\subsection{Sorbent Injection Study}

The following arrangement for sorbent injection was modeled: (1) four sorbent injection lances are placed unevenly across the duct and (2) sorbent is pre-mixed with transport air and enters the computational domain at the top of each lance. Sorbent and transport air then leave the lances at a high speed and in an alternate pattern to produce a good mixing between sorbent and flue gas as shown in Figure 17.

The distributions of sorbent concentration, however, are discrete based on CFD predictions as shown in Figure 18. Both temperature profiles Figure 19) and the sorbent concentration profiles indicate that the area between the lances lacks sorbent coverage. The lack of coverage increases between the two lances located at South side where the spacing between the lances is wider.

Figure 20 shows the sorbent trajectories in the duct. The sorbent does not penetrate far enough into the flue gas. The particles are carried along with the flue gas at a close distance from the holes. Further studies have demonstrated that the sorbent coverage between lances can be improved by increasing the transport-air flow rate and therefore, the momentum of the transport air.

Figure 20 also indicates that the sorbent injected near corners may enter the recirculation zone that is produced by the transition from the circular duct to the rectangular duct. The sorbent that is brought into the recirculation zone may enter the air heater. Reducing the sorbent flow rate near North comers may help to solve this problem. 


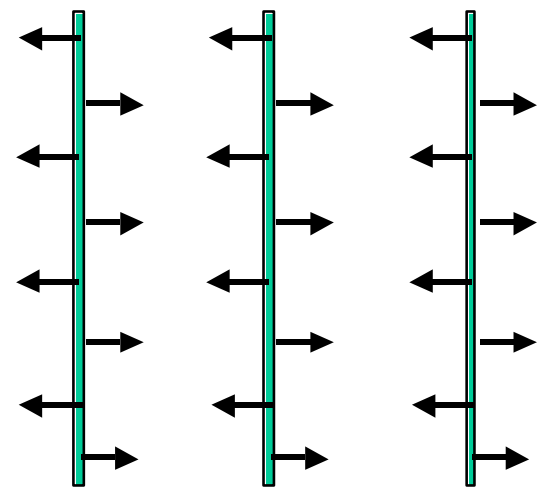

North

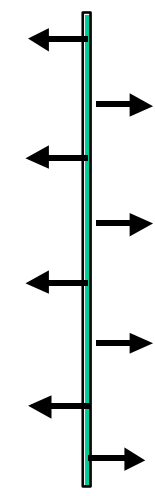

South

Figure 17. Sorbent injection lances.
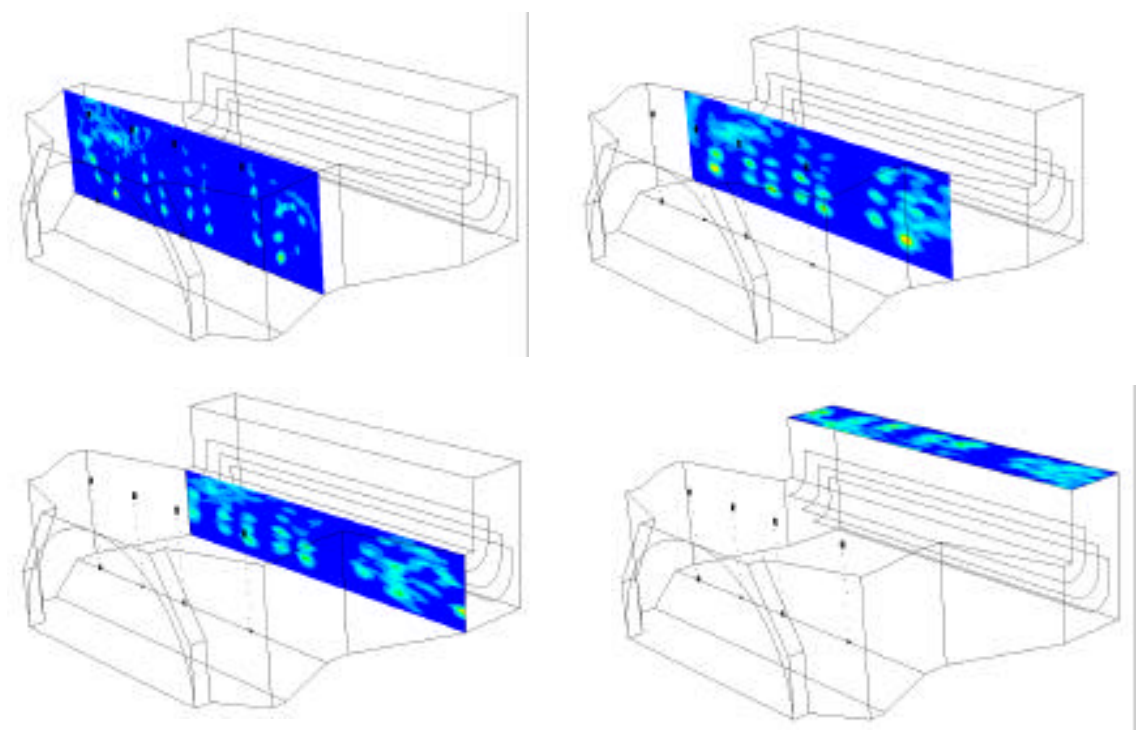

Figure 18. Sorbent particle concentrations. 


\section{$\mathrm{T}, \mathrm{oF}$}
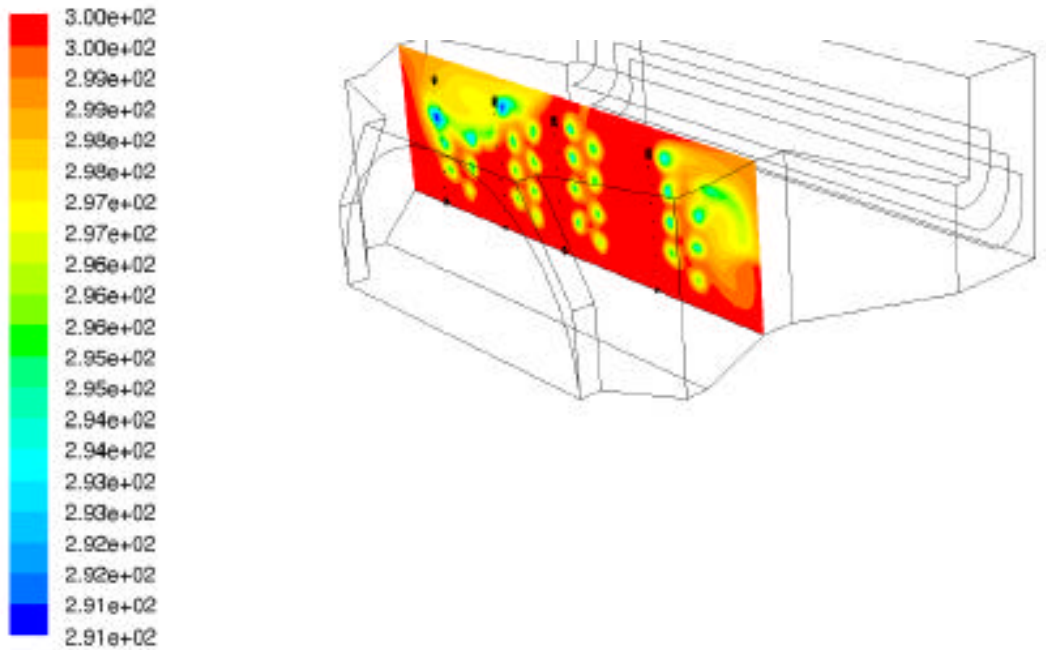

Figure 19. Temperature distribution.

Time, $\mathrm{s}$
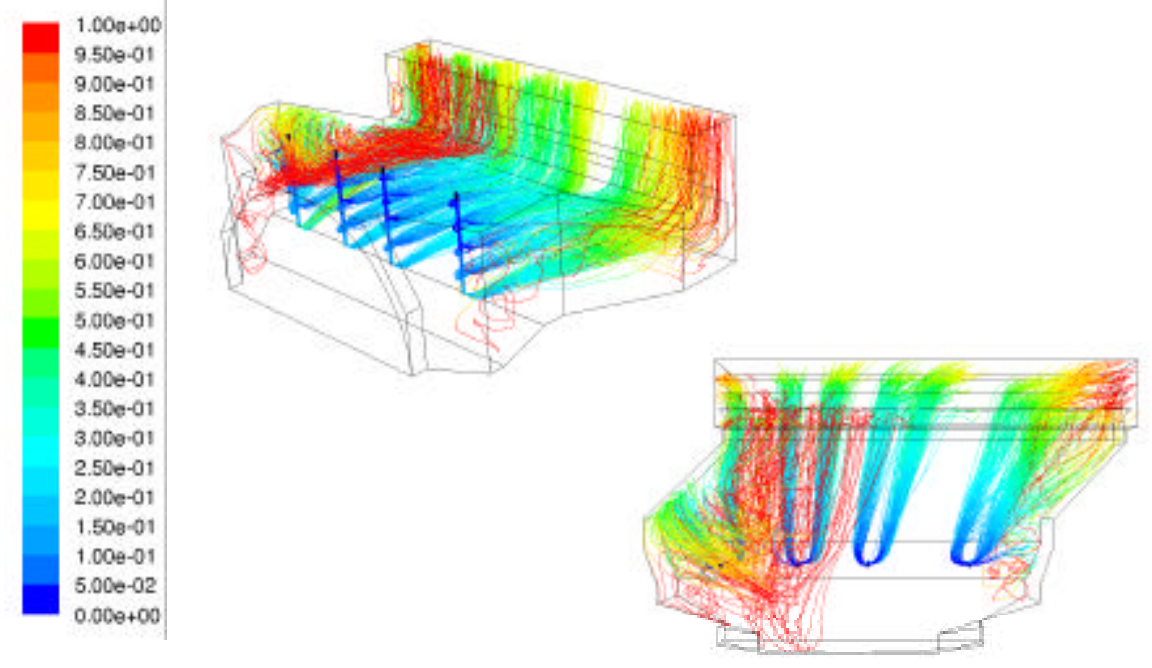

Figure 20. Sorbent trajectories colored by residence time.

\subsection{CFD Summary}

A three-dimensional CFD model was developed to study the flow distribution and sorbent injection in the post air heater duct in Lee Station Unit 3. Modeling of the flow pattern exiting the air pre-heater demonstrated that because of the duct transition from a circular opening at the exit of air pre-heater to a rectangular ESP inlet duct, flow separation occurs at the corners after the transition. Modeling also demonstrated that the flow is severely biased from the South side to the North side due to the bend of the duct. The flue gas temperature at the air pre-heater exit varies from 250 of to 300 of and the biased temperature 
distribution is carried out through the duct with the degree of biasing being reduced by thermal diffusion and convection.

Modeling of water injection demonstrated that $40 \mu \mathrm{m}$ water droplets (average droplet size) evaporated within 500 milliseconds after the injection. Modeling showed that because of flue gas temperature biasing, the droplet evaporation rate is slower on the North side than that on the South side of the duct. Modeling suggested that an improvement of water droplet evaporation could be achieved by closing the lance on the North side where flue gas temperatures were lower.

Modeling of sorbent injection demonstrated that for the baseline design of sorbent injection lances and sorbent transport air the area between the lances did not have good sorbent coverage. Further analysis demonstrated that the sorbent coverage between lances could be improved by increasing the transport-air flow rate. 


\subsection{Pilot-Scale Testing}

Pilot-scale testing was designed to provide an initial assessment of the sorbent selection and sorbent injection rate for full-scale testing. Evaluation of the effect of carbon-based sorbents injection on mercury reduction took place in a $1 \mathrm{MBtu} / \mathrm{hr}(300 \mathrm{~kW})$ Boiler Simulator Facility (BSF) equipped with an ESP at the GE Energy Test Site in Santa Ana, CA.

\subsection{BSF Description}

The BSF (Figure 21) is designed to simulate a coal-fired boiler. It consists of a burner, vertically down-fired radiant furnace, and horizontal convective pass. A variable-swirl diffusion burner with an axial fuel injector is used to simulate the approximate temperature and gas composition of a commercial burner in a full-scale boiler. Numerous ports located along the axis of the facility allow access for supplementary equipment such as OFA and additive injectors and sampling probes.

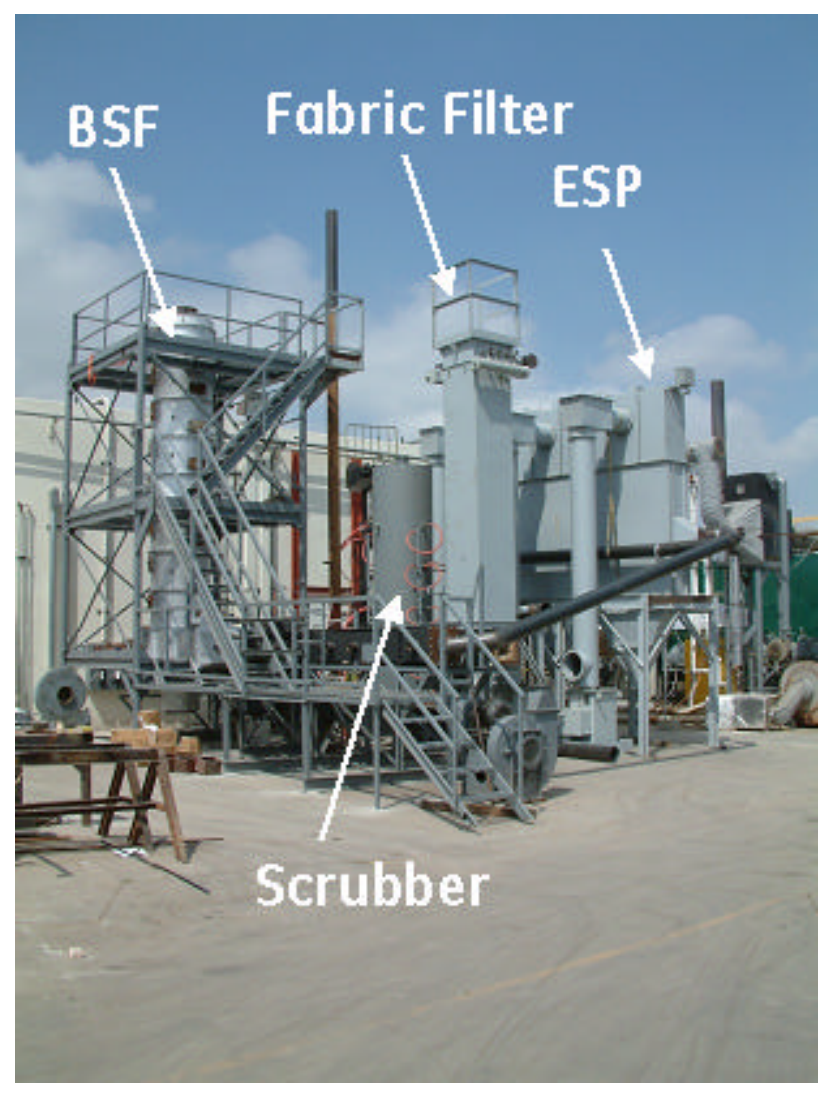

Figure 21. Boiler Simulator Facility (BSF).

The BSF was configured by using cooling rods in the convective pass to match the residence time-temperature profile and furnace exit gas temperature typical for coal fired units. The BSF was fired on natural gas overnight and on coal during the day. 
The Electrostatic Precipitator (ESP) for the BSF is a plate type unit with three electric fields, each measuring 3 feet by 4.5 feet. An individual transformer rectifier supplies power to each field. Each field contains two gas passages comprised of three parallel collecting panels. The gas passage width is defined at 4 inches. Specific Collection Area of ESP is $450 \mathrm{ft}^{2} / 1000$ ACFM. Flue gas treatment time in the ESP is about 10 seconds.

\subsection{Sorbent Performance Data}

Data on mercury removal were obtained using US EPA Appendix K method also known as Quick CEM or carbon tube method. Frontier Geosciences analyzed sorbent traps for total mercury. Mercury data were collected at the ESP outlet. All pilot sorbent injection tests were conducted with $\mathrm{SO}_{3}$ injection for ESP conditioning.

The BSF was fired on Lee coal and sorbent was injected upstream of the ESP. Lee coal is a low-sulfur bituminous coal, and $\mathrm{SO}_{2}$ emissions in pilot-scale tests were $\sim 610 \mathrm{ppm} @ 3 \% \mathrm{O}_{2}$. Chlorine content in Lee coal is $1,500 \mathrm{ppm}$. Two sorbents were tested: DARCO ${ }^{\circledR} \mathrm{Hg}$ (basic activated carbon from Norit Americas, Inc.) and DARCO ${ }^{\circledR} \mathrm{Hg}$-LH (brominated activated carbon from Norit Americas, Inc.). Since baseline mercury testing (see Section 3.1) demonstrated that the percentage of oxidized mercury in flue gas was $\sim 80 \%$ and DARCO ${ }^{\circledR}$ $\mathrm{Hg}$ - $\mathrm{LH}$ reactivity with oxidized mercury is about the same as that of $\mathrm{DARCO}^{\circledR} \mathrm{Hg}$, it was expected that two sorbents would show similar performances.

Figure 22 shows the effect of sorbent injection on mercury reduction. Mercury reduction was calculated as a reduction from the baseline mercury concentration at the ESP outlet due to sorbent injection only. For comparison, data on DARCO ${ }^{\circledR} \mathrm{Hg}$ performance obtained during full-scale testing ${ }^{5}$ at Brayton Point are also shown. In general, pilot- and full-scale data are in good agreement, although pilot-scale testing showed slightly better DARCO ${ }^{\circledR} \mathrm{Hg}$ performance. This is not surprising since typically pilot-scale testing provides more uniform flow of flue gas and better sorbent mixing.

Two main conclusions can be derived from Figure 22. First, DARCO ${ }^{\circledR} \mathrm{Hg}$ and DARCO ${ }^{\circledR} \mathrm{Hg}-\mathrm{LH}$ showed similar performances in the absence of $\mathrm{SO}_{3}$ injection. For the last several years a number of carbon-based sorbents were evaluated $6,7,8,9$ in pilot- and full-scale test programs. These tests have determined that different sorbents deliver different performance. However, the tests also demonstrated that halogen impregnated sorbents such as B-PAC by Sorbent Technologies, Inc. and $\mathrm{DARCO}^{\circledR} \mathrm{Hg}-\mathrm{LH}$ by Norit Americas, Inc. delivered superior performance (both regarding to mercury removal efficiency and overall cost of mercury

5. Feeley, T.J. III., Murphy, J, Hoffmann J ., and Renninger, S.A.. 'A Review of DOE/NETL's Mercury Control Technology R\&D Program for Coal-Fired Power Plants". DOE/NETL Hg R\&D Program Review, April 2003.

6. Thompson et al. "Sorbent Injection into a slipstream baghouse for mercury Control: Screening and parametric Results", Presented at Air Quality V, September 2005.

7. Dombrowski et al. " Full-Scale Activated Carbon Injection for mercury Control in Flue Gas Derived from North Dakota Lignite and PRB Coal", Presented at Air Quality V, September 2005.

8. Sjostrom et al. "Full-Scale Evaluation of Mercury Control by Injecting Activated Carbon Upstream of a Spray Dryer and Fabric Filter", Presented at Combined Power Plant Air Pollutant Control Mega Symposium, Paper 71, August-September 2004.

9. Pavlish, et al. "Pilot-Scale Testing of Sorbent Injection and Fuel Additives for Mercury Control" Presented at Combined Power Plant Air Pollutant Control Mega Symposium, Paper 108, August-September 2004. 
control) to other sorbents for low-rank coal combustion. This is because bromine present in promoted sorbents oxidizes elemental mercury and thus improves the ability of activated carbon to remove mercury. Since flue gas generated during combustion of Lee coal already has about $80 \%$ of mercury present in the oxidized form, promoted sorbents do not offer additional performance advantage in comparison with the baseline sorbent. Pilot-scale testing confirmed this observation. Based on results of pilot-scale testing, the sorbent injection rate required to achieve incremental $70 \%$ mercury reduction without $\mathrm{SO}_{3}$ injection was estimated at $10 \mathrm{lb} / \mathrm{MMACF}$.

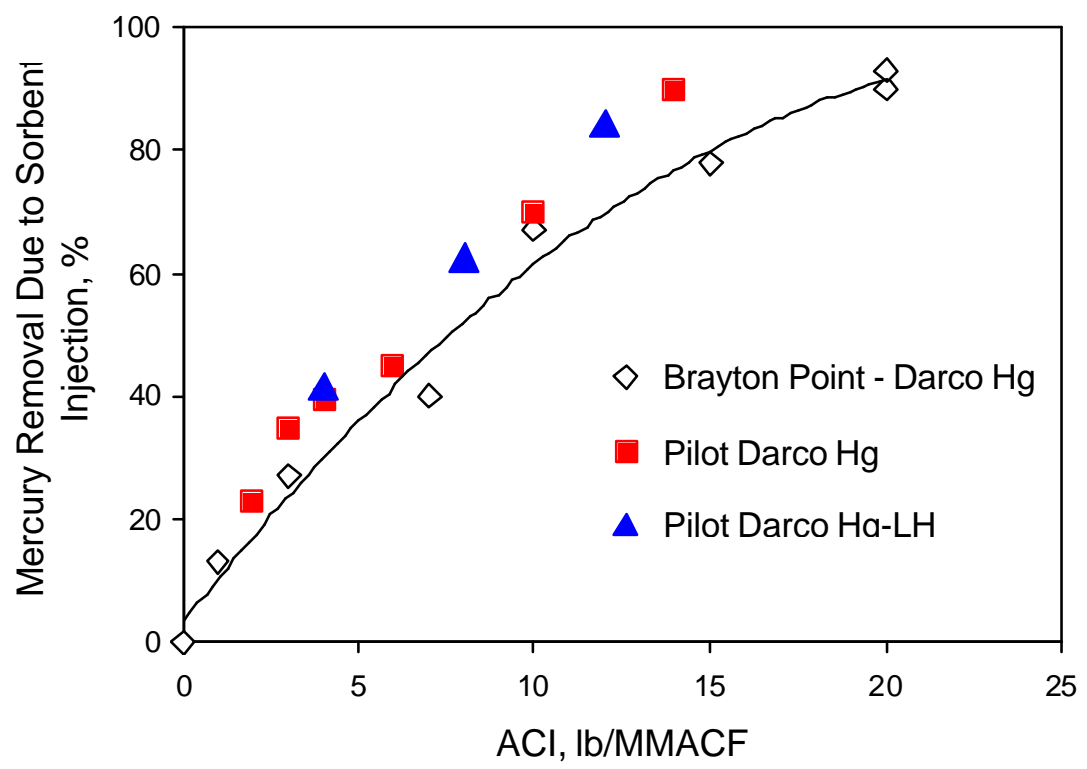

Figure 22. Effect of sorbent injection on mercury removal.

\subsection{Pilot-Scale Summary}

Evaluation of the effect of carbon-based sorbents injection on mercury reduction took place in a $1 \mathrm{MBtu} / \mathrm{hr}(300 \mathrm{~kW})$ Boiler Simulator Facility (BSF) equipped with an ESP. Testing demonstrated that DARCO ${ }^{\circledR} \mathrm{Hg}$ and DARCO ${ }^{\circledR} \mathrm{Hg}$ - $\mathrm{LH}$ showed similar performances. Based on results of pilot-scale testing, DARCO ${ }^{\circledR} \mathrm{Hg}$ was recommended for long-term testing. Sorbent injection rate required to achieve the $70 \%$ incremental improvement in mercury reduction was estimated at $10 \mathrm{lb} / \mathrm{MMACF}$. 


\subsection{Equipment Installation}

The following equipment was installed at Lee station in preparation for testing:

- Sorbent injection system

- Duct humidification system

- Mercury CEMs

In addition, steel piping to deliver sorbent to the injection location, flexible hoses for water and air for humidification system, and lances for water and sorbent injection were also installed. The following sections describe installed equipment in more detail.

\subsection{Sorbent Injection System}

The sorbent injection system was designed and fabricated by Nol-Tec using GE specifications. A system schematic is shown in Figure 23. The system is designed to inject up to $1,000 \mathrm{lbs}$ of sorbent per hour. It can accept sorbent from a pneumatic bulk trailer with $40,000 \mathrm{lb}$ sorbent capacity or from 900 -pound bulk bags. The bulk trailer is refilled from a delivery truck. The system includes a conveying interface with the stationary bulk trailer as well as a stand-alone dust collector to filter the conveying air produced by the delivery truck. The alternate supply of powdered activated carbon is via bulk bags. To handle these bags the system has a bulk bag discharger with integral hoist and trolley and a manual gate valve and rotary airlock with a pneumatic pickup shoe at the discharge.

A dilute phase pressure pneumatic conveying system accepts material from either the stationary site bulk trailer or the bulk bag discharger, and transfers the powdered activated carbon to a 250 cubic foot storage silo. The silo is equipped with a rigid fill line, an end receiver, a dust collector that captures nuisance dust and returns it to the process, three point level probes (material low level, material high level, emergency high level), fluidizing air pads, and a maintenance gate located on the silo hopper discharge. Attached to the maintenance gate at the discharge of the silo hopper is a rotary airlock with a pneumatic pickup shoe. This airlock is used to meter material into the injection conveying line. Calibration of the actual amount of sorbent injected at different airlock setting was performed during system shakedown.

A second dilute phase pressure pneumatic conveying system takes the powdered activated carbon metered by the holding silo rotary airlock and transfers it 35 feet horizontally and 80 feet vertically to a convey line splitter. The convey line splitter divides the powdered activated carbon feed into four equal streams, each stream feeding a flue gas duct injection lance Figure 24).

The installed sorbent injection system along with bulk trailer for sorbent storage are shown in Figure 25. 


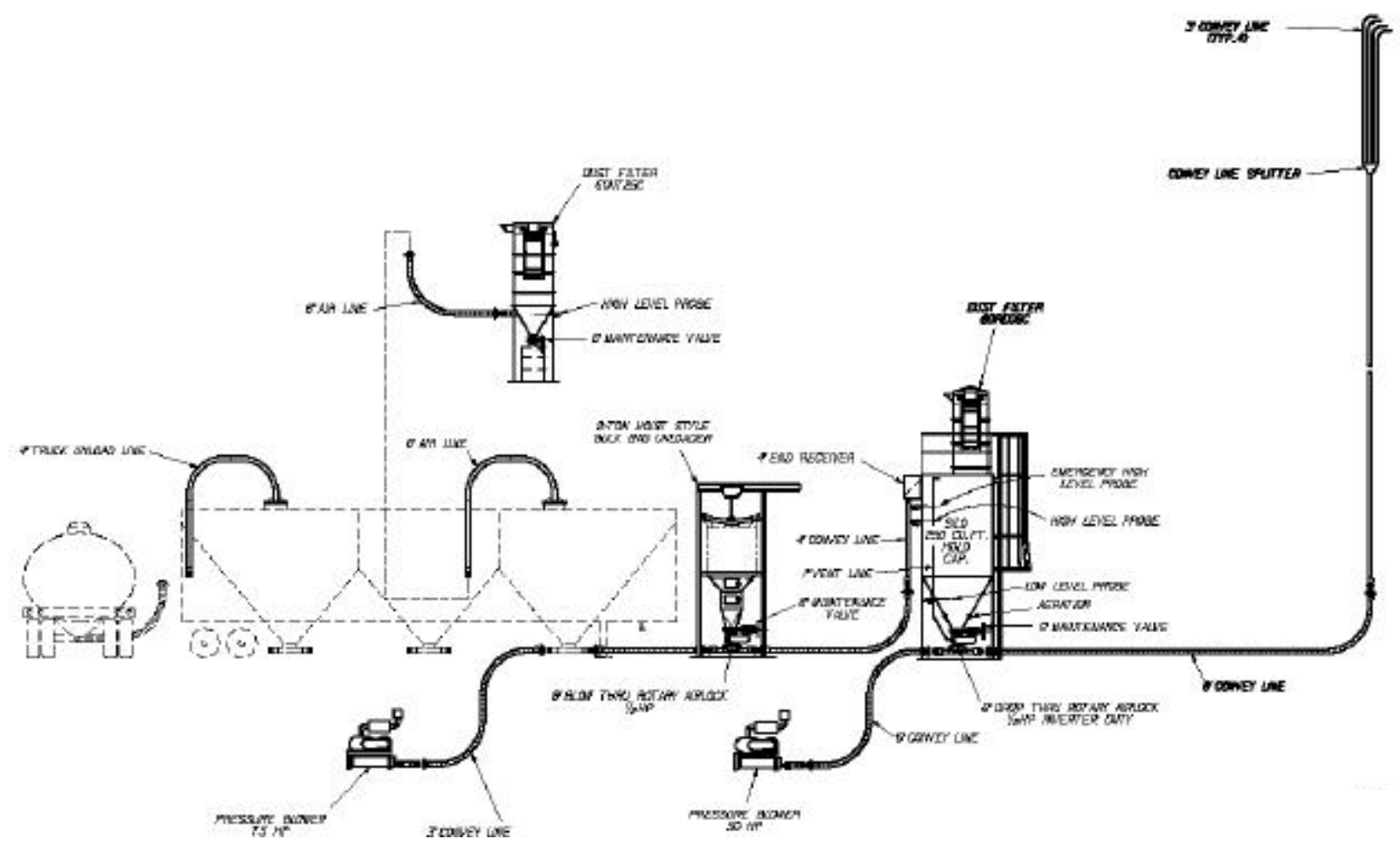

Figure 23. Sorbent injection system

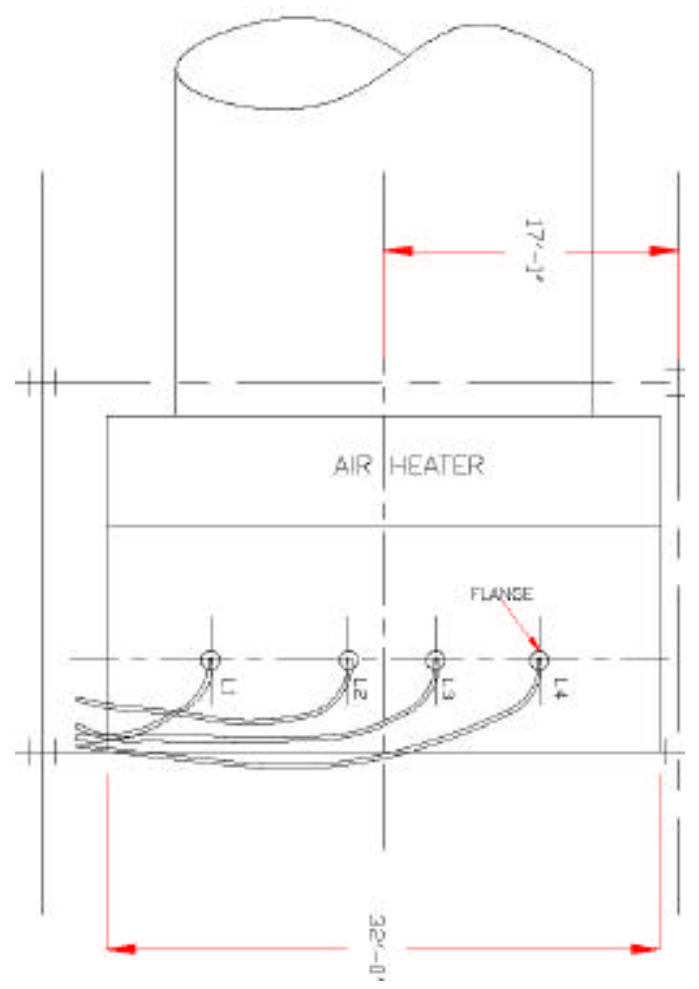

Figure 24. Arrangement for sorbent injection. 


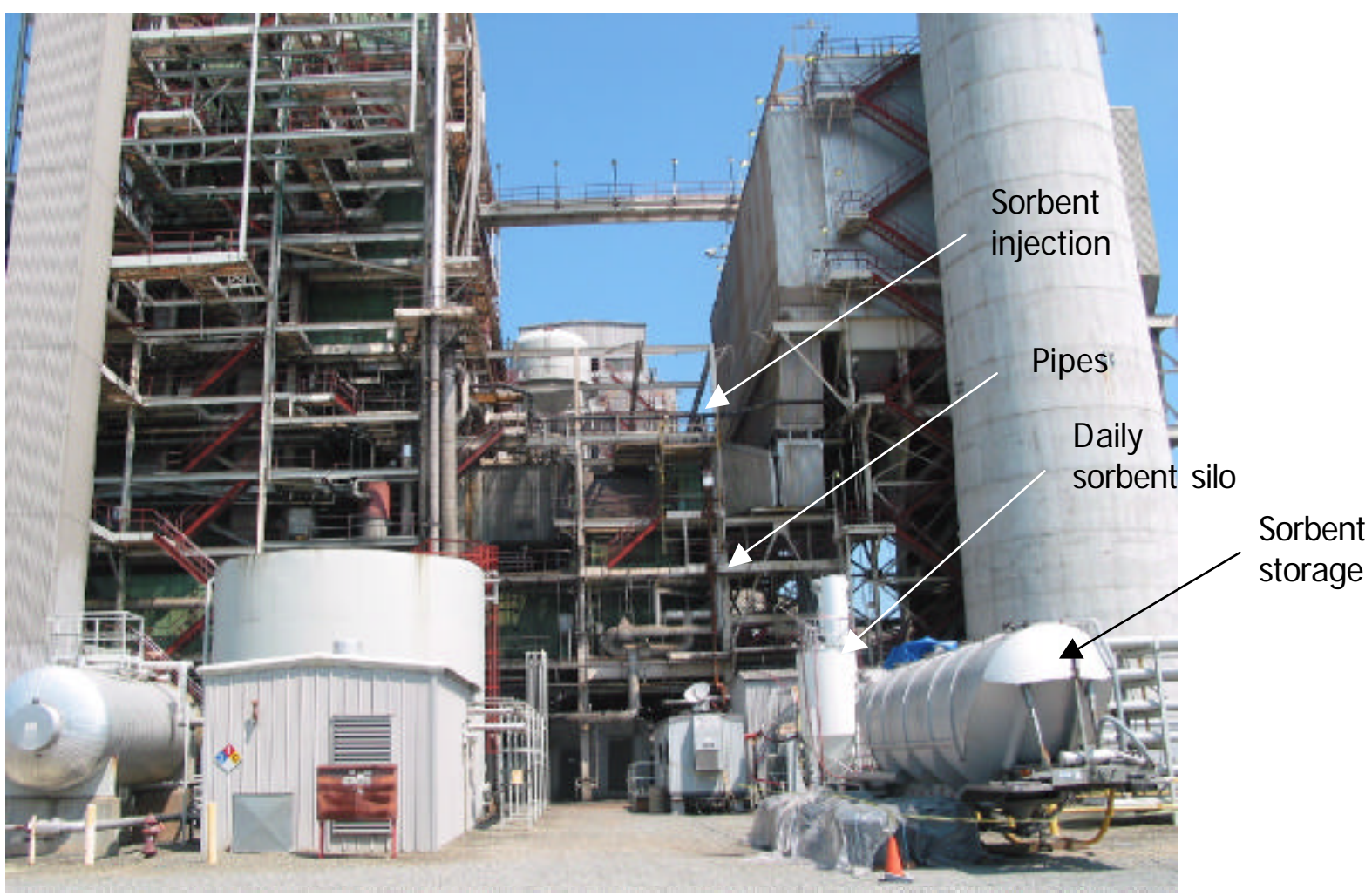

Figure 25. Installed sorbent injection system at Lee station.

Sorbent is delivered to the 4-way splitter using 6 inch steel pipe. Lances are connected with the 4-way splitter using flexible rubber hoses.

\subsection{Humidification System}

The humidification system uses a dual fluid nozzle system (compressed air and water) and is designed to cool flue gas by $30^{\circ} \mathrm{F}$ without water droplet carryover into the precipitator. The result of injecting and evaporating water is a gas at the precipitator inlet with reduced temperature. It was expected that lowering flue gas temperature would improve carbon reactivity towards mercury. Another potential benefit of lowering flue gas temperature is improved ESP performance. Humidification reduces the gas volume to be treated in the precipitator and decreases the electrical resistivity of the dust, which means the precipitator can operate more efficiently. As a result, the power input to the precipitator is higher because of an increased threshold voltage and reduced sparking, which results in better precipitator performance. It was expected that improved ESP performance could reduce potential increase in opacity as a result of sorbent injection.

Major system components are listed below:

- Spray lance assemblies with cluster head dual fluid nozzles.

- Spray lance mounting boxes, connecting hoses and hardware. 
- Pump skid assembly and control panel.

- Thermocouples for the inlet and outlet of the system in each inlet duct.

- A patented microprocessor based control system incorporating state-of-the-art software.

- A $500 \mathrm{G}$ water tank as a buffer in the water supply system.

- Air and water headers with pressure transmitters.

- Air compressor, dryer and receiver.

The nozzle pattern was selected to ensure a uniform spray over the cross section of the inlet ducts. A uniform gas-to-water ratio across the duct cross-section is required for proper cooling of gases, ensuring that all water droplets are vaporized before reaching the inlet plenum louvered screen at the ESP inlet. In the evaporation section of the duct, all the injected water droplets are evaporated utilizing the sensible heat of the hot boiler gases. Estimates showed that the largest water droplets created by nozzles would be vaporized after a distance of $\sim 25 \mathrm{ft}$ downstream of the nozzles.

The lance assembly is shown in Figure 26 and consists of two concentric stainless steel pipes for the air and water feed to the nozzle. The outer pipe is used for the air feed line, and thus, it air-cools the entire lance assembly even when the water is not flowing. The lances are aligned in an array that allows the atomized spray of water to cover the entire cross-section of the evaporative duct. Mounting boxes with a flange are designed to provide external support and easy removal of the spray lances for inspection and maintenance. Air and water pressure gauges provide air and water pressure taps at the supply point into the lance for ease of startup and troubleshooting. Flexible hose connections, 48" long, allow for the expansion and contraction differences between the lances and the air and water headers. Quick disconnects are used with the hose assemblies to provide a simple and quick method of removing the flex hoses from the lances, which allows for easy lance removal from the duct. Ball valves provide a local method of isolating individual lances for inspection or repair.

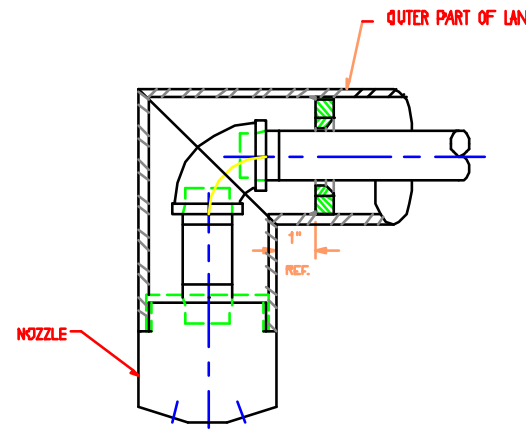

MRZZIE TIP DETAL

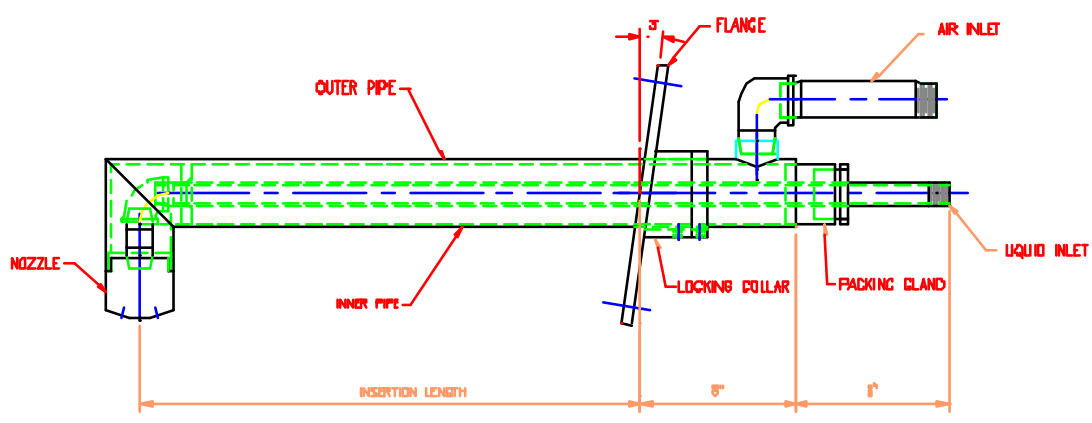

NOZZLE LANCE ASSENELY

Figure 26. Lances for water injection. 
The pump skid assembly is shown in Figure 27 and consists of a steel frame skid with two multistage vertical water pumps (one operating and one standby) that are automatically cycled to ensure equal run time. Duplex basket strainers are provided ahead of the pumps to remove large debris. The water piping includes two control valves that modulate the water flow rate to the lances as required by the microprocessor control. The water flow rate is measured and indicated by magnetic flow meters and transmitters.

Special software driven logic is used to implement control logic depending upon the frequency of process parameters variation. The variations in inlet and outlet gas temperatures are measured by fast response thermocouples, and these signals are processed by the PLC. The PLC then sends signals to the water and airflow control valves, calculated by a unique algorithm, based on the plant's operating conditions. The software evaluates the number of nozzles in service, water flow rates and the inlet/outlet temperature of the process.

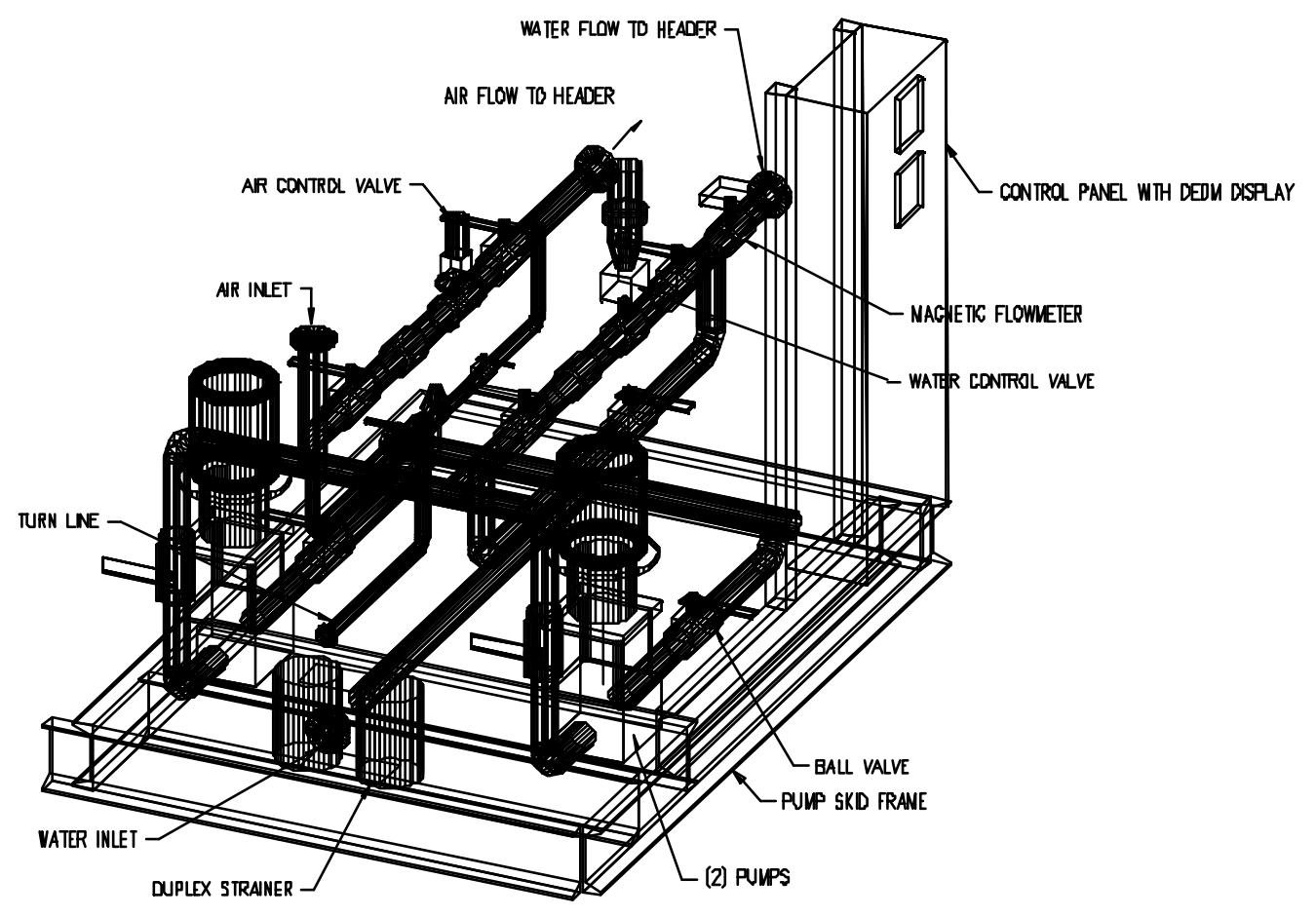

Figure 27. Pump skid and valve assembly.

\subsection{Mercury CEMs}

Mercury measurements during sorbent injection were performed by Apogee Scientific, Inc. (Apogee) using two Apogee Semi-Continuous Emissions Monitor systems with three extraction systems. Lee Unit 3 has a split ESP with sorbent injection conducted in side B. Mercury monitoring was performed at three locations as shown in Figure 28: ESP inlet and outlet on side $B$ and outlet on side $A$. Each analyzer was capable of measuring total and elemental mercury at one sampling location or total mercury at two sampling locations. The first analyzer reported speciated mercury data for the ESP inlet and the second analyzer reported total mercury concentrations for two ESP outlets. Periodically the second analyzer 
was switched to collect speciated mercury data for side B.

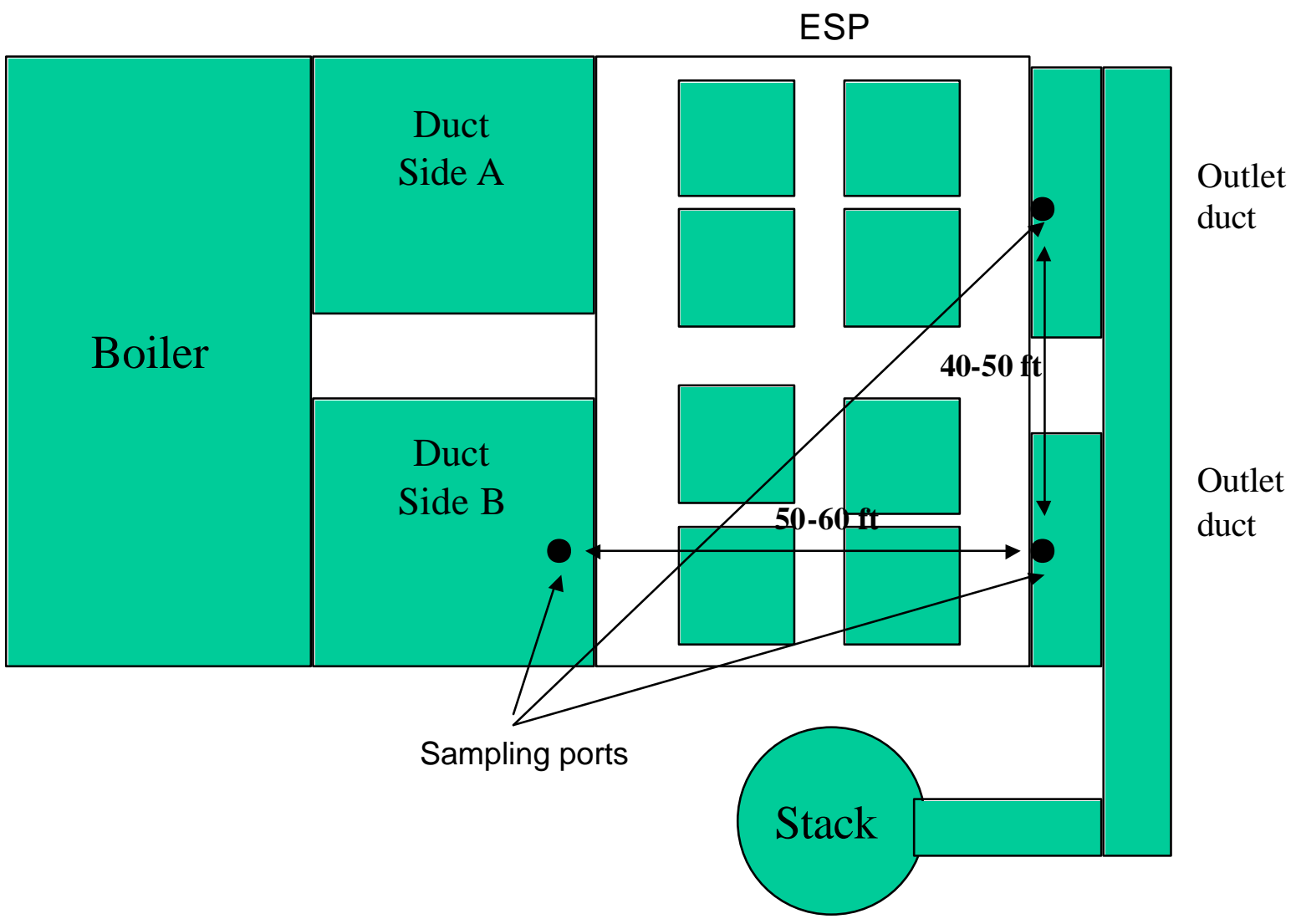

Figure 28. Arrangement for mercury sampling. 


\section{0 Optimization of Humidification and Sorbent Injection Systems}

\subsection{Optimization of Humidification System}

The following issues have to be addressed when water injection is used to lower flue gas temperature: (1) to avoid formation of slurry-type deposits, complete water evaporation has to be achieved prior to water droplets reaching turning vanes at the ESP inlet, (2) to avoid duct corrosion, the flue gas temperature always has to stay above the acid dew point. The first issue is addressed by designing nozzles to produce water droplets small enough to achieve $99 \%$ evaporation prior to reaching turning vanes. Average design droplet size for the Lee system is $40 \mu \mathrm{m}$ at water consumption through individual lances not exceeding 4 $\mathrm{G} / \mathrm{min}$.

Temperature traversing at the location of water injection lances was done prior to humidification system shakedown to ensure that water injection would not lower local flue gas temperatures below $260{ }^{\circ} \mathrm{F}$ - the acid dew temperature estimated for Lee coal in the absence of $\mathrm{SO}_{3}$ injection. Figure 29 shows locations were thermocouples were inserted in the duct. Temperature measurements were done using total 8 ports at $1 \mathrm{ft}, 2 \mathrm{ft}, 3 \mathrm{ft}$, and $4 \mathrm{ft}$ depths of the duct. The duct at the location where ports for water lances are installed is $30 \mathrm{ft}$ wide and $5 \mathrm{ft}$ deep.

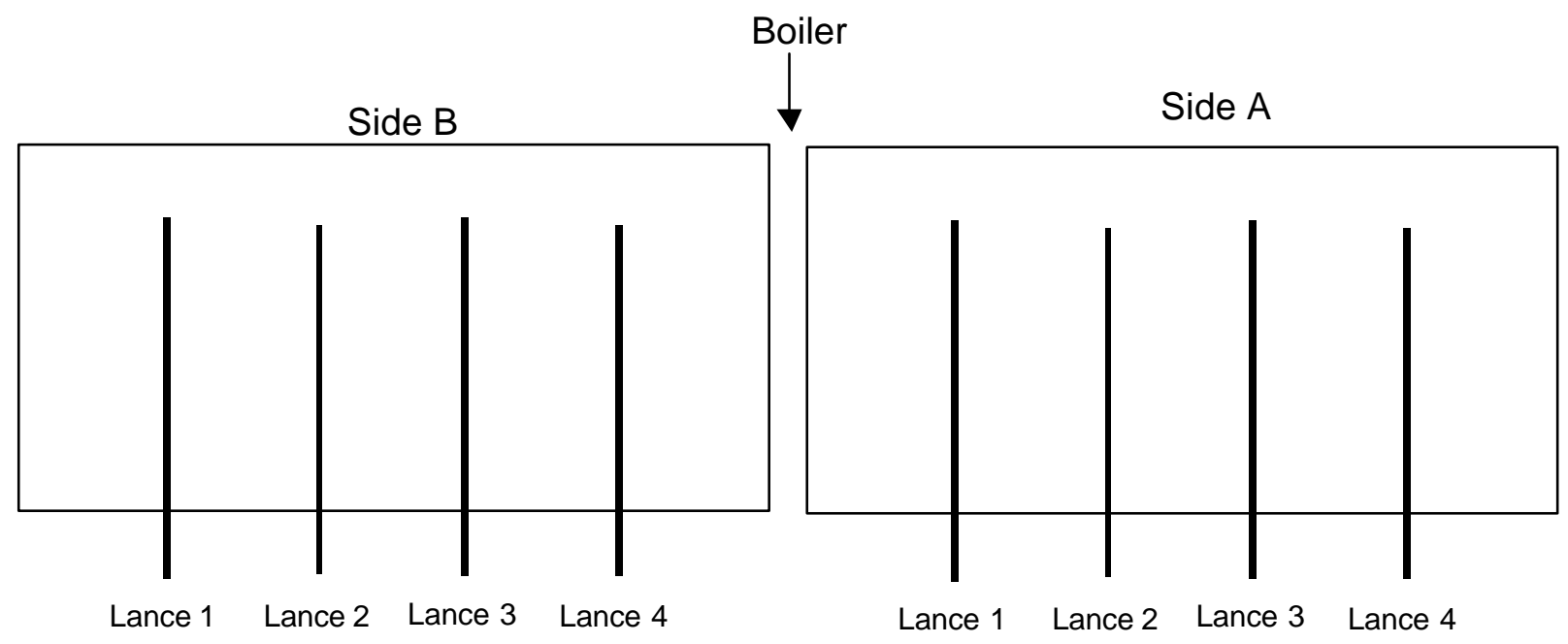

Figure 29. Arrangement of lances for water injection.

Figure 30 shows results of temperature measurements in sides A and B. Measurements showed that temperatures on both sides for two outside ports are below or slightly above $260 \mathrm{oF}$. It suggests that some duct corrosion may already take place, and water injection through these ports would only make corrosion worse. Thus, the decision was made to use only two inner lances ( 3 and 4 on side $B$ and 1 and 2 on side A) for water injection. Since the humidification system was designed to reduce flue gas temperature by 20-30 oF using 8 lances at a water consumption of up to $4 \mathrm{G} /$ min through each lance, using 4 lances instead of 8 was projected to reduce flue gas temperature on average by $10-15$ o F. Actual reduction in flue gas measured with two per side lances in operation was $12 \mathrm{oF}$, which was within the 
expected range.
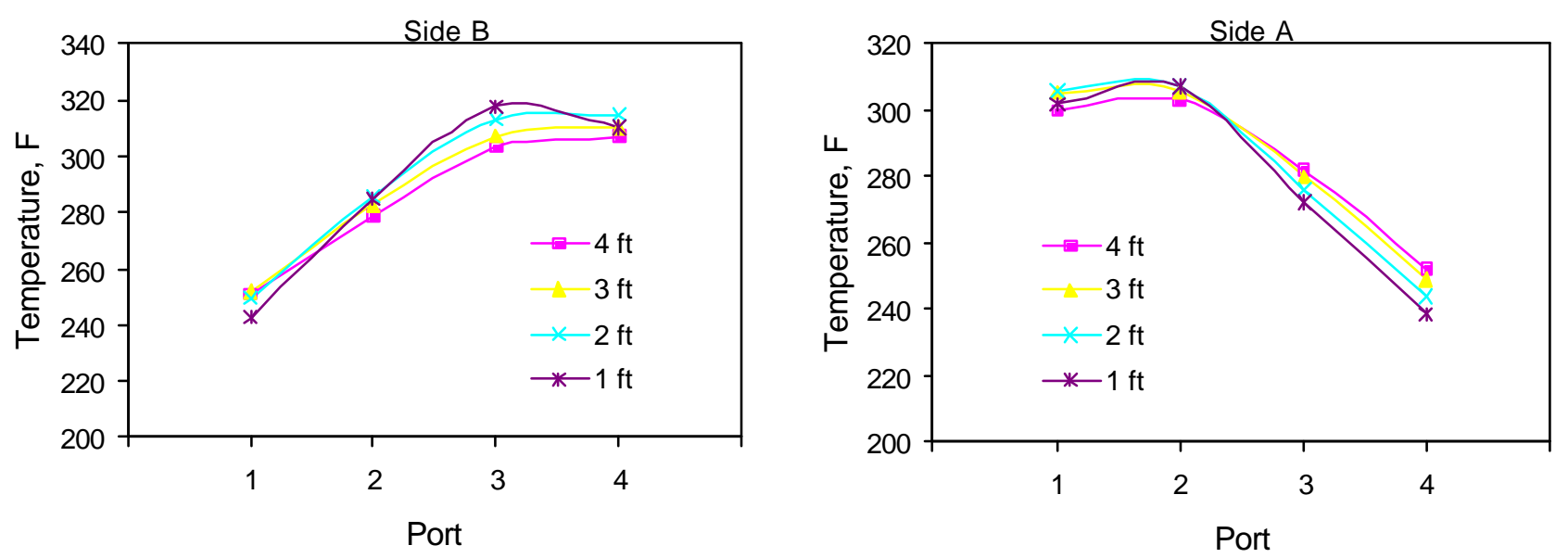

Figure 30. Temperature traversing at the location of humidification lances.

A 2-hour test was conducted in which $4 \mathrm{G} / \mathrm{min}$ of water were injected through 2 inner lances per duct. The $\mathrm{SO}_{3}$ conditioning system was not operational during the test. Although a test of this duration may not be long enough to observe the effect of duct humidification on opacity and ESP performance, it was sufficiently long to detect effect of temperature on "native" mercury reduction on fly ash. Figure 31 shows concentrations of total mercury at ESP inlet and outlet before, during, and after water injection test. No noticeable improvement in "native" mercury capture on fly ash was observed. Although mercury removal on fly ash improves with reduction of ESP temperature, it is possible that the 12 of temperature decrease was not significant enough to result in noticeable improvement in mercury capture.

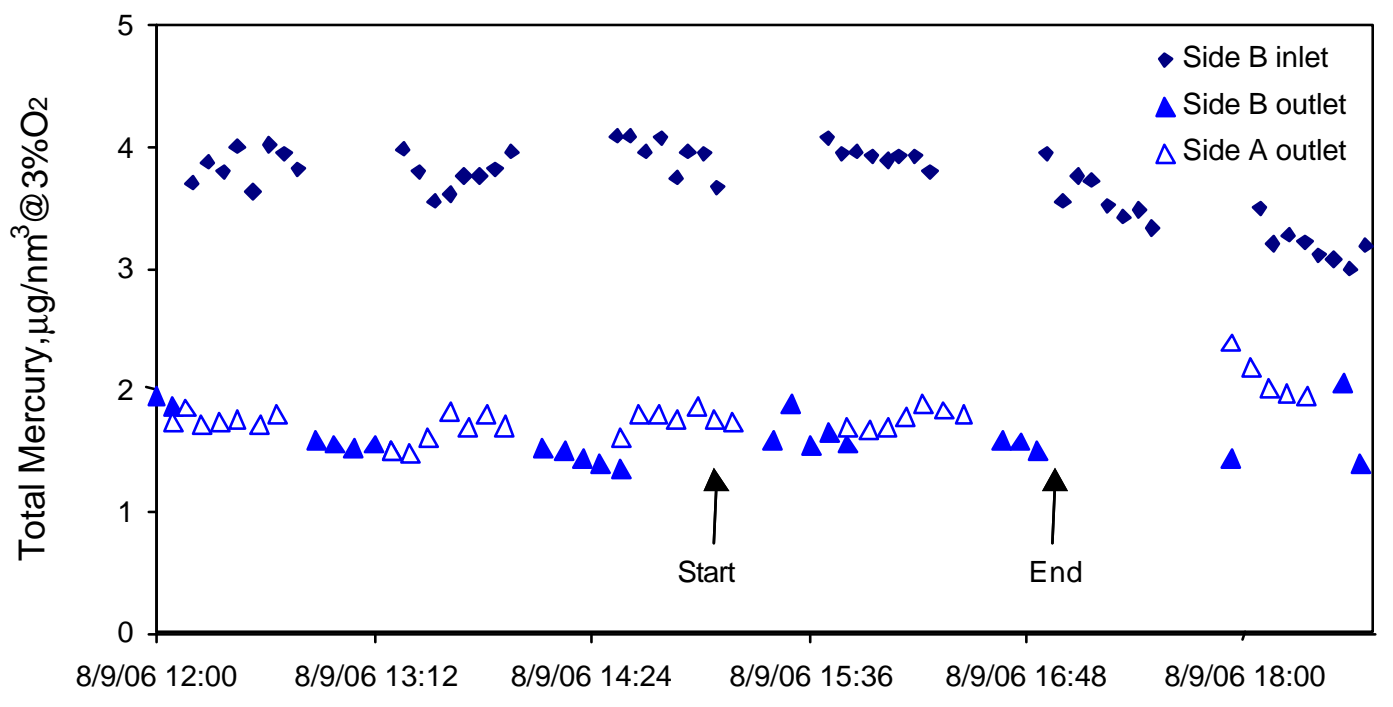

Figure 31. Mercury concentrations with and without duct humidification. 
The lances for water injection are designed to inject up to $12 \mathrm{G} /$ min of water. As water injection rate increases, average droplet size also increases resulting in longer mist evaporation time. Water injection rate during testing was limited to $4 \mathrm{G} / \mathrm{min}$ to limit average droplet size to $40 \mu \mathrm{m}$ to allow for $>99 \%$ water evaporation prior to entering ESP. Although increasing water injection rate above $4 \mathrm{G} /$ min would result in a more significant flue gas temperature decrease, because of concerns that incomplete water evaporation may result in formation of slurry deposits at the ESP inlet and unit shutdown, the decision was made to postpone tests with higher water injection rate.

\subsection{Baseline and Sorbent Optimization Tests}

Figure 32 shows results of mercury measurements at the outlet of Side B during baseline tests conducted prior to sorbent injection. Unit 3 load and results of Ontario Hydro measurements conducted at optimized combustion conditions are also shown (see Section 3.6). Unit 3 typically operates at full load during day and reduced load at night. Figure 32 shows that mercury concentration at full load was about half of that at reduced load. It was speculated that Unit $3 \mathrm{LO}$ at full load was higher than that at reduced load resulting in more effective mercury capture on fly ash.

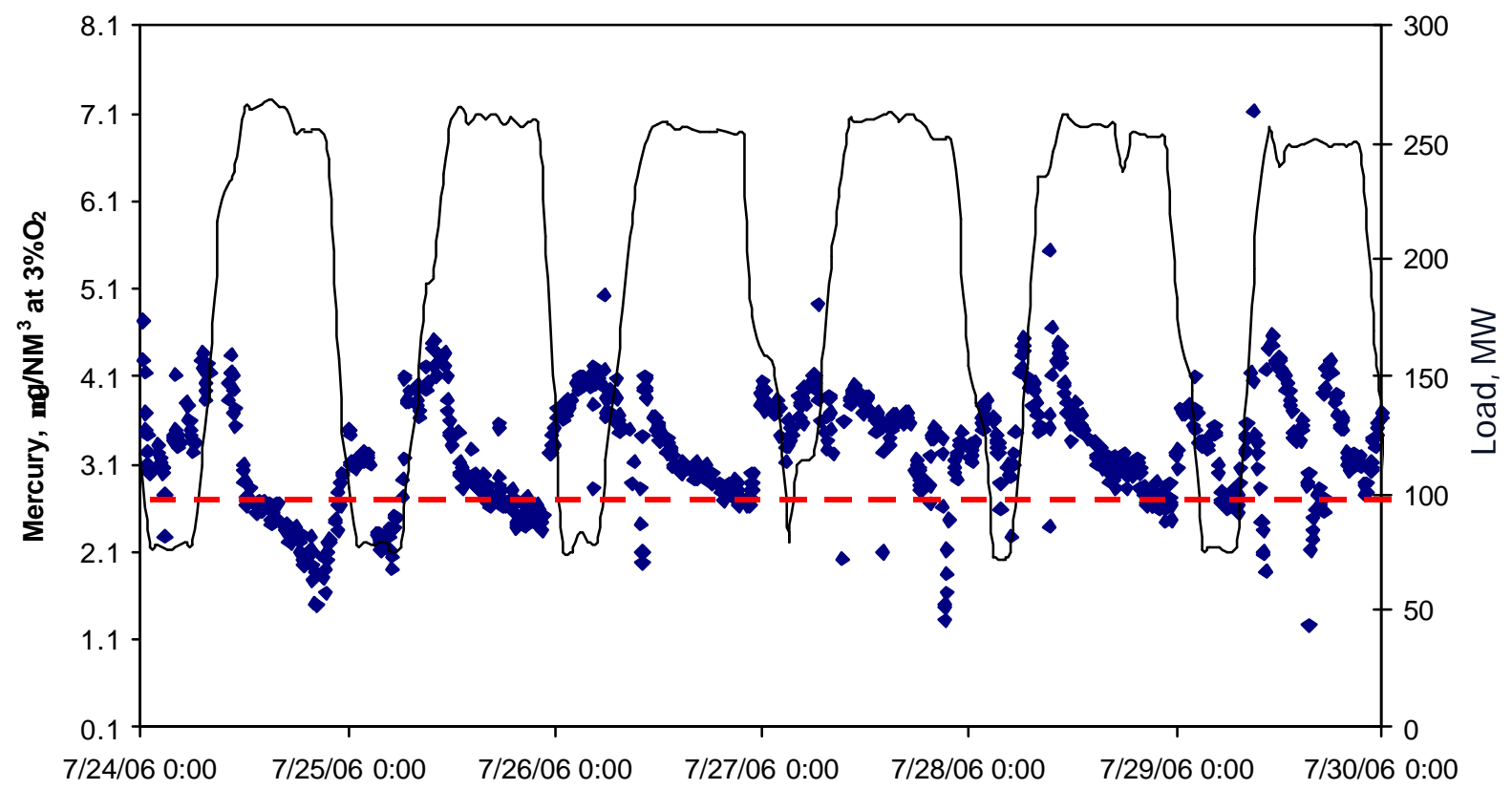

Figure 32. Concentration of mercury at Side B outlet (symbols), unit 3 load (solid line) and results of Ontario Hydro measurements (red line).

To confirm LOI observations, samples of fly ash were taken at ESP inlet on Sides A and B. Results of sampling are presented in Figure 33 and confirm that LOI in Unit 3 depends on unit load and increases with load increase. It was speculated that this increase in LOI was 
partially due to the way coal mills performed at full and reduced loads and partially to the fact that to maintain steam temperatures, operators typically increased boiler excess oxygen from $\sim 3 \%$ at $250 \mathrm{MW}$ load to $\sim 12 \%$ at $70 \mathrm{MW}$ load.

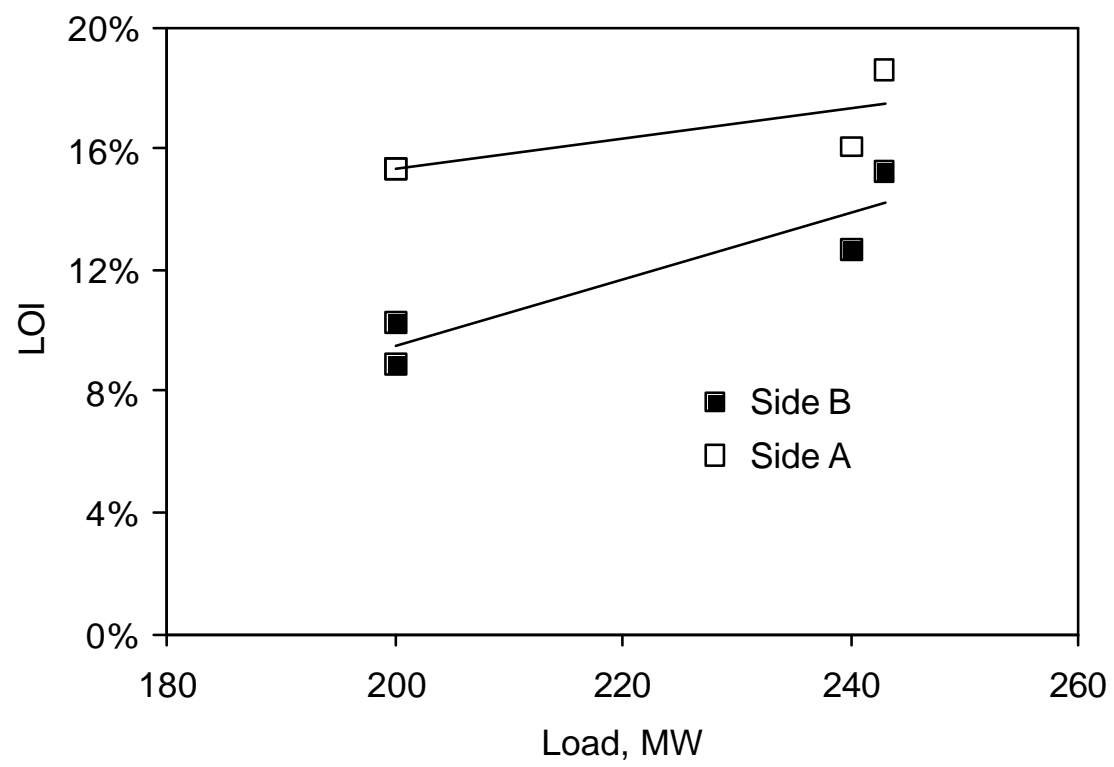

Figure 33. Unit 3 LOI.

Figure 32 also shows a comparison of mercury CEM data with Ontario Hydro data collected in J une 2006. The Ontario Hydro data were collected at full Unit 3 load. Figure 32 shows good agreement between CEM and Ontario Hydro data.

Figure 34 compares results of sorbent optimization tests with results of pilot-scale testing and testing 10 of B-PAC sorbent by Sorbent technologies, Inc. in Lee unit 1 conducted in J anuary 2006. Open symbols in Figure 34 represent results of DARCO ${ }^{\circledR} \mathrm{Hg}$ and DARCO ${ }^{\circledR} \mathrm{Hg}$ LH testing with Lee coal conducted in $1 \mathrm{MMBtu} / \mathrm{hr}$ BSF in Santa Ana, CA. Pilot-scale testing showed that DARCO ${ }^{\circledR} \mathrm{Hg}$ and DARCO ${ }^{\circledR} \mathrm{Hg}$ - $\mathrm{LH}$ demonstrated similar performances in the absence of $\mathrm{SO}_{3}$ injection and that sorbent injection rate required to achieve $70 \%$ reduction from baseline conditions was about $10 \mathrm{lb} / \mathrm{MMACF}$. Sorbent optimization tests in Lee unit 3 confirmed these findings. Field tests have also shown that in the presence of about $15 \mathrm{ppm}$ of $\mathrm{SO}_{3}$ in flue gas, the sorbent injection rate required to achieve $70 \%$ mercury reduction increased to about 18-20 lb/MMACF. Comparison of Unit 3 data for DARCO ${ }^{\circledR} \mathrm{Hg}$ and B-PAC injection 10 in Unit 1 with $\mathrm{SO}_{3}$ conditioning shows that both sorbents performed about equally in the presence of $\mathrm{SO}_{3}$.

10. Landreth, R. "New Full-Scale Results from BPAC Mercury Control Trials", Paper 82. Presented at Power Plant Air Pollutant Control "Mega" Symposium, Baltimore, MD, August 28 - 31, 2006. 


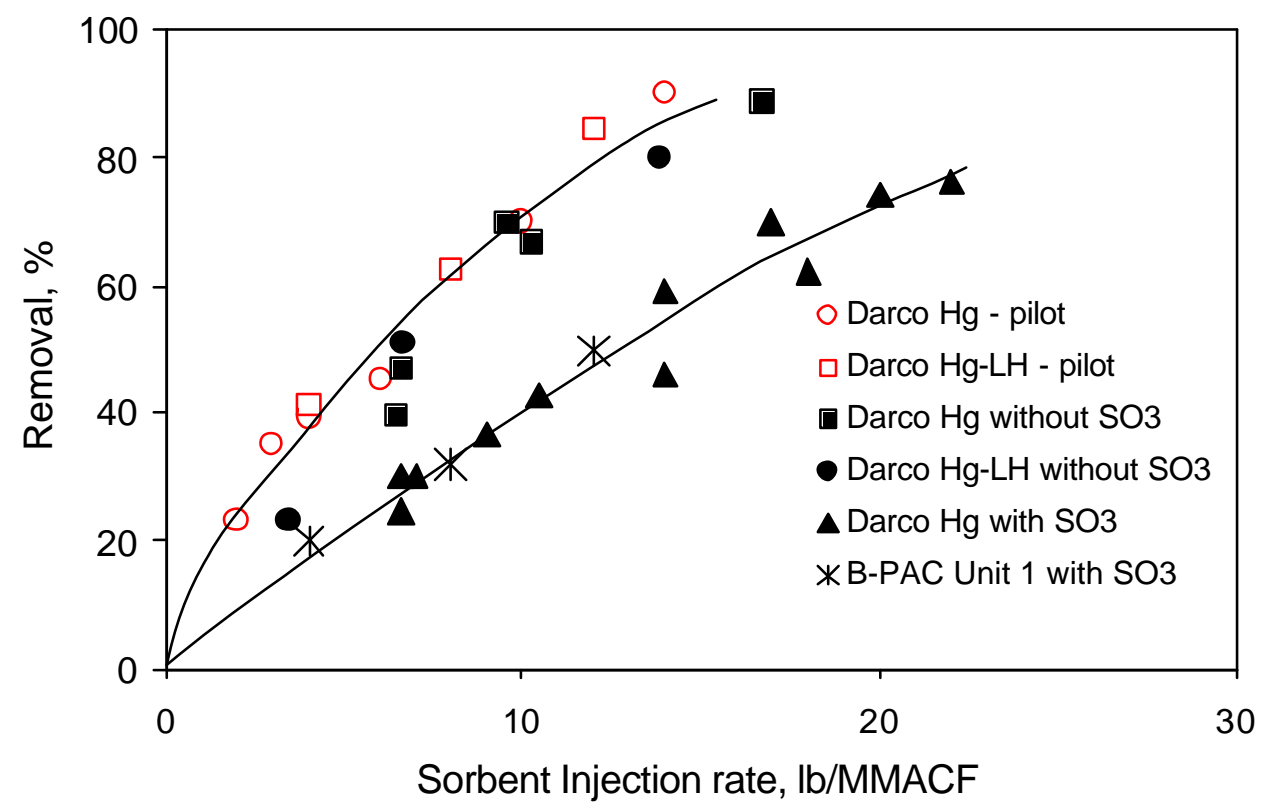

Figure 34. Comparison of sorbent injection data.

Based on results of sorbent optimization tests, DARCO ${ }^{\circledR} \mathrm{Hg}$ was selected for the 30 -day continuous sorbent injection. Recommended sorbent injection rate without $\mathrm{SO}_{3}$ conditioning was $10 \mathrm{lb} / \mathrm{MMACF}$ and with $\mathrm{SO}_{3}$ conditioning $20 \mathrm{lb} / \mathrm{MMACF}$.

\subsection{System Optimization Summary}

Temperature traversing at the location of water injection ports was done prior to the humidification system shakedown to ensure that water injection would not lower local flue gas temperatures below 260 of - the acid dewpoint temperature estimated for Lee coal. Measurements showed that flue gas temperatures in some locations were close to or even below 260 oF. Therefore the decision was made to use only 4 out of 8 lances to avoid water injection in the lower temperature areas of the duct. A 2-hour test was conducted in which 4 $\mathrm{G} / \mathrm{min}$ of water were injected through each lance. The $\mathrm{SO}_{3}$ conditioning system was not operational during the test. No noticeable improvement in "native" mercury capture on fly ash was observed. Although mercury removal on fly ash improves with reduction of ESP temperature, it is possible that the 12 of decrease in temperature of flue gas measured in the test was not significant enough to result in noticeable improvement in mercury capture.

During the peak summer season, Unit 3 typically operates at full load during the day and reduced load at night. Mercury measurements using CEMS in the absence of sorbent injection showed that mercury concentration at the ESP outlet at full load was about half of that at reduced load. Samples of fly ash were taken at the ESP inlet and analyzed for LOI. Analysis showed that LOI depended on unit load and increased with load increase. This increase may account for more effective "native" mercury capture on fly ash at full load. 
Results of mercury measurements at baseline conditions were in good agreement with Ontario Hydro data taken in J une 2006.

One week of sorbent optimization tests was conducted to evaluate and select sorbent and define sorbent injection rate for long-term testing. Sorbent optimization tests showed that DARCO ${ }^{\circledR} \mathrm{Hg}$ and DARCO ${ }^{\circledR} \mathrm{Hg}$ - $\mathrm{LH}$ performances were about the same in the absence of $\mathrm{SO}_{3}$ injection. Based on results of sorbent optimization tests, DARCO ${ }^{\circledR} \mathrm{Hg}$ was selected for the 30 day trial. Recommended sorbent injection rate without $\mathrm{SO}_{3}$ conditioning was $10 \mathrm{lb} / \mathrm{MMACF}$ and with $\mathrm{SO}_{3}$ conditioning $20 \mathrm{lb} / \mathrm{MMACF}$. 


\subsection{Continuous Sorbent Injection}

The 30-day continuous sorbent injection test started on August 21, 2006. Sorbent DARCO ${ }^{\circledR}$ $\mathrm{Hg}$ was used in the long-term testing. Since Unit 3 load was not constant, sorbent injection rate was adjusted as load changed to maintain sorbent injection rates at $10 \mathrm{lb} / \mathrm{MMACF}$ and $20 \mathrm{lb} / \mathrm{MMACF}$ without and with $\mathrm{SO}_{3}$ conditioning, respectively. Since Unit 3 opacity increases when the boiler operates at full load, the $\mathrm{SO}_{3}$ system was usually on during the day and was turned off at night.

Mercury data during the 30-day test were collected using mercury CEMS, Ontario Hydro, and carbon traps methods. The following sections describe results of these measurements.

\subsection{Ontario Hydro Measurements}

For quality assurance purpose a total of 13 Ontario Hydro tests were performed during sorbent injection at the ESP outlet on the B side (where sorbent was injected) by GE Management Services, Inc. Four tests were performed on August 25 and September 9, three tests on September 14, and two tests on September 5. Test results are summarized in Table 10.

\subsection{Carbon Trap Measurements}

The mercury CEMs utilized in mercury measurements were made available for the program only until September 14, 2006 after which they had to be moved to different site. Mercury measurements during the last week of sorbent injection were performed using modified U.S. EPA Appendix K method (carbon traps). Some of the modifications in the method included using one carbon trap per test instead of two and shortening sampling time to 1 hour. On average, total amount of flue gas pulled through carbon trap was $~ 30$ standard liters whic $h$ required usage of smaller traps than in U.S. EPA Appendix K method. Table 11 shows summary of carbon traps measurements. 
Table 10. Results of sampling using Ontario Hydro method.

\begin{tabular}{|c|c|c|c|c|c|c|}
\hline Test Run Number & 1 & 2 & 3 & 4 & 5 & 6 \\
\hline Date & $8 / 25 / 2006$ & $8 / 25 / 2006$ & $8 / 25 / 2006$ & $8 / 25 / 2006$ & $9 / 5 / 2006$ & $9 / 5 / 2006$ \\
\hline Start Time & $11: 55$ & 13:35 & $16: 12$ & $18: 35$ & $12: 05$ & $14: 45$ \\
\hline End Time & $13: 55$ & $15: 35$ & 18:12 & $20: 05$ & $14: 05$ & $16: 45$ \\
\hline \multicolumn{7}{|c|}{$\begin{array}{l}\text { Particle Bound Mercury } \\
\text { Emissions }\end{array}$} \\
\hline ppm & $7.63 \mathrm{E}-06$ & $1.75 \mathrm{E}-05$ & $2.32 \mathrm{E}-05$ & $3.84 \mathrm{E}-05$ & $2.37 \mathrm{E}-05$ & 2.61E-05 \\
\hline$\mu \mathrm{g} / \mathrm{dscm}$ & 0.068 & 0.156 & 0.208 & 0.344 & 0.212 & 0.234 \\
\hline \multicolumn{7}{|c|}{ Elemental Mercury Emissions } \\
\hline ppm & $5.55 \mathrm{E}-05$ & $9.51 \mathrm{E}-05$ & $1.10 \mathrm{E}-04$ & $8.83 \mathrm{E}-05$ & $6.26 \mathrm{E}-05$ & $8.29 \mathrm{E}-05$ \\
\hline$\mu \mathrm{g} / \mathrm{dscm}$ & 0.5 & 0.85 & 0.98 & 0.79 & 0.56 & 0.74 \\
\hline \multicolumn{7}{|c|}{ Oxidized Mercury Emissions } \\
\hline ppm & $7.45 \mathrm{E}-05$ & $5.95 \mathrm{E}-05$ & $1.59 \mathrm{E}-04$ & $1.42 \mathrm{E}-04$ & 8.04E-05 & 2.01E-04 \\
\hline$\mu \mathrm{g} / \mathrm{dncm}$ & 0.67 & 0.53 & 1.43 & 1.27 & 0.72 & 1.8 \\
\hline \multicolumn{7}{|c|}{ Total Mercury Emissions } \\
\hline$\mu \mathrm{g} / \mathrm{dscm}$ & 1.238 & 1.536 & 2.618 & 2.404 & 1.492 & 2.774 \\
\hline$\mu \mathrm{g} / \mathrm{dscm} @ 3 \% \mathrm{O}_{2}$ & 1.39 & 1.73 & 2.95 & 2.70 & 1.73 & 3.22 \\
\hline
\end{tabular}

Table 10. Results of sampling using Ontario Hydro method (cont.)

\begin{tabular}{|c|c|c|c|c|c|c|c|}
\hline Test Run Number & 7 & 8 & 9 & 10 & 11 & 12 & 13 \\
\hline Date & $9 / 8 / 2006$ & 9/8/2006 & 9/8/2006 & 9/8/2006 & 9/14/2006 & $9 / 14 / 2006$ & $9 / 14 / 2006$ \\
\hline Start Time & $8: 55$ & $11: 16$ & $13: 52$ & $16: 11$ & $14: 14$ & $16: 32$ & $18: 49$ \\
\hline End Time & $10: 05$ & $13: 16$ & $15: 52$ & $18: 11$ & $16: 14$ & $18: 32$ & $20: 49$ \\
\hline \multicolumn{8}{|c|}{$\begin{array}{l}\text { Particle Bound Mercury } \\
\text { Emissions }\end{array}$} \\
\hline ppm & $3.96 \mathrm{E}-05$ & $4.15 \mathrm{E}-05$ & $2.79 \mathrm{E}-05$ & $5.42 \mathrm{E}-05$ & $1.32 \mathrm{E}-05$ & $2.50 \mathrm{E}-05$ & $3.78 \mathrm{E}-05$ \\
\hline$\mu \mathrm{g} / \mathrm{dscm}$ & 0.355 & 0.372 & 0.25 & 0.486 & 0.118 & 0.224 & 0.339 \\
\hline \multicolumn{8}{|c|}{ Elemental Mercury Emissions } \\
\hline ppm & 7.07E-05 & $6.57 \mathrm{E}-05$ & $5.68 \mathrm{E}-05$ & $7.24 \mathrm{E}-05$ & $9.28 \mathrm{E}-05$ & $8.36 \mathrm{E}-05$ & $8.60 \mathrm{E}-05$ \\
\hline$\mu \mathrm{g} / \mathrm{dscm}$ & 0.63 & 0.59 & 0.51 & 0.65 & 0.83 & 0.75 & 0.77 \\
\hline \multicolumn{8}{|c|}{ Oxidized Mercury Emissions } \\
\hline ppm & $1.22 \mathrm{E}-04$ & $1.17 \mathrm{E}-04$ & $1.09 \mathrm{E}-04$ & $1.06 \mathrm{E}-04$ & $9.89 \mathrm{E}-05$ & $9.94 \mathrm{E}-05$ & $2.14 \mathrm{E}-05$ \\
\hline$\mu \mathrm{g} / \mathrm{dncm}$ & 1.09 & 1.05 & 0.97 & 0.95 & 0.89 & 0.89 & 0.19 \\
\hline \multicolumn{8}{|c|}{ Total Mercury Emissions } \\
\hline $\mathrm{ppm}$ & $2.32 \mathrm{E}-04$ & $2.25 \mathrm{E}-04$ & $1.93 \mathrm{E}-04$ & $2.33 \mathrm{E}-04$ & $2.05 \mathrm{E}-04$ & $2.08 \mathrm{E}-04$ & $1.45 \mathrm{E}-04$ \\
\hline$\mu \mathrm{g} / \mathrm{dscm}$ & 2.075 & 2.012 & 1.73 & 2.086 & 1.838 & 1.864 & 1.299 \\
\hline$\mu_{\mathrm{g}} / \mathrm{dscm} @ 3 \% \mathrm{O}_{2}$ & 2.36 & 2.26 & 1.95 & 2.35 & 2.07 & 2.10 & 1.46 \\
\hline
\end{tabular}


Table 11. Summary of carbon traps measurements.

\begin{tabular}{|c|c|c|c|c|c|}
\hline \multirow{2}{*}{ Date } & \multirow{2}{*}{ Time } & \multicolumn{2}{|c|}{ Mercury Content, ng } & & \\
\cline { 3 - 4 } & & $\begin{array}{c}\text { Trap } \\
\text { Section 1 }\end{array}$ & $\begin{array}{c}\text { Trap } \\
\text { Section } 2\end{array}$ & Volume, $\mathrm{L}$ & $\mathrm{Hg}, \mu \mathrm{g} / \mathrm{nm}^{3}$ \\
\hline $9 / 12 / 2006$ & $17: 40$ & 20 & $<5$ & 25 & 0.8 \\
\hline $9 / 13 / 2006$ & $10: 00$ & 32 & $<5$ & 30 & 1.1 \\
\hline $9 / 13 / 2006$ & $11: 40$ & 37 & $<5$ & 30 & 1.2 \\
\hline $9 / 13 / 2006$ & $13: 30$ & 39 & $<5$ & 30 & 1.3 \\
\hline $9 / 13 / 2006$ & $14: 40$ & 46 & $<5$ & 30 & 1.5 \\
\hline $9 / 13 / 2006$ & $17: 45$ & 38 & $<5$ & 30 & 1.3 \\
\hline $9 / 14 / 2006$ & $8: 25$ & 48 & $<5$ & 30 & 1.6 \\
\hline $9 / 14 / 2006$ & $9: 40$ & 50 & $<5$ & 30 & 1.7 \\
\hline $9 / 14 / 2006$ & $15: 35$ & 68 & $<5$ & 30 & 2.3 \\
\hline $9 / 14 / 2006$ & $17: 00$ & 64 & $<5$ & 30 & 2.1 \\
\hline $9 / 14 / 2006$ & $19: 20$ & 55 & $<5$ & 30 & 1.8 \\
\hline $9 / 15 / 2006$ & $17: 05$ & 87 & $<5$ & 30 & 2.9 \\
\hline $9 / 15 / 2006$ & $9: 05$ & 84 & $<5$ & 30 & 2.8 \\
\hline $9 / 15 / 2006$ & $10: 40$ & 119 & $<5$ & 30 & 4.0 \\
\hline $9 / 15 / 2006$ & $14: 45$ & 111 & $<5$ & 30 & 3.7 \\
\hline $9 / 15 / 2006$ & $15: 00$ & 111 & $<5$ & 30 & 3.7 \\
\hline $9 / 16 / 2006$ & $10: 50$ & 84 & $<5$ & 30 & 2.8 \\
\hline $9 / 16 / 2006$ & $12: 10$ & 91 & $<5$ & 30 & 3.0 \\
\hline $9 / 16 / 2006$ & $13: 30$ & 100 & $<5$ & 30 & 3.3 \\
\hline $9 / 16 / 2006$ & $15: 10$ & 138 & $<5$ & 30 & 4.6 \\
\hline $9 / 16 / 2006$ & $16: 25$ & 126 & $<5$ & 30 & 4.2 \\
\hline $9 / 17 / 2006$ & $9: 35$ & 32 & $<5$ & 30 & 1.1 \\
\hline $9 / 17 / 2006$ & $11: 00$ & 55 & $<5$ & 30 & 1.8 \\
\hline $9 / 17 / 2006$ & $13: 15$ & 132 & $<5$ & 30 & 4.4 \\
\hline $9 / 17 / 2006$ & $14: 40$ & 124 & $<5$ & 30 & 4.1 \\
\hline $9 / 18 / 2006$ & $7: 25$ & 194 & $<5$ & 30 & 6.5 \\
\hline $9 / 18 / 2006$ & $8: 25$ & 174 & $<5$ & 30 & 5.8 \\
\hline $9 / 18 / 2006$ & $10: 40$ & 58 & $<5$ & 30 & 1.9 \\
\hline $9 / 18 / 2006$ & $12: 00$ & 66 & $<5$ & 30 & 2.2 \\
\hline $9 / 19 / 2006$ & $8: 35$ & 192 & $<5$ & 30 & 6.4 \\
\hline $9 / 19 / 2006$ & $10: 45$ & 156 & $<5$ & 30 & 5.2 \\
\hline $9 / 19 / 2006$ & $11: 55$ & 148 & $<5$ & 30 & 4.9 \\
\hline $9 / 19 / 2006$ & $13: 35$ & 118 & $<5$ & 30 & 3.9 \\
\hline $9 / 19 / 2006$ & $14: 50$ & 125 & $<5$ & 30 & 4.2 \\
\hline
\end{tabular}




\subsection{Mercury CEMS}

Apogee Scientific provided continuous measurements of mercury emissions during sorbent injection. Two mercury continuous emissions monitors (CEMS) were used during this program to monitor vapor-phase mercury concentrations in duct flue gas. The CEMS were research-oriented instruments that employed wet-chemistry impinger-based sample conditioning equipment. The mercury instruments consisted of a commercially available cold vapor atomic absorbance spectrometer coupled with a gold amalgamation system. Each CEM was calibrated daily using elemental vapor-phase mercury (EM). Each CEM was configured to automatically switch between sampling total vapor-phase mercury (TVM) and EM at each sampling location. This enabled the real-time evaluation of TVM and EM and by difference, the concentrations of oxidized vapor mercury (OVM).

Mercury concentration in flue gas was measure at Side A ESP outlet and Side B ESP inlet and outlet. Sorbent injection was performed on the Side B ESP just downstream of the inlet sample extraction point. The inlet CEM was setup to sample both total and elemental vaporphase mercury and by difference the oxidized vapor-phase mercury fraction was calculated. The outlet CEM was setup to sample the total vapor-phase mercury concentration on both ESP outlet ducts. At times, speciation on the individual outlet ducts was also performed.

\subsubsection{Mercury CEMS Data}

Figure 35 shows data on mercury concentration upstream and downstream of the ESP on side B during the 30-day sorbent injection test. Ontario Hydro and carbon tube data are also shown.

Unit 3 was firing Lee coal during most of the 30-day test. At the end of August 2006 for about 1 week Unit 3 fired Nicholas coal with higher mercury content. Figure 35 shows that the average mercury concentration in flue gas at ESP inlet for Lee and Nicholas coals were $\sim 3.4 \mu \mathrm{g} / \mathrm{nm}^{3}$ and $7.6 \mu \mathrm{g} / \mathrm{nm}^{3}$, respectively. Several coal samples were collected prior and during sorbent injection program and analyzed on proximate and ultimate composition and mercury content (Table 12). This information was used to calculate theoretical mercury concentration in flue gas, which is also shown in Figure 35. Calculated mercury concentration in flue gas compares well with measured mercury concentration at ESP inlet except for the August 22 and August 26 data. Comparison of Ontario Hydro, sorbent trap and mercury CEMS data at ESP outlet shows reasonable agreement, although some of the Ontario Hydro data show higher mercury concentrations. 


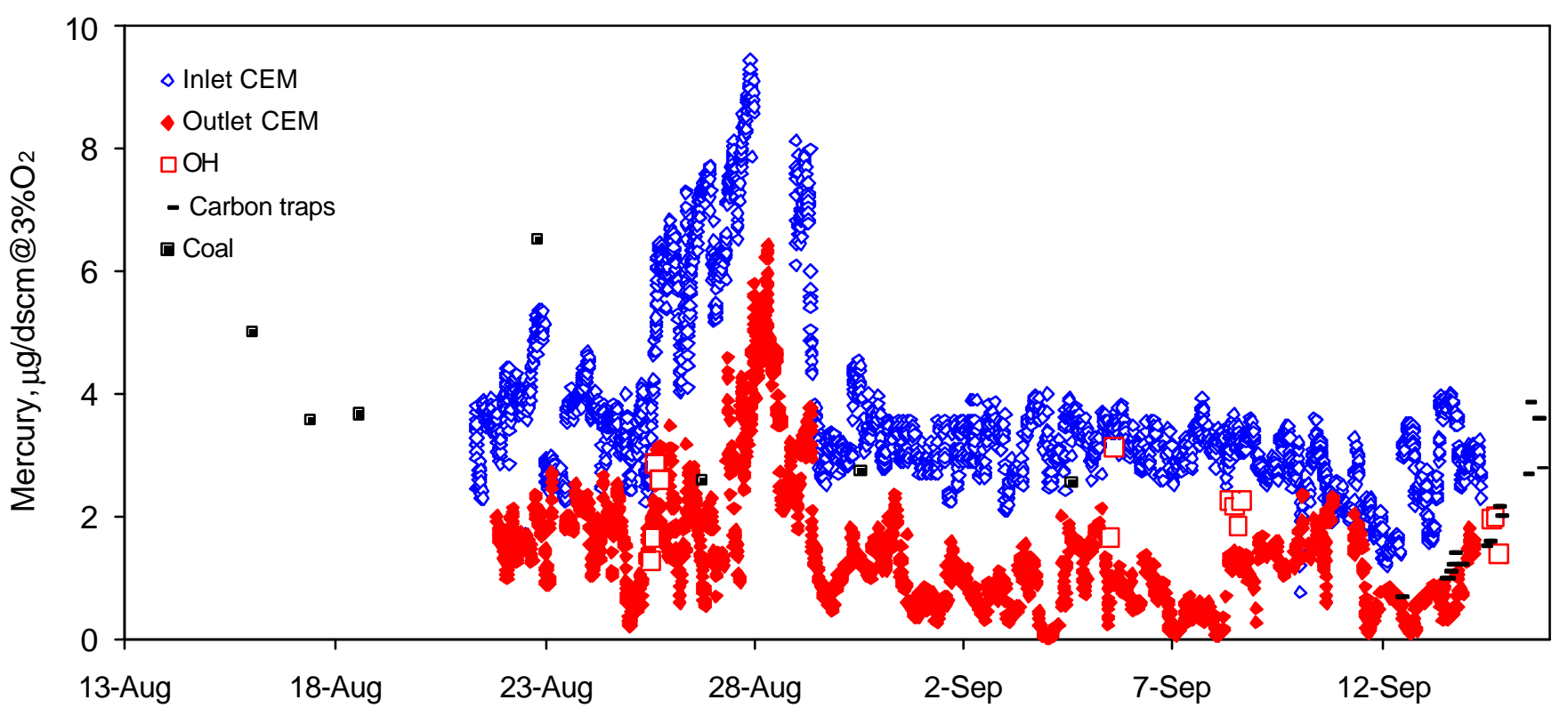

? - CEM data upstream of ESP

$\checkmark$ - CEM data downstream of ESP

$\square$ - Ontario Hydro data downstream of ESP

- - carbon trap data downstream of ESP

- mercury in coal

Figure 35. Mercury concentrations upstream and downstream of Side B ESP.

Table 12. Composition of coal samples.

\begin{tabular}{|c|c|c|c|c|c|c|c|c|}
\hline Date & & $16-$ Aug & 17 -Aug & 18-Aug & 22-Aug & 26-Aug & 30-Aug & 4-Sep \\
\hline $\mathrm{C}$ & wt \% & 69.78 & 72.69 & 69.16 & 67.05 & 70.1 & 68.79 & 67.86 \\
$\mathrm{H}$ & wt \% & 4.73 & 4.46 & 4.56 & 4.48 & 4.74 & 4.7 & 4.26 \\
$\mathrm{~N}$ & wt \% & 1.33 & 1.35 & 1.1 & 1.35 & 1.36 & 1.34 & 1.31 \\
$\mathrm{~S}$ & wt \% & 0.8 & 0.79 & 0.86 & 0.76 & 0.72 & 0.76 & 0.71 \\
$\mathrm{Ash}$ & wt \% & 10.42 & 10.46 & 12.61 & 13.47 & 9.07 & 10.79 & 8.73 \\
$\mathrm{O}$ & wt \% & 7 & 7.23 & 7.53 & 8.24 & 7.22 & 7.33 & 7.42 \\
$\mathrm{H}_{2} \mathrm{O}$ & wt \% & 5.94 & 3.02 & 4.18 & 4.56 & 6.79 & 6.29 & 8.73 \\
Wet HV & Btu/lb & 12448 & 12977 & 12305 & 12001 & 12449 & 12252 & 12024 \\
\hline Mercury & ppb, dry & 60 & 43 & 43 & 73 & 32 & 33 & 31 \\
\hline
\end{tabular}

Figure 36 shows total and elemental mercury concentrations at ESP inlet measured on August 3, 2006 by mercury CEM. Figure 36 shows that elemental mercury comprises $\sim 25 \%$ of total mercury, which is consistent with Ontario Hydro measurements. 


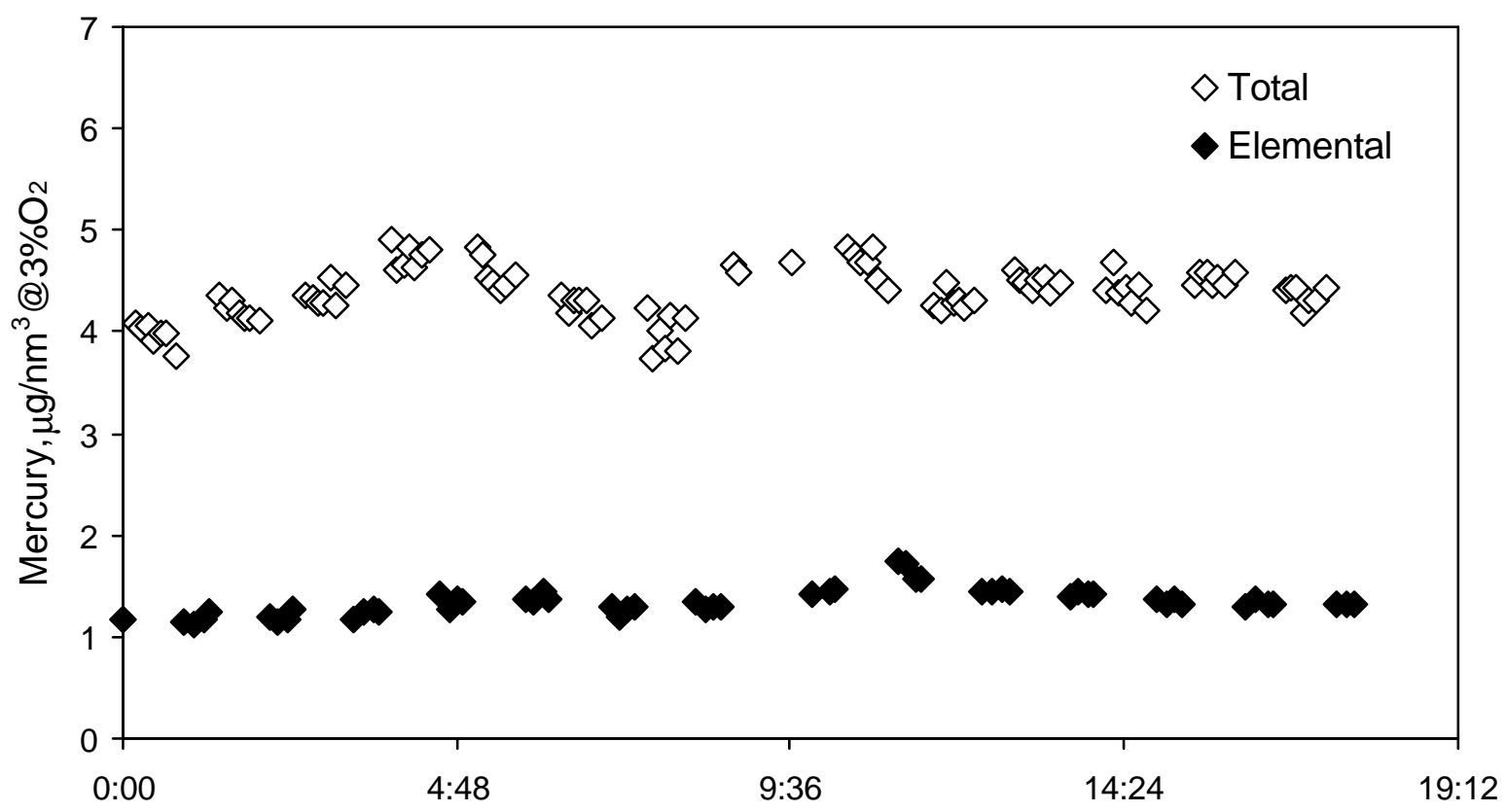

Figure 36. Total and elemental mercury concentrations at ESP inlet measured on August 3, 2006.

All mercury measurements data collected during the 30-day test are presented in Attachment A.

\subsubsection{Mercury Reduction}

Figure 37 shows mercury reductions on ESP sides A (no sorbent) and B (sorbent injection). Since ESP inlet mercury was measured only on side $B$, it was assumed that mercury concentration at ESP inlet on sides $A$ and $B$ were the same. Since sorbent was injected only in side $B$, side $A$ mercury reduction data represent "natural" mercury reduction on fly ash. Mercury reduction on side $B$ is a combined effect on mercury removal on fly ash and activated carbon. Lines in Figure 37 show time when $\mathrm{SO}_{3}$ conditioning system was not operational. 


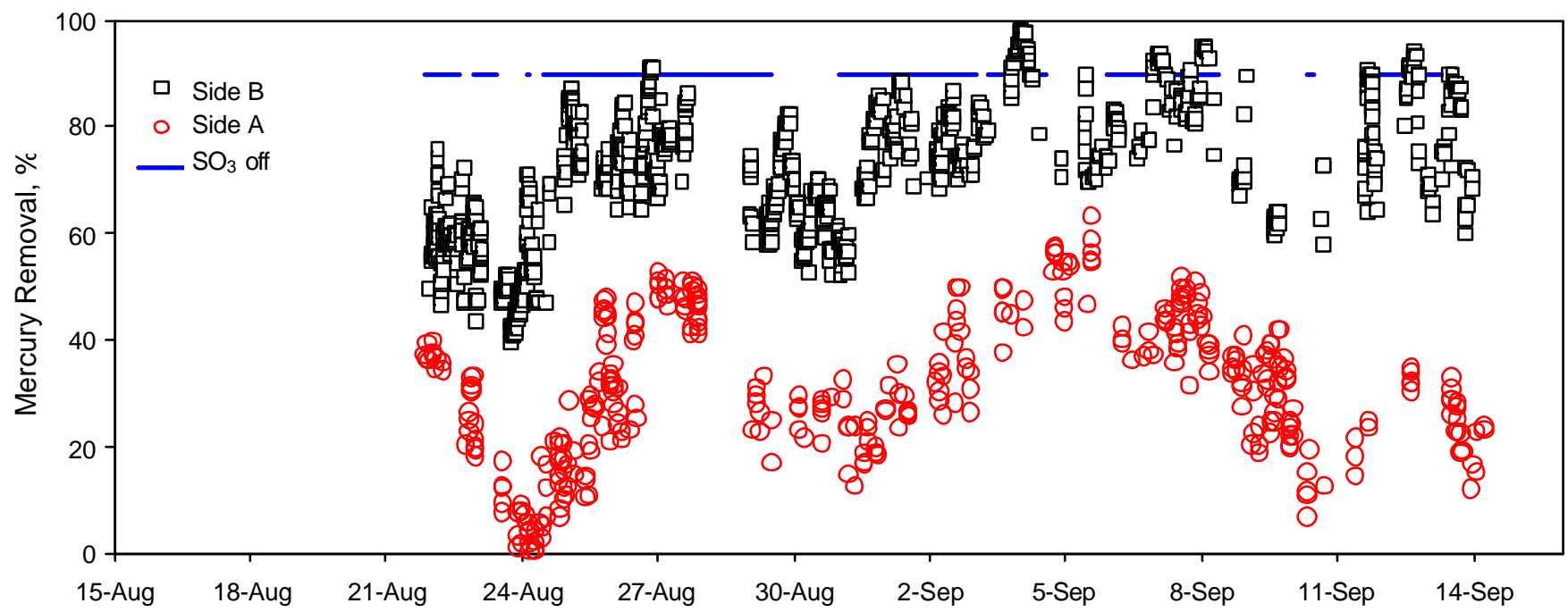

Figure 37. Mercury reduction on ESP sides A and B.

Figure 37 demonstrates that "natural" mercury reduction on fly ash and reduction due to sorbent injection were affected by $\mathrm{SO}_{3}$. In the absence of $\mathrm{SO}_{3}$ injection reduction on fly ash ( $E S P$ side $A$ ) was in the range of $20-60 \%$ while in the presence of $\mathrm{SO}_{3}$ on average it was below $20 \%$. Combined mercury removal due to sorbent injection and fly ash without $\mathrm{SO}_{3}$ injection was in $70-90 \%$ range while with $\mathrm{SO}_{3}$ injection it was typically in the range of 50$80 \%$. It should be noted that although all attempts were made to maintain sorbent injection rate constant relative to the Unit 3 load, there was some variability in the sorbent injection rate, which accounts for some variation in mercury reduction efficiency in Figure 37. Figure 38 in Section 9.0 presents data on the effect of sorbent injection on mercury reduction with and without $\mathrm{SO}_{3}$ injection collected during the 30 -day test. Figure 37 demonstrates that on average mercury removal efficiencies during the 30 -day test were close to the target $80 \%$ removal from coal.

\subsection{Sorbent Injection Summary}

Sorbent DARCO ${ }^{\circledR} \mathrm{Hg}$ was used in the long-term testing at injection rates of $10 \mathrm{lb} / \mathrm{MMACF}$ and $20 \mathrm{~b} /$ MMACF without and with $\mathrm{SO}_{3}$ conditioning, respectively. Mercury data during the 30day test were collected using mercury CEMS, Ontario Hydro, and carbon traps methods. Mercury concentration in flue gas was measure at Side A ESP outlet and Side B ESP inlet and outlet. Comparison of Ontario Hydro, sorbent trap and mercury CEMS data at ESP outlet shows reasonable agreement. Mercury content in coal samples collected during testing compares well with measured mercury concentration at ESP inlet. Combined mercury removal due to sorbent injection and fly ash during the 30-day tests without $\mathrm{SO}_{3}$ injection was in $70-90 \%$ range while with $\mathrm{SO}_{3}$ injection it was in the range of $50-80 \%$. Thus, the program objective of achieving $70 \%$ improvement in mercury reduction from the baseline emissions or $80 \%$ mercury reduction from coal has been achieved although ability of achieving target mercury reduction with $\mathrm{SO}_{3}$ injection was marginal. 


\subsection{Effect of $\mathrm{SO}_{3}$ on Sorbent Performance}

Since Unit 3 operated with $\mathrm{SO}_{3}$ injection system for ESP conditioning at least part of the time during the 30-day sorbent injection tests, it allowed collecting data on the effect of $\mathrm{SO}_{3}$ on sorbent performance. The following sections present a summary of these data.

\subsection{DARCO ${ }^{\circledast} \mathrm{Hg}$ and DARCO ${ }^{\circledR} \mathrm{HgE25C}$ Performance}

According to the information provided by the plant, $\mathrm{SO}_{3}$ concentration in flue gas during ESP conditioning was $\sim 15 \mathrm{ppm}$. Figure 38 compares data obtained during the 30-day test on mercury removal by DARCO ${ }^{\circledR} \mathrm{Hg}$ with and without $\mathrm{SO}_{3}$ injection. A least squares fit to the data is also shown. Data obtained during long-term sorbent injection confirmed results of sorbent optimization tests (Section 7.2): $\mathrm{SO}_{3}$ reduced ability of $\mathrm{DARCO}^{\circledR} \mathrm{Hg}$ to remove mercury by $50-70 \%$.

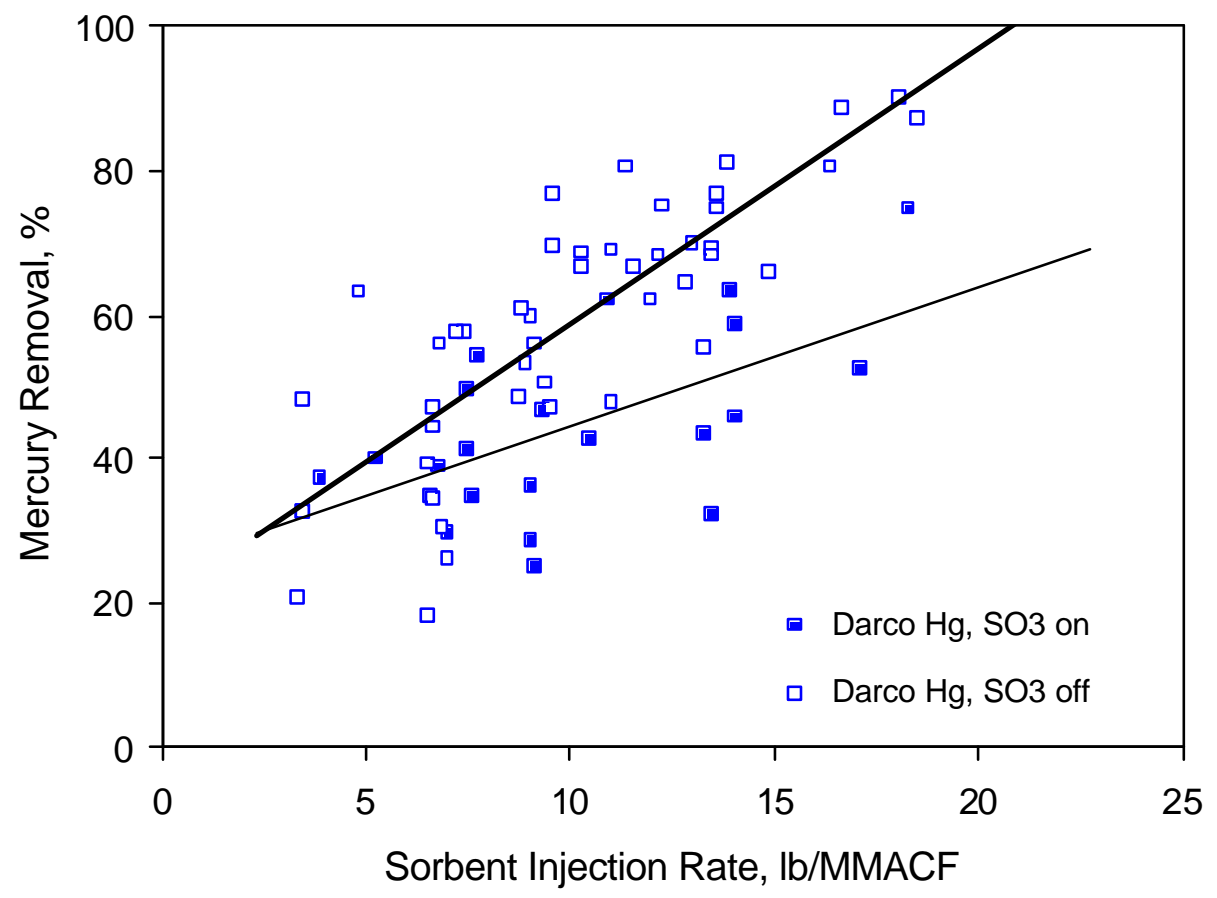

Figure 38. Mercury removal as function of $\mathrm{DARCO}{ }^{\circledR} \mathrm{Hg}$ injection rate with and without $\mathrm{SO}_{3}$ injection.

When these results were shared with Rob Nebergall, Business Manager from NORIT Americas, Inc., Mr. Nebergall indicated that Norit had been developing a new sorbent DARCO ${ }^{\circledR} \mathrm{Hg}$ E25C that showed better performance than DARCO ${ }^{\circledR} \mathrm{Hg}$ in the presence of $\mathrm{SO}_{3}$. Mr. Nebergall suggested that this experimental sorbent could be tested at Lee station. After consultations with U.S. DOE Program Manager Lynn Brickett and Lee Station personnel, the decision was made to test DARCO ${ }^{\circledR} \mathrm{Hg}$ E25C during last week of Lee Unit 3 test program. As a result, the last truckload of DARCO ${ }^{\circledR} \mathrm{Hg}$ (a total of four $40,000 \mathrm{lb}$ truckloads were ordered 
for the program) was replaced with DARCO ${ }^{\circledR} \mathrm{Hg}$ E25C. However, because of the experimental nature of the sorbent production and limited time available to manufacture the sorbent, only $30 \%$ of the design load of the promoter reducing $\mathrm{SO}_{3}$ interference was actually loaded on the sorbent.

Figure 39 compares results of $\mathrm{DARCO}^{\circledR} \mathrm{Hg}$ and DARCO ${ }^{\circledR} \mathrm{Hg}$ E25C (30\% strength) performance with and without $\mathrm{SO}_{3}$ injection. A least squares fit to the data is also shown. Figure 39 demonstrates that DARCO ${ }^{\circledR}$ E25C with $30 \%$ strength performance was similar to that of $\mathrm{DARCO}{ }^{\circledR} \mathrm{Hg}$.
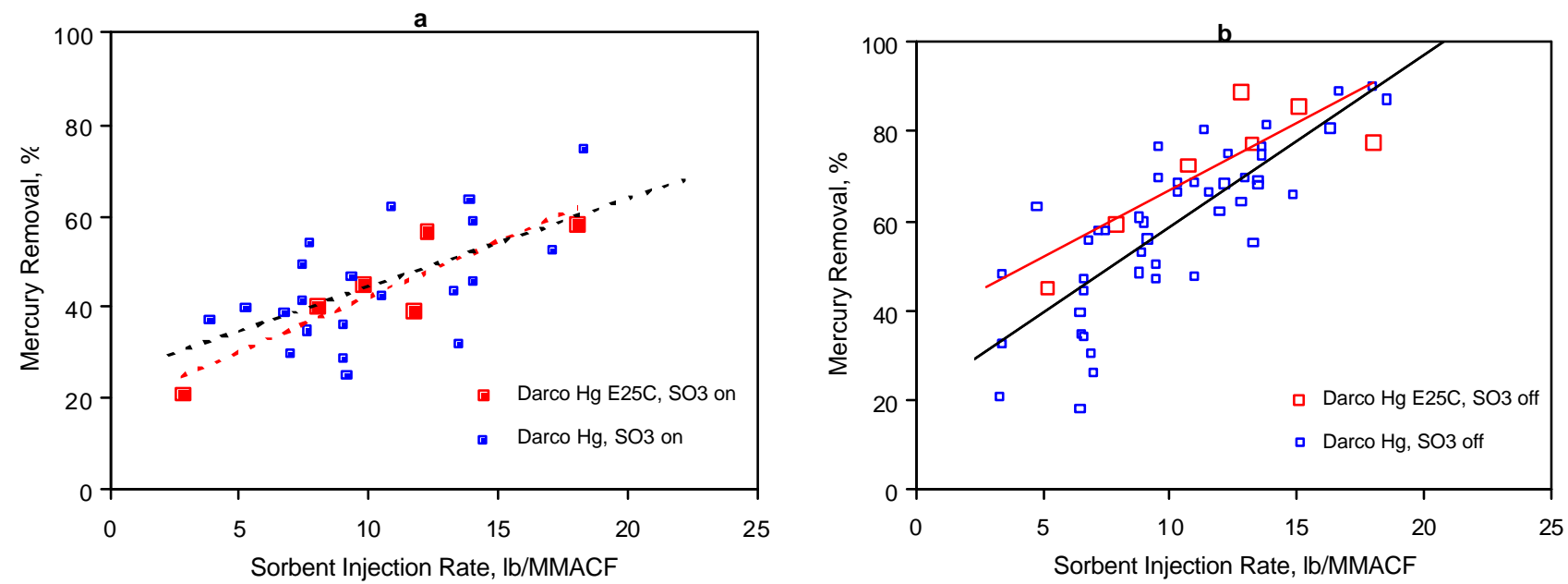

Figure 39. Comparison of DARCO ${ }^{\circledR} \mathrm{Hg}$ and DARCO ${ }^{\circledR}$ E25C performance with (a) and without $\mathrm{SO}_{3}$ (b) injection.

Norit America, Inc. also prepared 2 bulk bags of DARCO ${ }^{\circledR}$ E25C with $100 \%$ loading of the promoter. That sorbent was tested during last day of the 30-day program. Figure 40 compares performances of DARCO ${ }^{\circledR} \mathrm{Hg}$ and DARCO ${ }^{\circledR} \mathrm{HgE} 25 \mathrm{C}$ with $30 \%$ and $100 \%$ strength in the presence of $\mathrm{SO}_{3}$. 


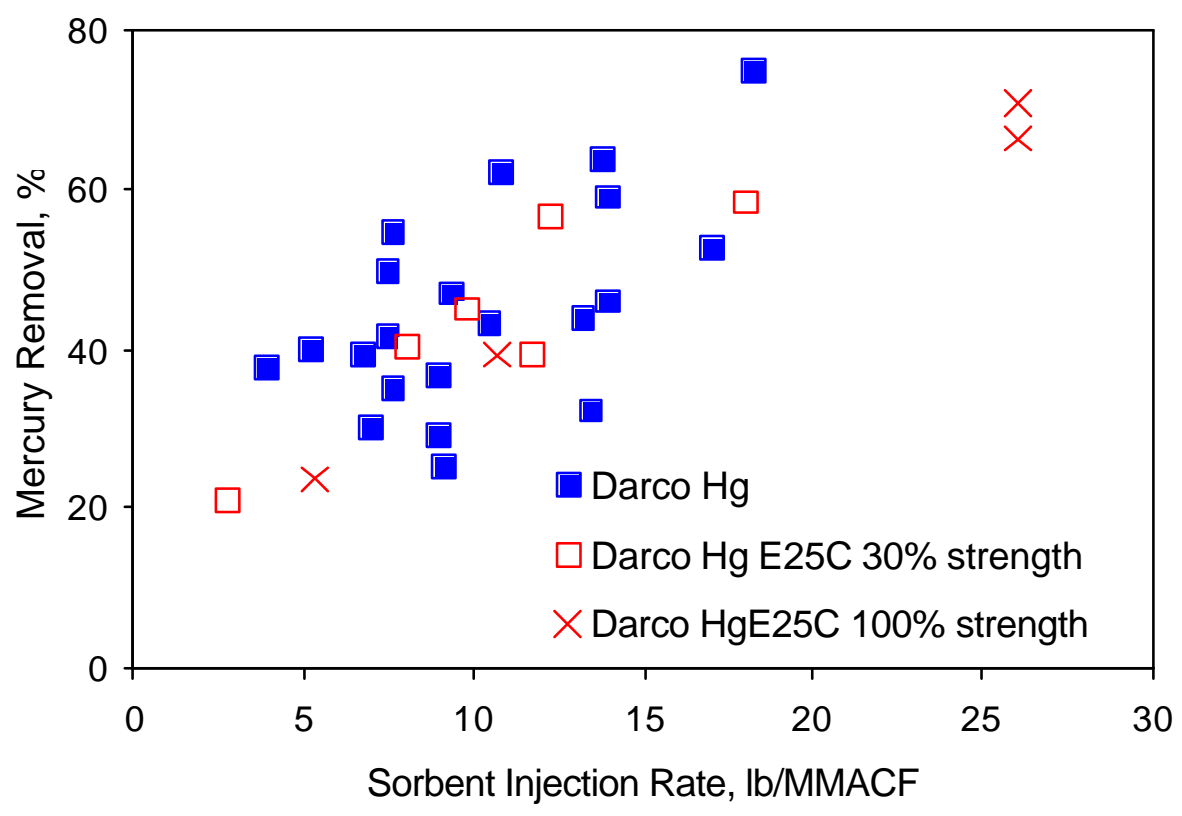

Figure 40 . Sorbent performance in the presence of $\mathrm{SO}_{3}$.

Figure 40 shows that sorbent DARCO ${ }^{\circledR} \mathrm{HgE25C}$ did not show better performance than DARCO ${ }^{\circledR} \mathrm{Hg}$.

\section{$9.2 \mathrm{SO}_{3}$ Effect Summary}

Data obtained during long-term sorbent injection confirmed results of sorbent optimization tests: $\mathrm{SO}_{3}$ reduced ability of DARCO ${ }^{\circledR} \mathrm{Hg}$ to remove mercury by $50-70 \%$. Novel $\mathrm{SO}_{3}$ resistant sorbent DARCO ${ }^{\circledR} \mathrm{Hg}$ E25C from Norit Americas, Inc. was tested during the last week of sorbent injection. Two DARCO ${ }^{\circledR} \mathrm{HgE} 25 \mathrm{C}$ products with $30 \%$ and $100 \%$ strength were tested. Testing has demonstrated that DARCO ${ }^{\circledR}$ E25C performance was similar to that of DARCO ${ }^{\circledR}$ $\mathrm{Hg}$ with and without $\mathrm{SO}_{3}$ injection. 


\subsection{Economics of Mercury Control}

One of the main requirements for the commercialization of a mercury control technology is its cost competitiveness. This section of the report describes the economic analysis of mercury control at Lee Station. The following options were considered: (1) injection of Darco $\mathrm{Hg}$ with and without ESP conditioning and (2) integration of combustion optimization with sorbent injection with and without ESP conditioning. The methodology used by Hoffman and Ratafia-Brown ${ }^{11}$ for bituminous coals was used to estimate the cost of $70 \%$ incremental mercury reduction at Lee Station. Assumed equipment lifetime was 20 years and the cost of an installed activated carbon injection system was assumed 12 to be $\$ 1.2 \mathrm{M}$. The capital cost of combustion optimization was $\$ 500,000$ and included costs of installed riffle boxes and boiler tuning. Since fly ash at Lee Station is not sold, no additional impact of mercury control on fly ash sales or disposal was taken into consideration. The cost benefit of an additional $18 \% \mathrm{NO}_{x}$ control as a result of combustion optimization was estimated using a $\mathrm{NO}_{\mathrm{x}}$ trading credit value of $\$ 2,500 /$ ton.

Figure 41 shows mercury reduction efficiencies that were achieved at Lee Station through sorbent injection and capture on fly ash at baseline and optimized combustion conditions.

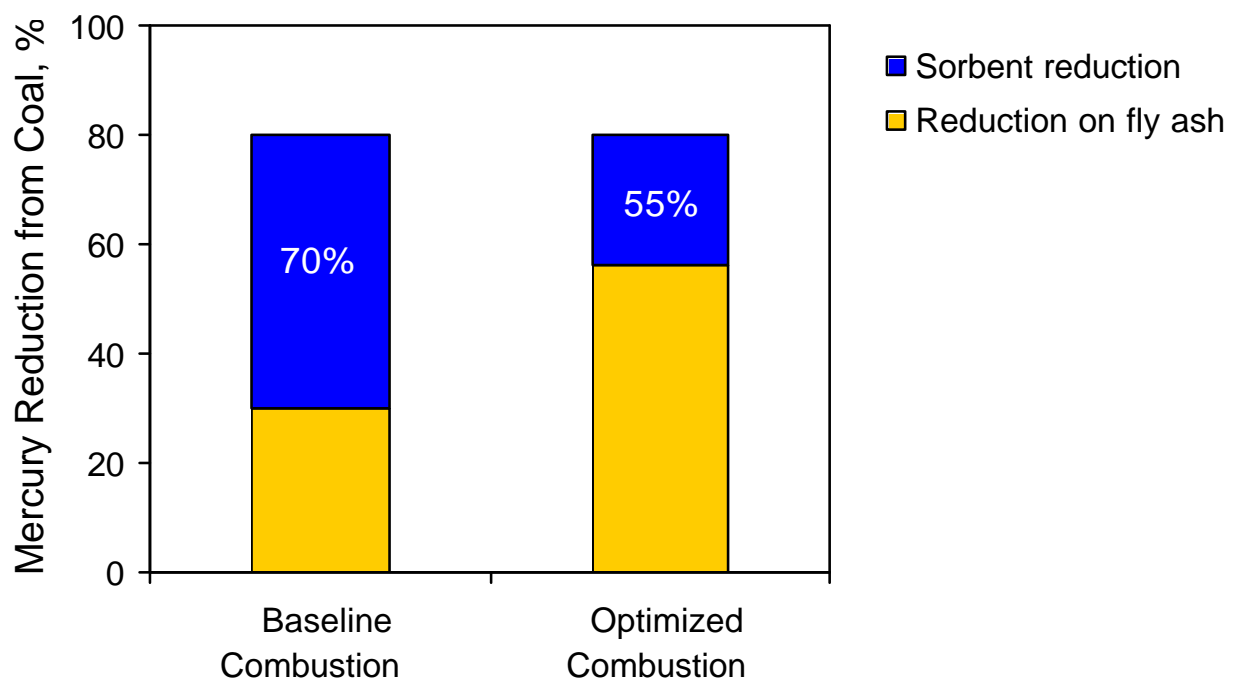

Figure 41. Mercury reductions at baseline and optimized combustion conditions.

At baseline conditions, sorbent injection provides a $70 \%$ incremental mercury reduction over the baseline, which is the performance target of this project. Overall mercury reduction from coal due to sorbent injection and capture on fly ash is $80 \%$. At optimized combustion conditions due to the improved mercury capture on fly ash, sorbent injection has to provide

11. J. Hoffman and J. Ratafia-Brown. "Preliminary Cost Estimate of Activated Carbon Injection for Controlling Mercury Emissions from an Un-Scrubbed 500 MW Coal-Fired Power Plant". Final Report. Prepared for U.S. DOE NETL Innovations for Existing Plants Program, November 2003.

12. A. P. J ones, J. W. Hoffmann, D. N. Smith, T. J. Feeley, III, and J. T. Murphy. "Preliminary Economic Analysis of Activated Carbon Injection", DOE/NETL's Phase II Mercury Control Technology Field Testing Program, April 2006. 
only $55 \%$ incremental mercury reduction to maintain the same overall $80 \%$ mercury reduction from the coal.

Figure 42 shows sorbent injection rates required to achieve the project target of overall $80 \%$ mercury reduction at baseline and optimizing conditions with and without $\mathrm{SO}_{3}$ injection for ESP conditioning.

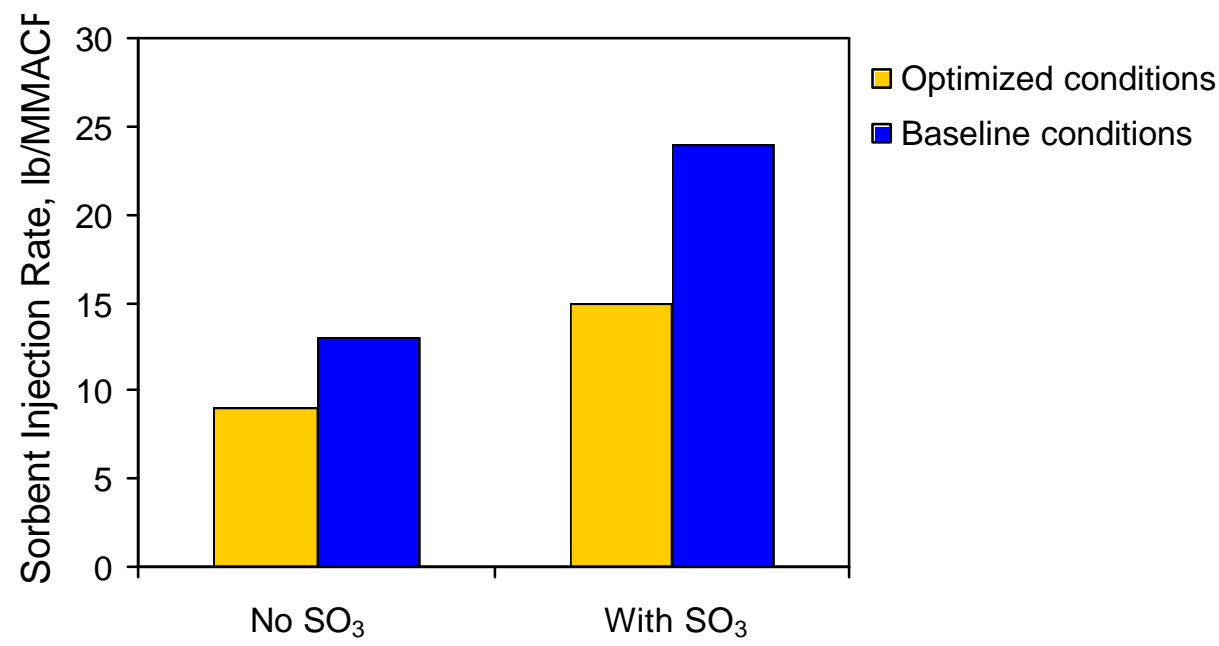

Figure 42. Sorbent injection rates at baseline and optimized combustion conditions.

Figure 43 shows the incremental cost of electricity due to the implementation of the mercury control technology for two approaches: activated carbon injection and integration of activated carbon injection with combustion optimization. The cost of mercury control using the integrated approach is about $40 \%$ lower than that of activated carbon injection alone. This is because the requirements for sorbent consumption are lower in the integrated approach, it also provides an additional $18 \% \mathrm{NO}_{x}$ control. Figure 43 also shows that cost of mercury control is about $40 \%$ higher when $\mathrm{SO}_{3}$ injection is used for ESP conditioning.

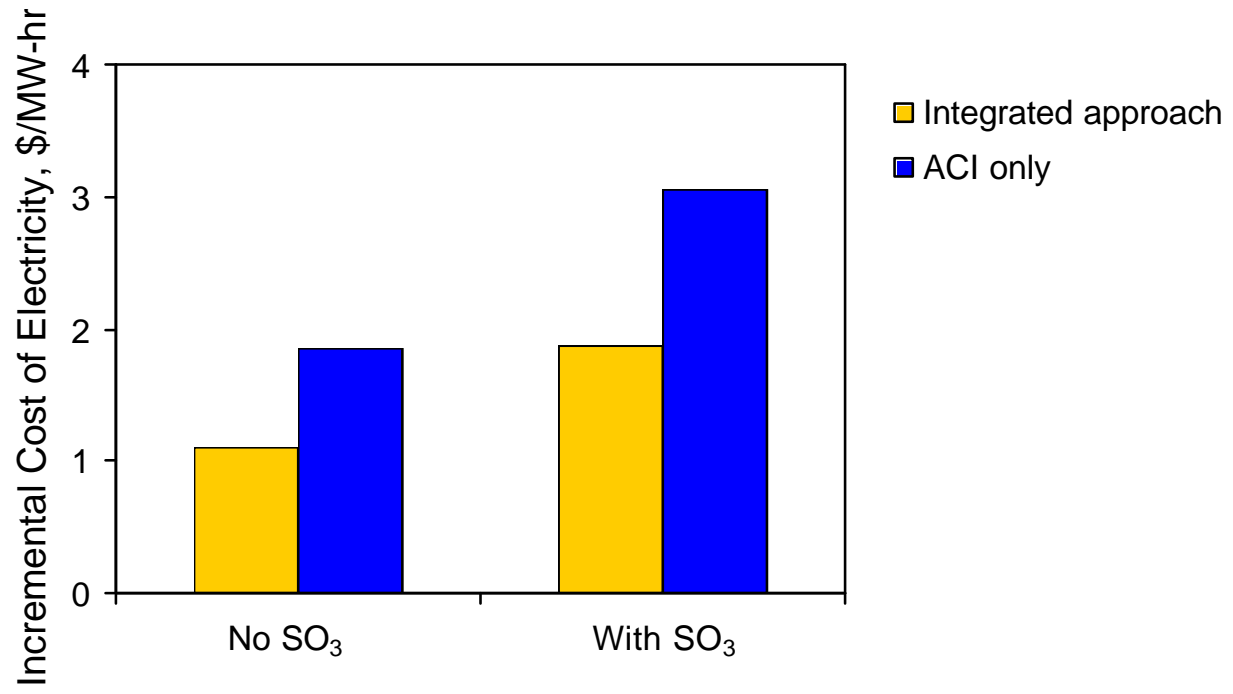

Figure 43. Incremental cost of electricity. 
Figure 44 shows variable annual $O \& M$ costs for the integrated approach and activated carbon injection alone. Figure 44 shows that the $0 \& M$ cost of the integrated approach is $\sim \$ 950,000$ less. Considering that the capital costs of combustion optimization at Lee Station were $\sim \$ 500,000$, pay back time on that capital investment is less than one year. It should be noted, however, that maintaining optimized combustion conditions over a long period of time may require periodic manual coal balancing or installation of additional hardware and software that will allow maintaining balanced coal flow to individual burners. Depending on option chosen, it may increase pay back time on the capital investment to 2-3 years.

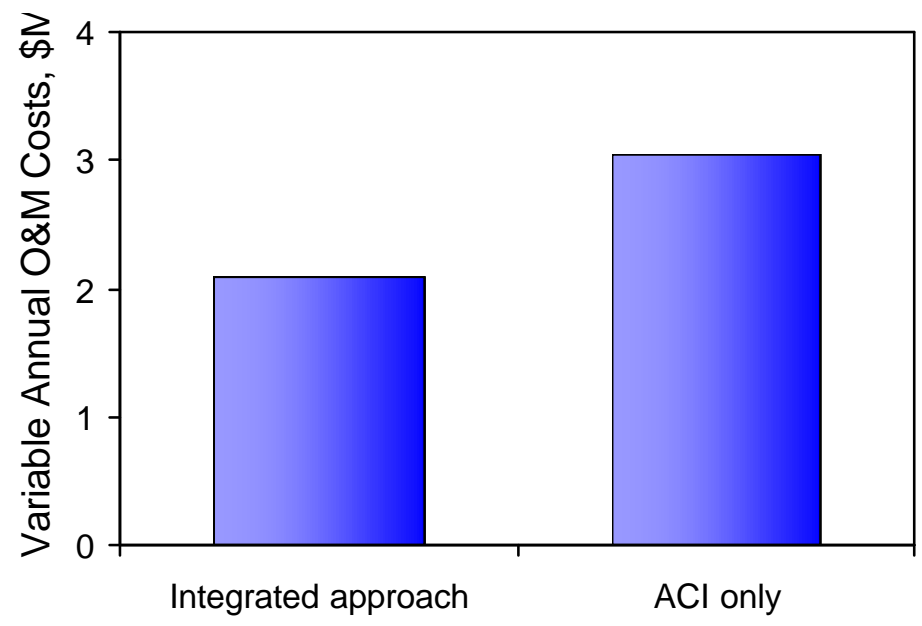

Figure 44. Variable annual O\&M costs. 


\subsection{Effect of Sorbent Injection on ESP}

One of the concerns with sorbent injection for mercury control is the potential effect of activated carbon on stack opacity. Because carbon particles have different electrical properties than fly ash and are smaller in size, they are not easily collected in ESPs and potentially may increase stack opacity. Figure 45 shows data on Unit 3 opacity at baseline conditions with $\mathrm{SO}_{3}$ conditioning and with sorbent injection with and without $\mathrm{SO}_{3}$ conditioning. Figure 45 demonstrates that without sorbent injection Unit 3 opacity usually stayed below $10 \%$ at unit loads in the range of 70-240 MW. However, opacity increased dramatically as unit load became higher than $240 \mathrm{MW}$. This is consistent with the plant operating history: typically the $\mathrm{SO}_{3}$ conditioning system is operational when Unit 3 is on full load. Figure 45 also demonstrates that with $\mathrm{SO}_{3}$ conditioning sorbent injection did not have significant effect on opacity. Without $\mathrm{SO}_{3}$ conditioning opacity with sorbent injection was generally higher than that with $\mathrm{SO}_{3}$ injection. Opacity data without sorbent injection and without $\mathrm{SO}_{3}$ conditioning are not available.

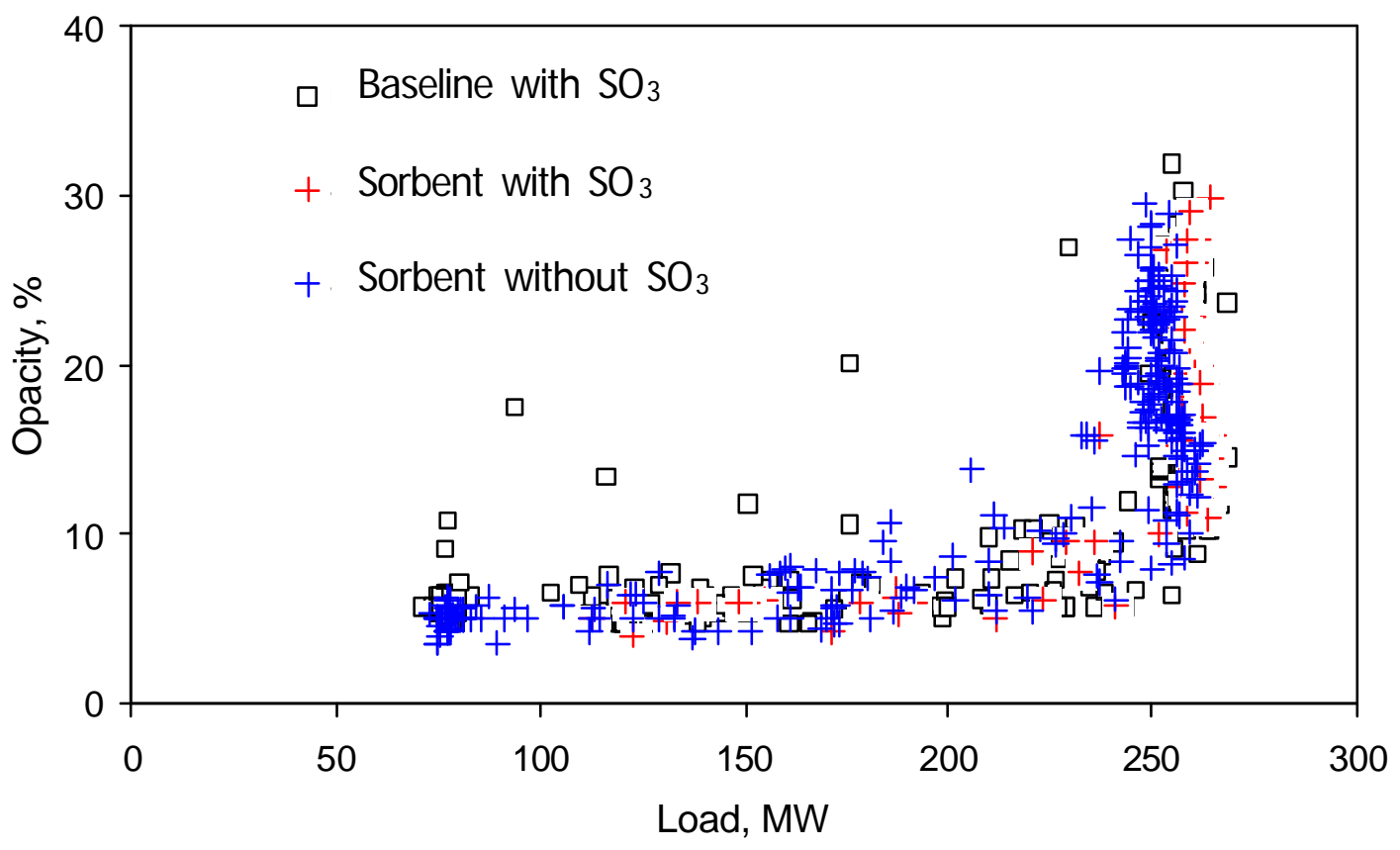

Figure 45. Data on Unit 3 opacity. 


\section{Attachment A. Mercury CEM Data}


Vapor-Phase Mercury Measurements During the Evaluation of Mercury Control Technologies for VaporPhase Mercury Control at Progress Energy's Plant Lee Unit 3

Final Report

Prepared For:

GE Energy

1831 E. Carnegie Ave

Santa Ana, CA 92705

Project Manager: Vitali Lissianski

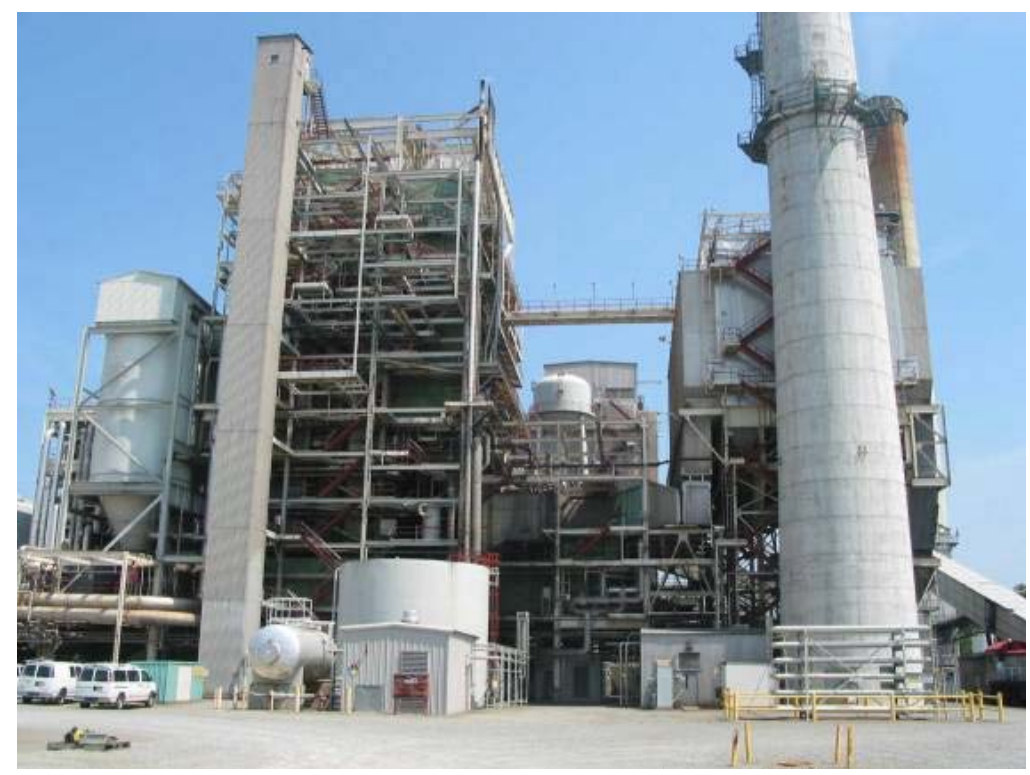

Prepared by:

Apogee Scientific, Inc.

2895 West Oxford Ave, Suite 1

Englewood, CO 80110

(303) 783-9599

Trevor Ley

February 7, 2007 


\section{Project Task}

Apogee Scientific, Inc. (Apogee) was tasked by GE Energy to perform mercury measurements at Progress Energy's Plant Lee Station Unit 3 during a Department of Energy Phase II demonstration for mercury control technologies. The period of performance for this task was from July 21 through September 14, 2006. Under the direction of GE Energy's program manager, Apogee installed three continuous mercury monitor (CMM) extraction systems; at the inlet of the Side B ESP, at the outlet of Side B ESP, and at the outlet of Side A ESP as shown in Figure 1. Sorbent injection was performed on the Side B ESP just downstream of the inlet sample extraction point. The inlet CMM was setup to sample both total and elemental vapor-phase mercury and by difference the oxidized vapor-phase mercury fraction was calculated. The outlet CMM was setup to sample the total vapor-phase mercury concentration on both ESP outlet ducts. At times, speciation on the individual outlet ducts was also performed.

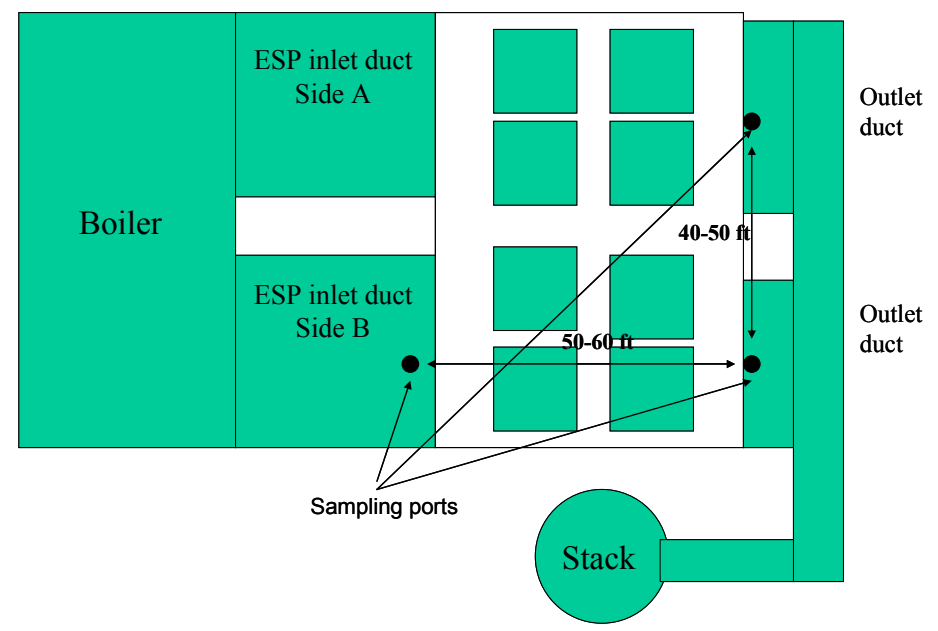

Figure 1. Apogee CMM sampling Locations on Plant Lee's Unit 3.

\section{Apogee's Continuous Mercury Monitor (CMM)}

Two mercury continuous emissions monitors (CMMs) were used during this program to monitor vapor-phase mercury concentrations in duct flue gas. The CMMs are researchoriented instruments that employ wet-chemistry impinger-based sample conditioning equipment. The mercury instruments consist of a commercially available cold vapor atomic absorbance (CVAA) spectrometer coupled with a gold amalgamation system (AuCVAA). A sketch of the Apogee-model CMM is shown below in Figure 2 and a photograph of an Apogee-model CMM and sample extraction system is shown in Figure 3. Each CMM is calibrated daily using elemental vapor-phase mercury (EM). Each $\mathrm{CMM}$ is configured to automatically switch between sampling total vapor-phase mercury 
(TVM) and EM at each sampling location. This enables the real-time evaluation of TVM and EM and by difference, the concentrations of oxidized vapor mercury (OVM).

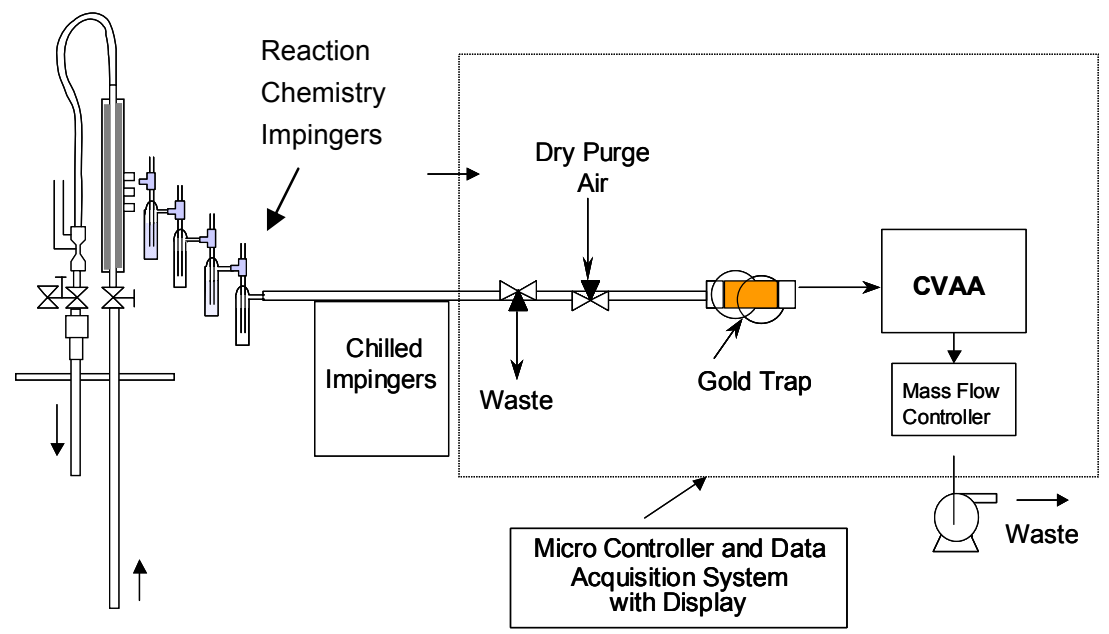

Figure 2. Apogee-Type CMM Sketch.

Although it is very difficult to transport non-EM in sampling lines, EM $\left(\mathrm{Hg}^{0}\right)$ can be transported without significant problems. Since the Au-CVAAS measures mercury by using the distinct lines of the UV absorption characteristic of $\mathrm{Hg}^{0}$, the non-elemental fraction is either converted to EM (for total mercury measurement) or removed (for measurement of the elemental fraction) near the sample extraction point. This minimizes any losses due to the sampling system.

For TVM measurements, all non-elemental vapor-phase mercury in the flue gas must be converted to EM. A reduction solution of stannous chloride in hydrochloric acid is used to convert $\mathrm{Hg}^{2+}$ to $\mathrm{Hg}^{0}$. The solution is mixed as prescribed in the draft Ontario Hydro Method for Manual Mercury Measurements. To measure elemental mercury, an impinger of potassium chloride $(\mathrm{KCl})$ solution mixed as prescribed by the draft Ontario Hydro Method replaces the stannous chloride solution to capture oxidized mercury. The oxidized fraction of the vapor-phase mercury concentration $\left(\mathrm{OVM}\right.$ or $\mathrm{Hg}^{2+}$ ) is computed by difference. The impinger solutions are continuously refreshed to assure continuous exposure of the sample gas to active chemicals.

Apogee QSIS ${ }^{\mathrm{TM}}$ sample extraction systems were used for this program. The QSIS ${ }^{\mathrm{TM}}$ extraction system includes the Apogee QSIS ${ }^{\top M}$ Probe and controls. This system enables the sampling of vapor-phase mercury from combustion flue gas without introducing sampling artifacts. The Apogee QSIS ${ }^{\mathrm{TM}}$ sample extraction system has been in use by group such as Western Kentucky University, URS Group, ADA-ES, EERC, and others for several years and has a proven track record of performance. Figure 4 shows a schematic of the Apogee QSIS ${ }^{\mathrm{TM}}$ Probe. 


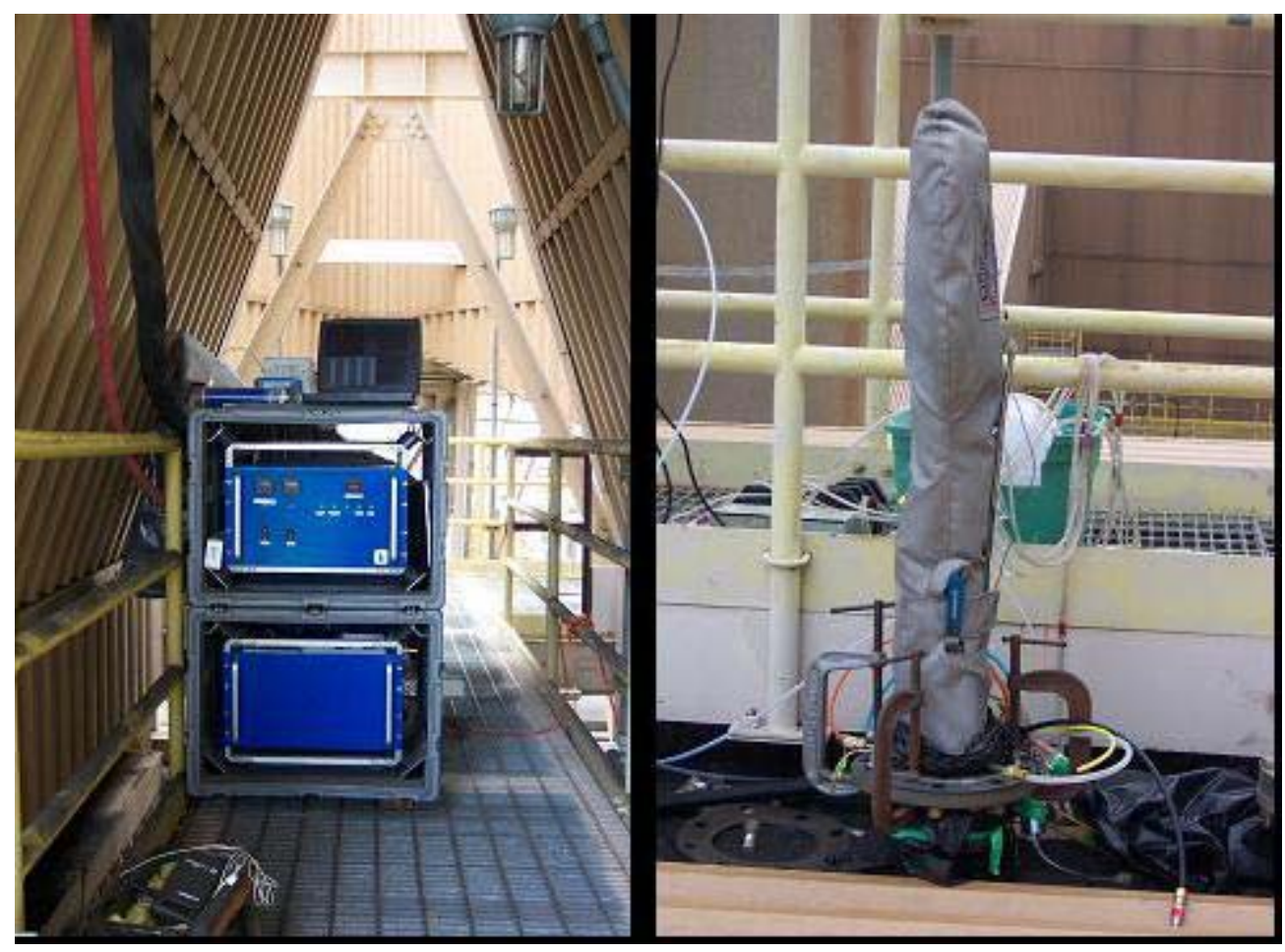

Figure 3. Apogee CMM and Sample Extraction System.

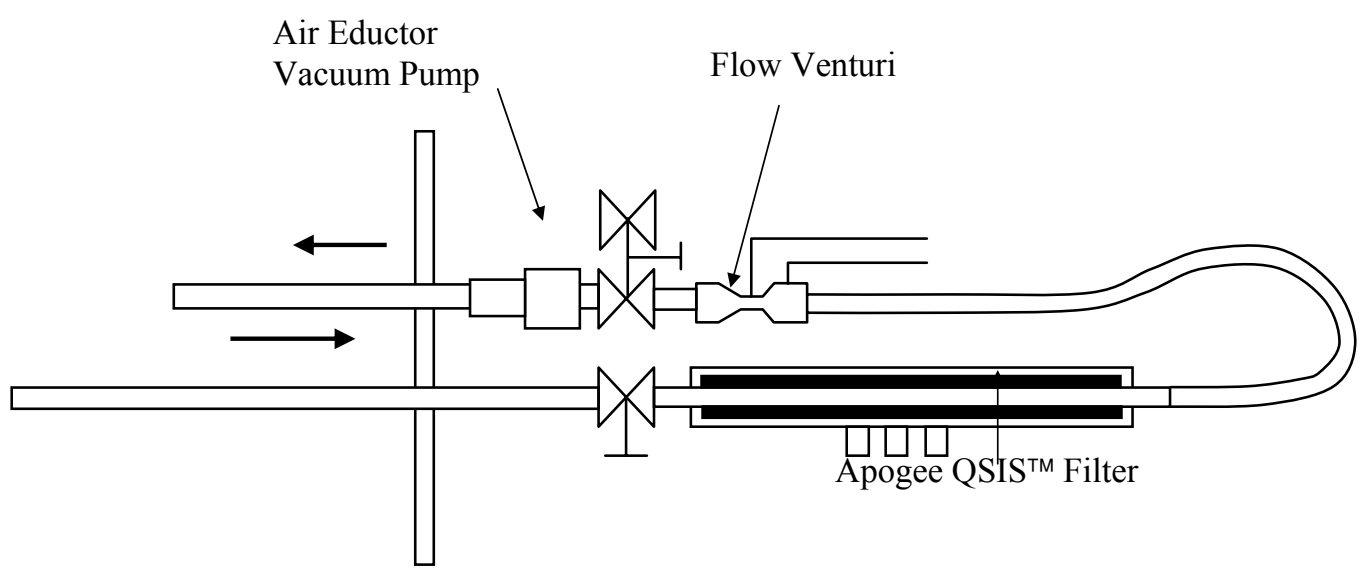

Figure 4. Apogee QSIS'M Probe. 


\section{Sampling and QA/QC Procedures}

During testing, the CMM sampling time was set to collect nominally 20 ng of mercury per sampling cycle. The noise level of the analyzer operating at a field site is approximately $1-n g$, thus collecting $20 \mathrm{ng}$ provides a signal-to-noise ratio of 20 . The CMM was calibrated following installation at the field site for elemental mercury, sample flow rate, and oxygen concentration. The calibration of both the Au-CVAA component of the CMM, which measures the mass of elemental mercury desorbed, and the mass flow controller, which measures the total sample volume through the CMM, was checked daily during testing. The CMM was calibrated by introducing a spike of vapor-phase elemental mercury into the CMM upstream of the gold-amalgamation system. The mercury vapor for the spike was drawn from the air space in a vial containing liquid elemental mercury. The mercury spike concentration was calculated from the vapor pressure of mercury and the temperature of the vial. The vial temperature was measured with a precision thermistor. Connecting the operating controller in series with a calibrated mass flow meter checks the calibration of the mass flow controller within the CEM.

Over-board spiking at different locations within the CMM sampling system was also performed on a daily basis. This was done to verify that there was no loss of vapor-phase mercury within the sampling system. Typically, a known mass of vapor-phase elemental mercury was injected before the wet-chemistry impingers (after the extraction probe) before sample conditioning begins. Over-board spiking was performed at each sampling location and for each sample stream (TVM and EVM). When the spike recovery was within $20 \%$ no action was taken. If the spike recovery did not fall within the $20 \%$ range, trouble-shooting of the CMM sampling system was performed. During this project, the majority of the problems were corrected by replacing the particulate filter downstream of the water dropout device. Other corrections that occurred were replacement of the water dropout impinger or replacement of the gold in the CMM. A table of the daily overboard spikes is presented in Appendix B.

Documentation of all CMM calibrations and overboard spikes were recorded on calibration data sheets and any system maintenance was recorded in the project notebook. CMM calibration data sheets are kept on file at Apogee and are available upon request. A calibration file for additional equipment, which contains manufacturers' certification of calibration, is also maintained by Apogee.

Data verification of computer calculations was conducted manually on a periodic basis. Any data collected during periods of suspected operational inconsistencies was rejected as questionable data. 


\section{Data Variability Protocols and Procedures}

In the normal course of mercury monitoring activities with a continuous emissions monitor, variability in collected data is encountered. Variability can be attributed to several factors including normal plant operation, changes in fuel source characteristics, individual operator style/procedures, environmental changes, and instrument variability/repeatability error. Error of the instrument is not included in variance reporting. Apogee Scientific, Inc. has the following procedures and protocols to communicate and report the variability encountered in data collected.

- Standard variance is assumed and reported as one standard deviation.

- Unless otherwise reported all data/results have been quality checked for instrument malfunction and operator error.

- $\quad$ Average values are calculated using all data values unless QA/QC has marked a value or series of values as anomalous or suspect.

- $\quad$ All statistical quantities are calculated using accepted standard equations and procedures.

\section{Mercury Measurements}

Mercury speciation measurements were started on the outlet Side B ESP late on July 21. Measurements on the inlet Side B ESP and outlet Side A ESP began mid-day on July 28. Mercury measurements were made continuously at the three locations through September 14, 2006.

The CMM data was given to the GE Energy project site manager on a daily basis after the QA/QC procedures had been completed. Calibration and over-board spike data were taken out prior to delivery.

Mercury concentrations can vary a great deal depending on coal burned and plant operations (including in this case application of mercury control technologies). Correlating plant operation and mercury concentrations can provide valuable information for mercury control options. The daily mercury concentration trend plots provided in Appendix A show the affect of the demonstrated mercury control technologies on the mercury concentrations on the treated portion of the Unit 3 ESP. 


\section{Appendix A}

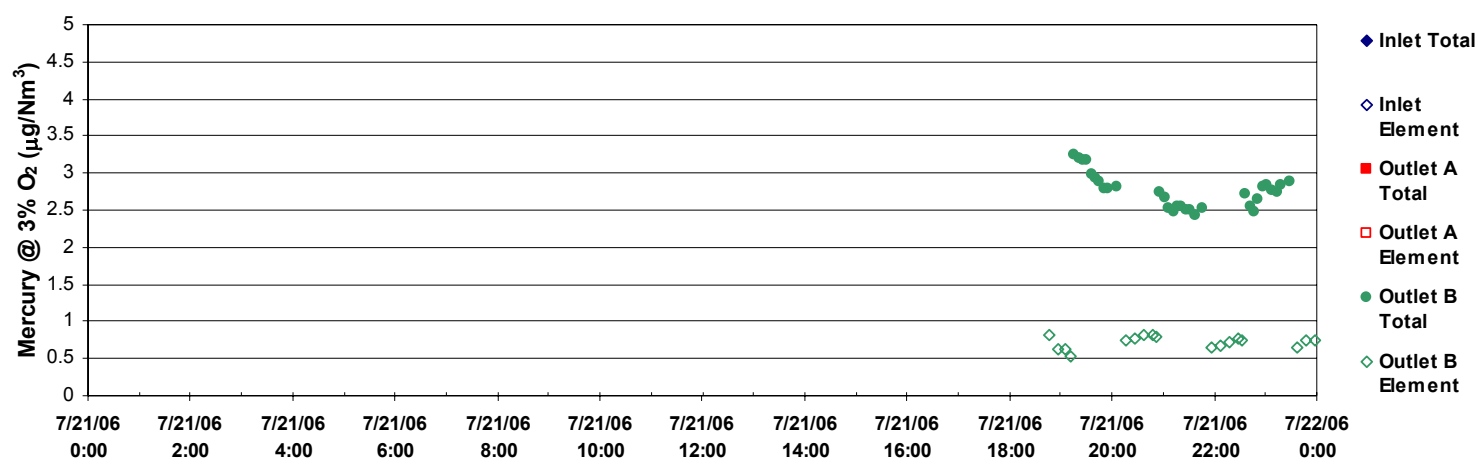

Figure A1. Mercury Concentration Trace for July 21, 2006.

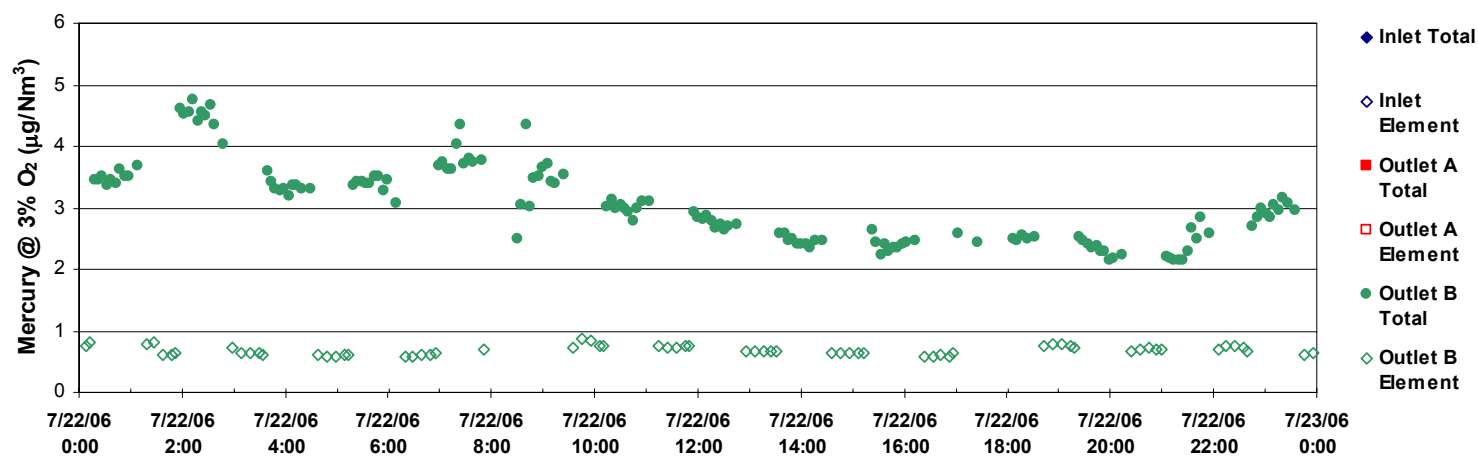

Figure A2. Mercury Concentration Trace for July 22, 2006.

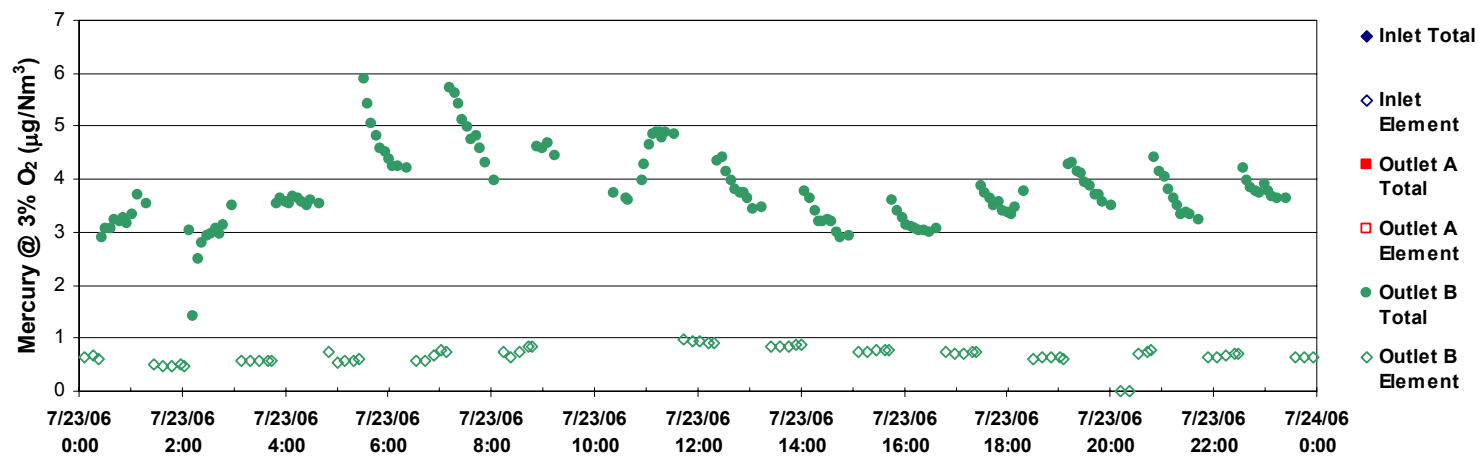

Figure A3. Mercury Concentration Trace for July 23, 2006. 


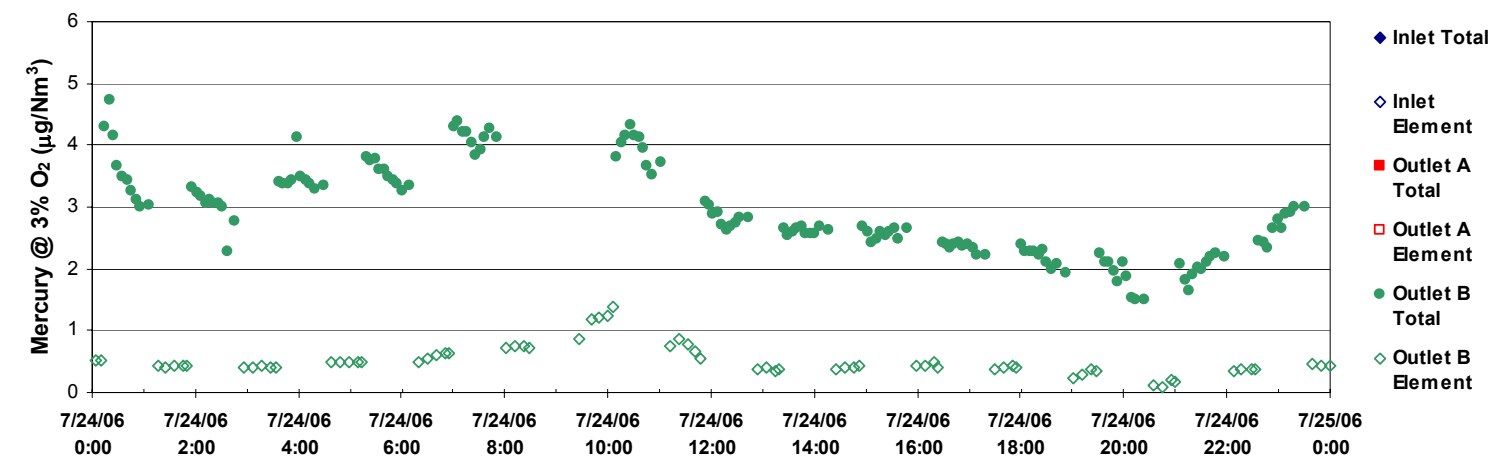

Figure A4. Mercury Concentration Trace for July 24, 2006.

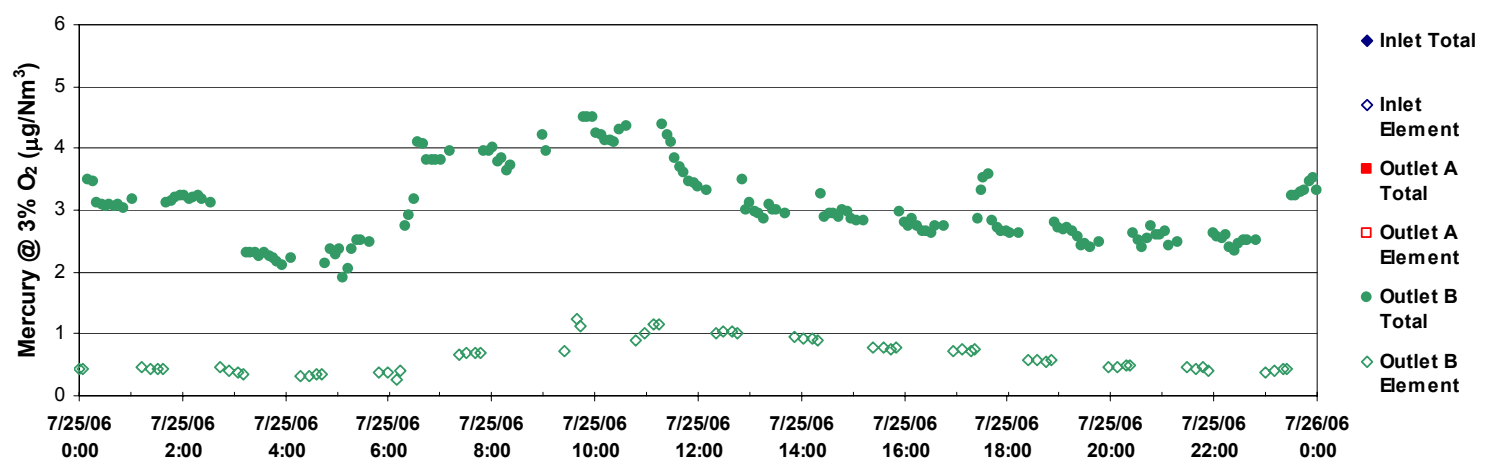

Figure A5. Mercury Concentration Trace for July 25, 2006.

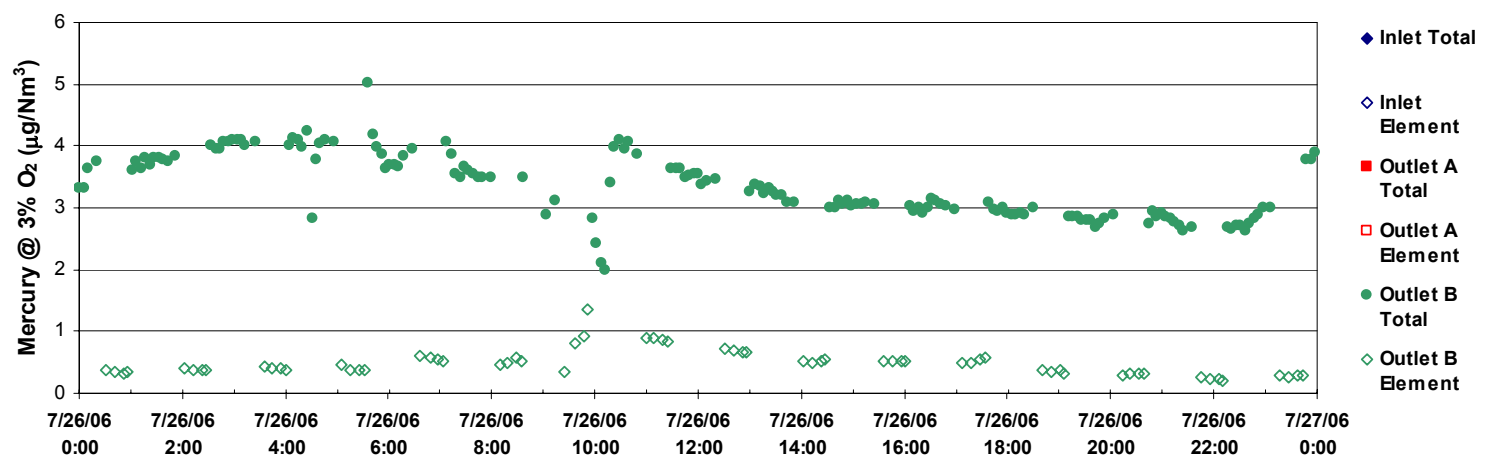

Figure A6. Mercury Concentration Trace for July 26, 2006. 


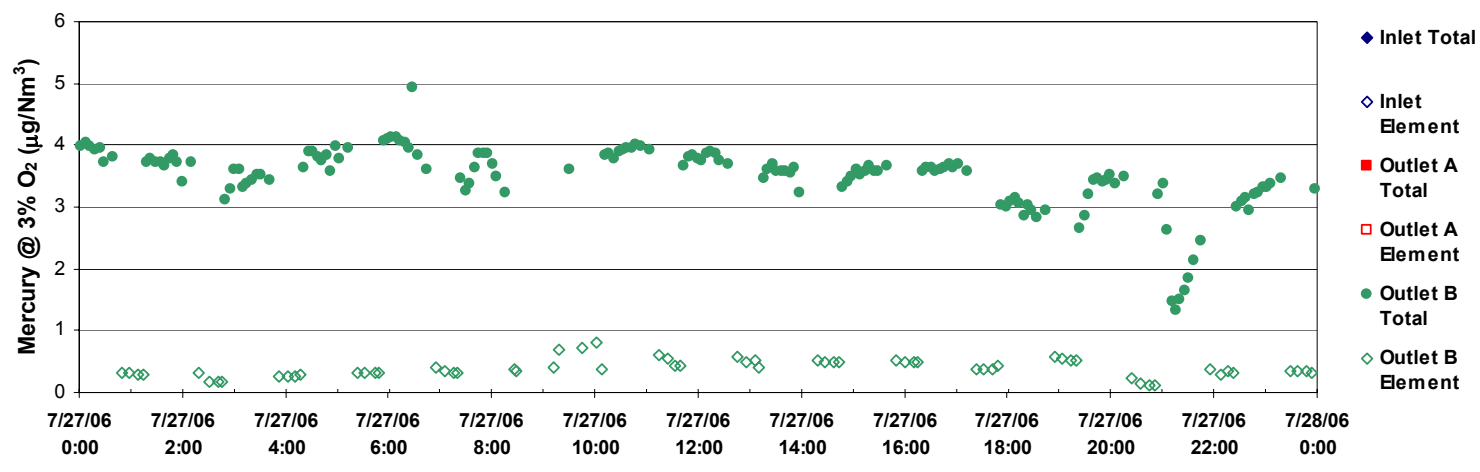

Figure A7. Mercury Concentration Trace for July 27, 2006.

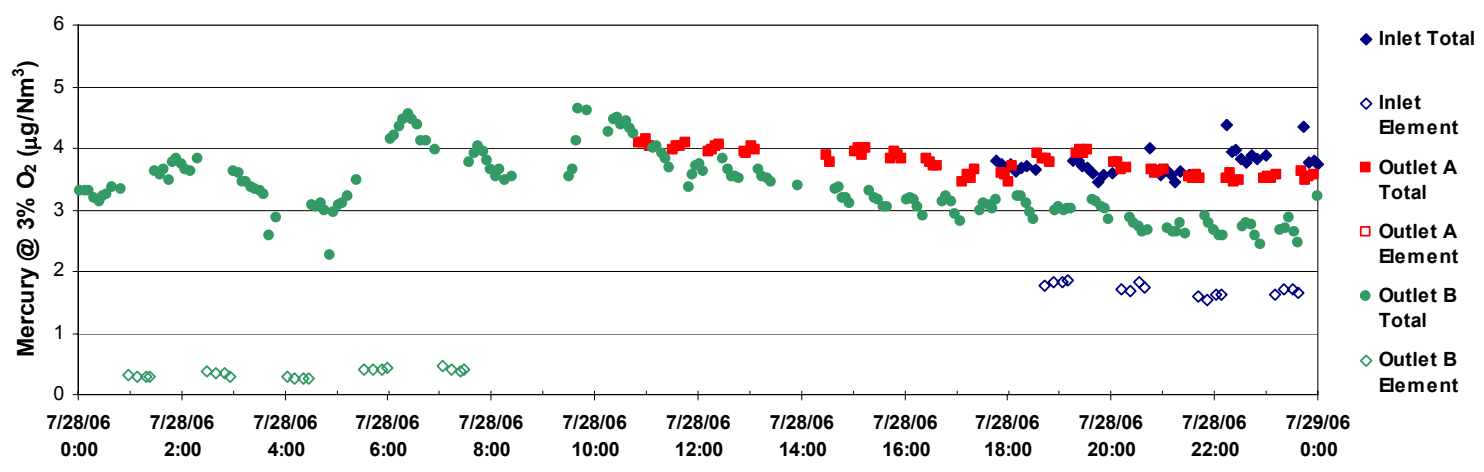

Figure A8. Mercury Concentration Trace for July 28, 2006.

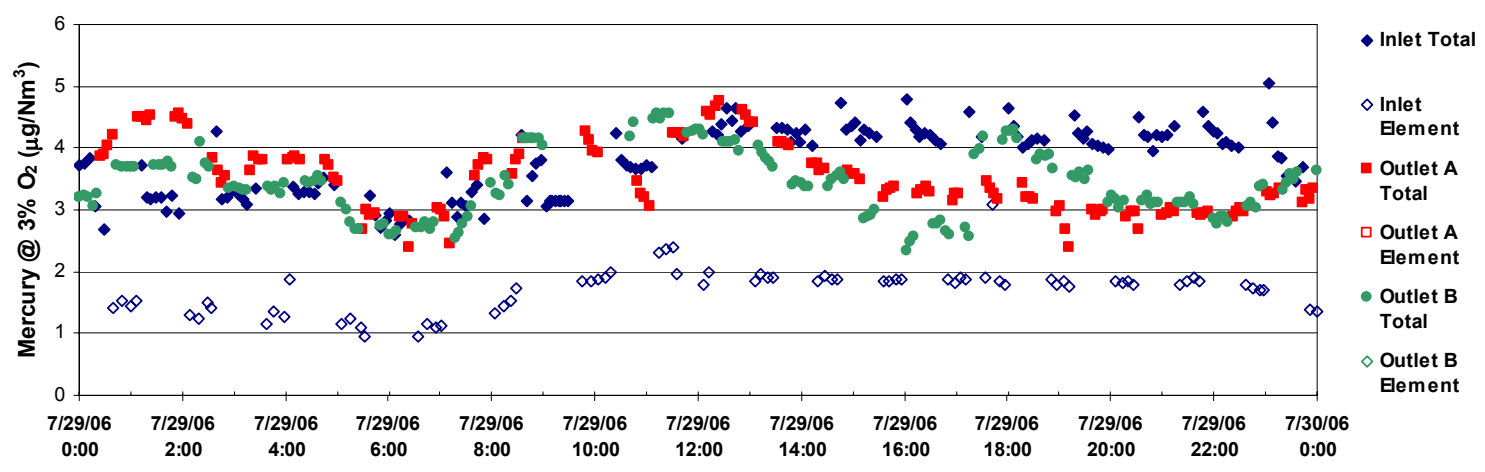

Figure A9. Mercury Concentration Trace for July 29, 2006. 


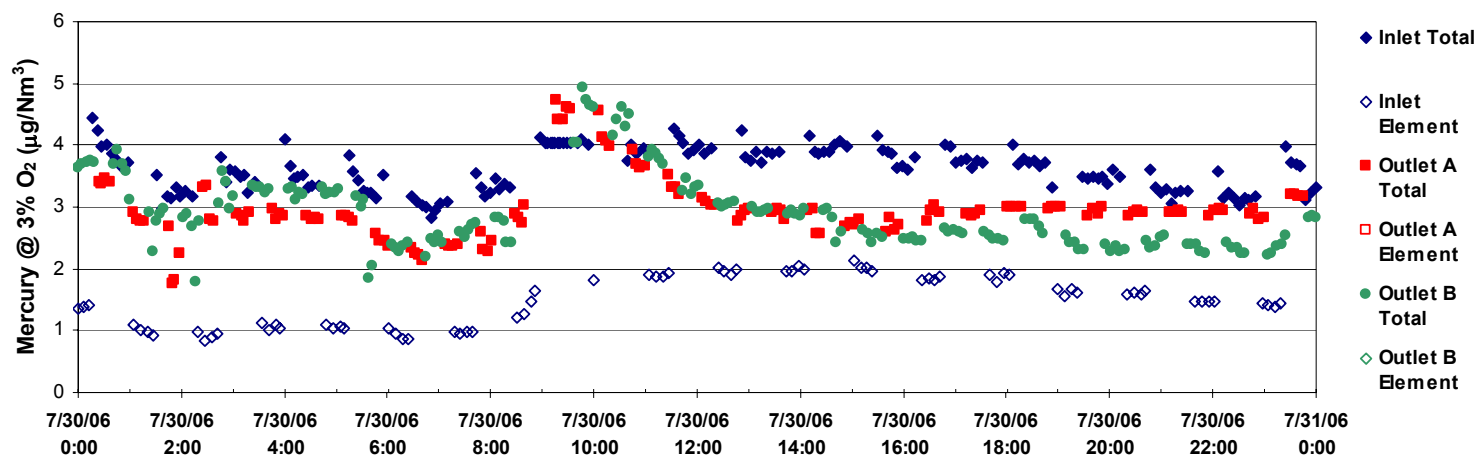

Figure A10. Mercury Concentration Trace for July 30, 2006.

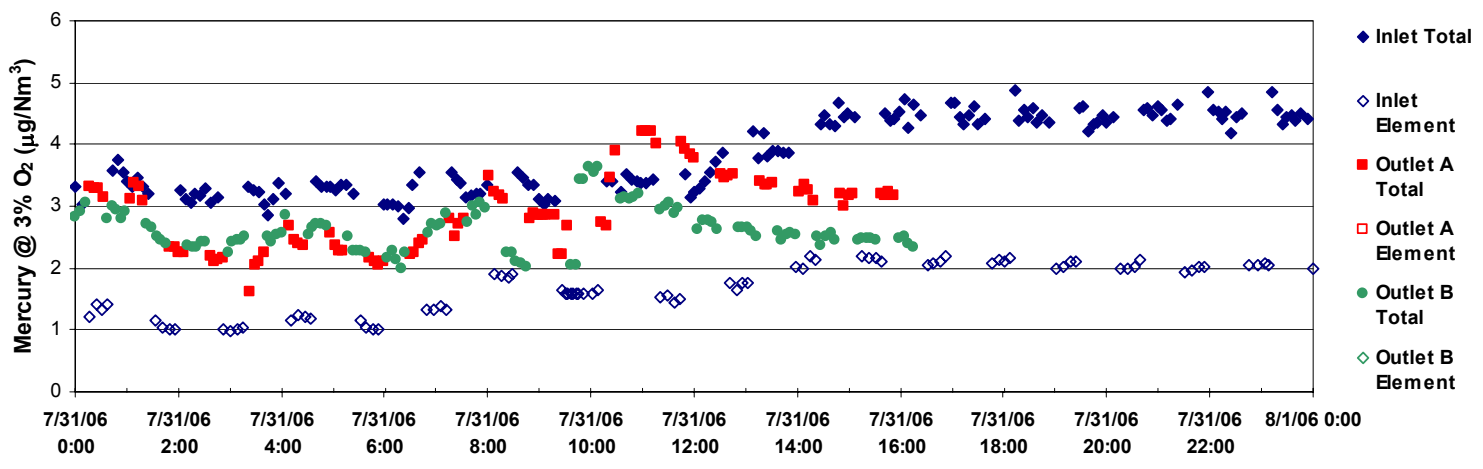

Figure A11. Mercury Concentration Trace for July 31, 2006.

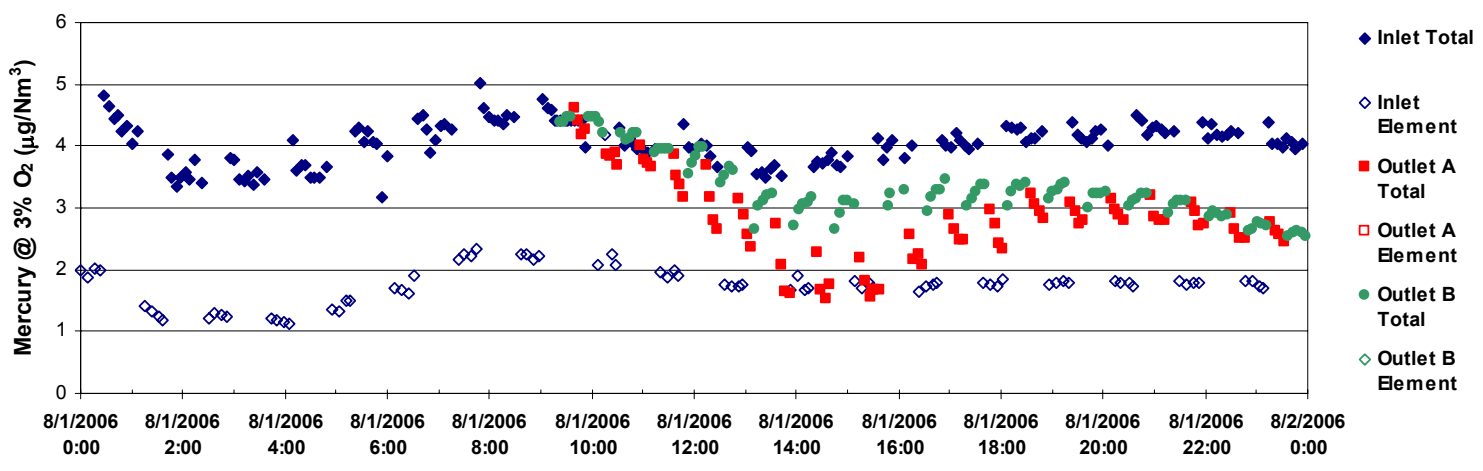

Figure A12. Mercury Concentration Trace for August 1, 2006. 


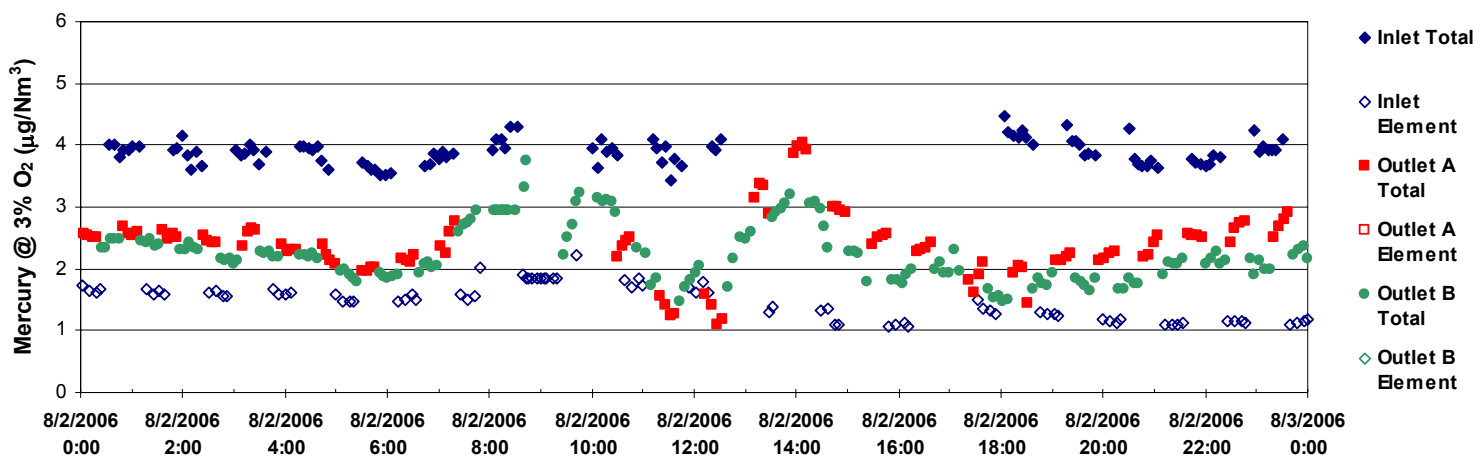

Figure A13. Mercury Concentration Trace for August 2, 2006.

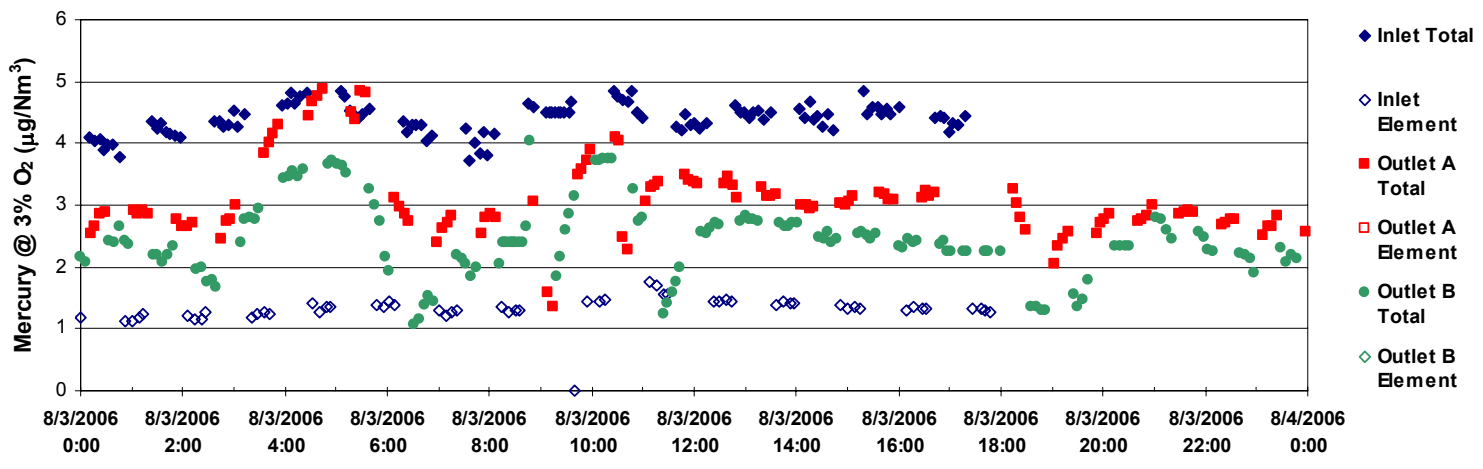

Figure A14. Mercury Concentration Trace for August 3, 2006.

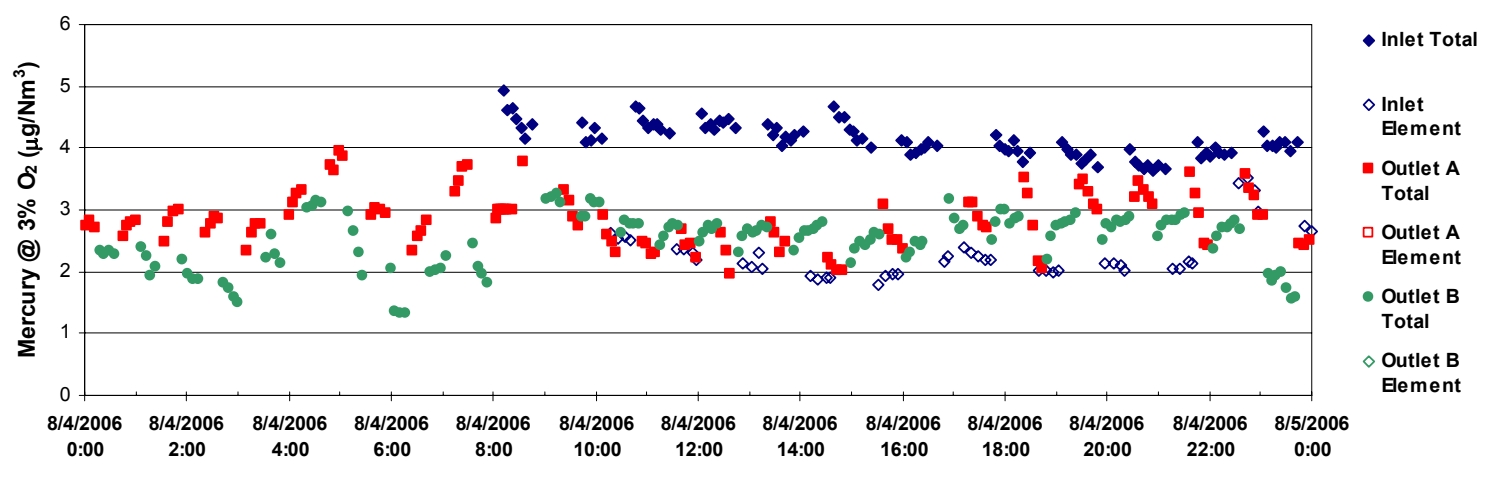

Figure A15. Mercury Concentration Trace for August 4, 2006. 


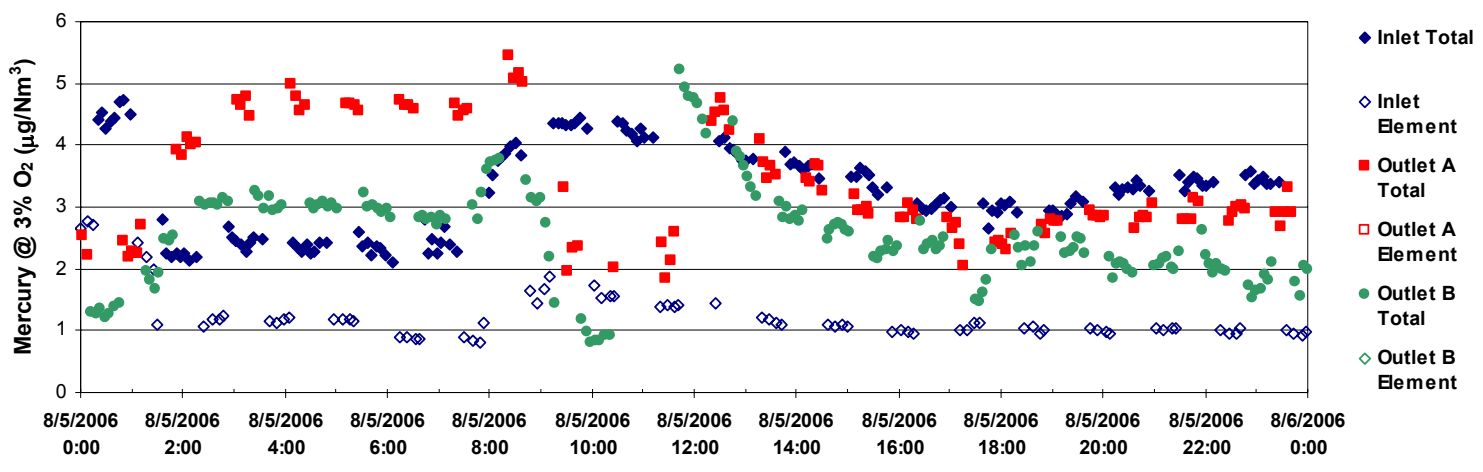

Figure A16. Mercury Concentration Trace for August 5, 2006.

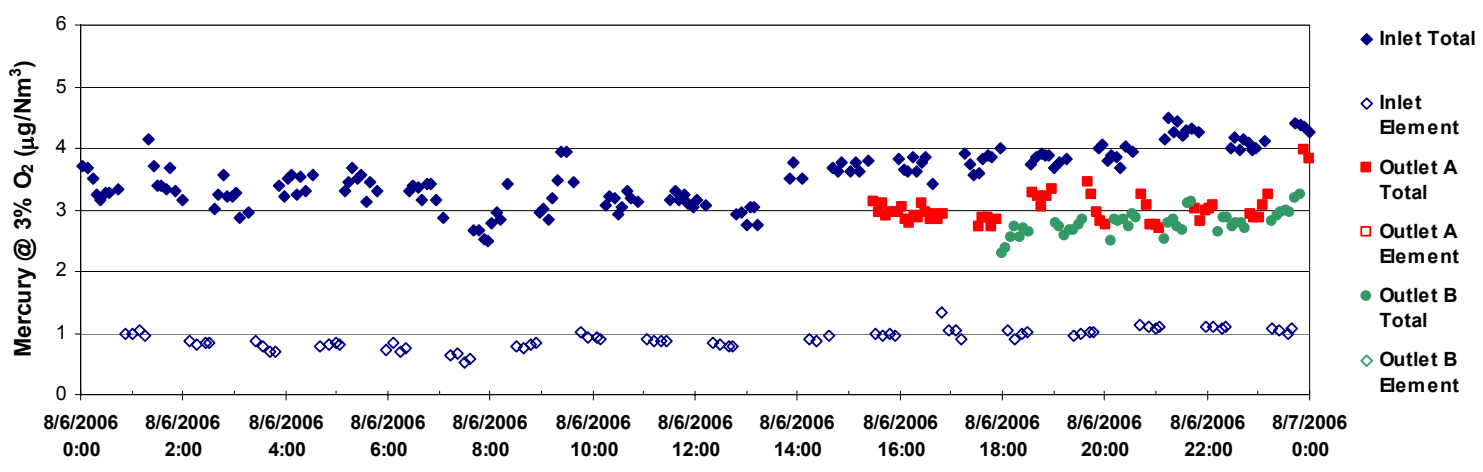

Figure A17. Mercury Concentration Trace for August 6, 2006.

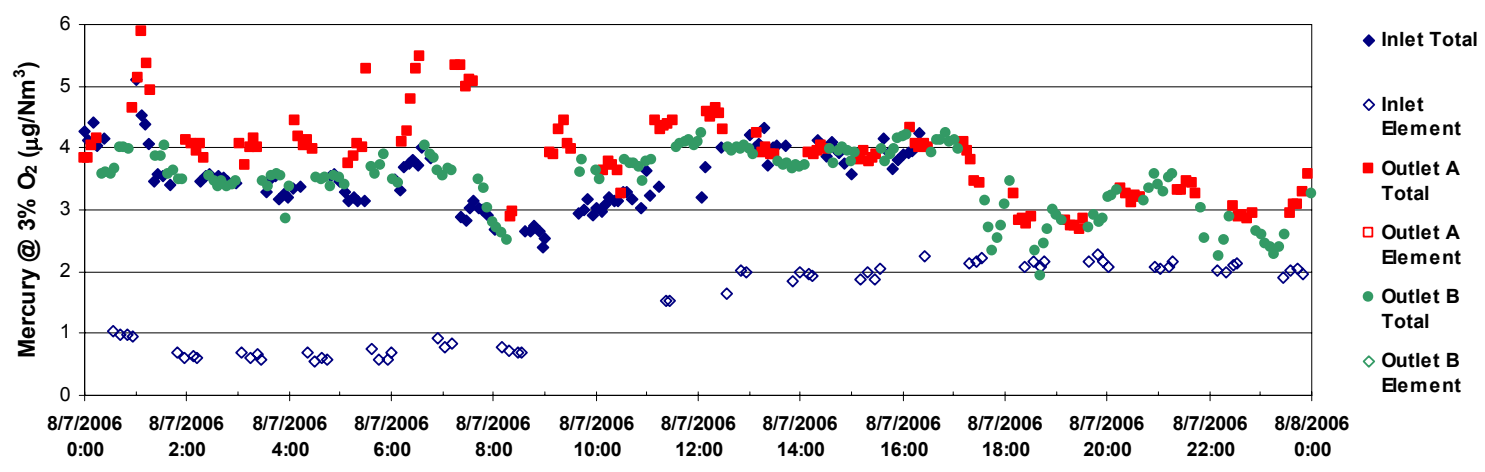

Figure A18. Mercury Concentration Trace for August 72006. 


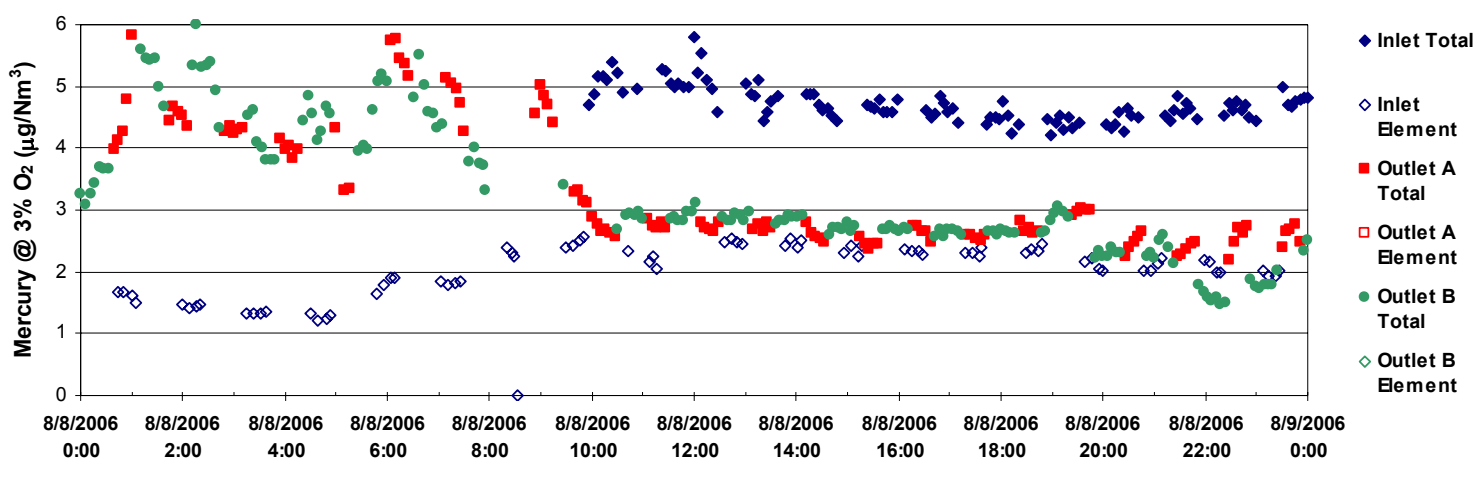

Figure A19. Mercury Concentration Trace for August 82006.

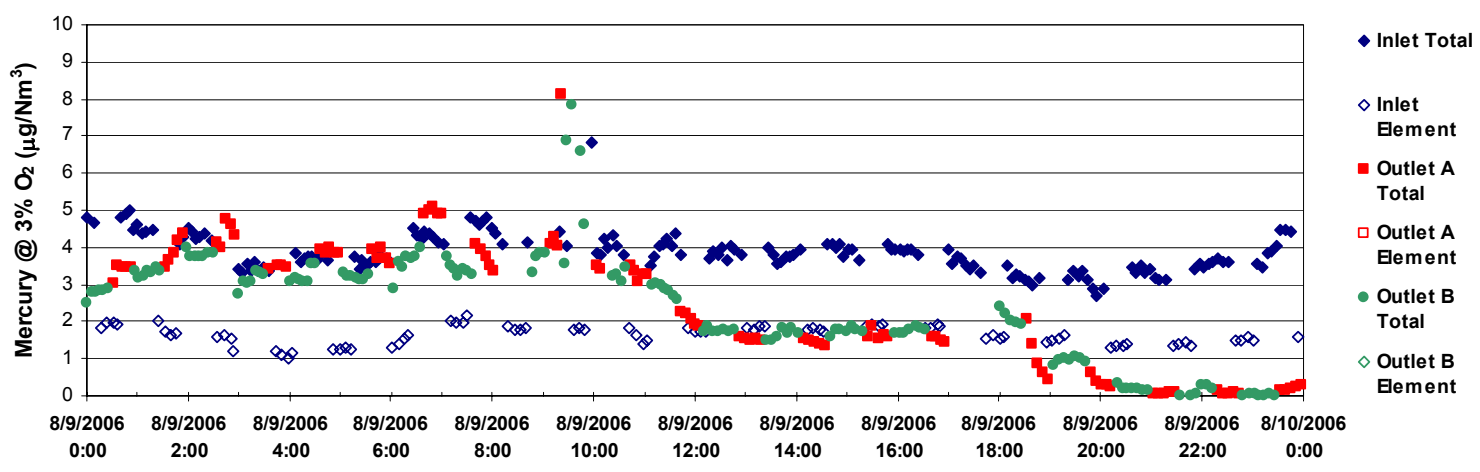

Figure A20. Mercury Concentration Trace for August 92006.

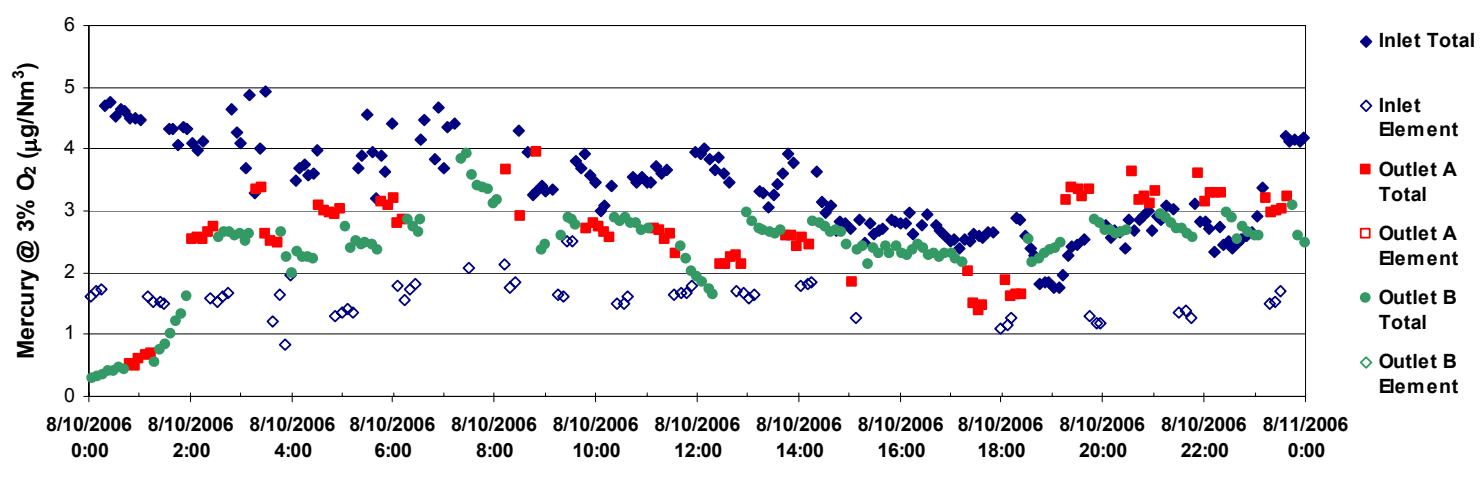

Figure A21. Mercury Concentration Trace for August 102006. 


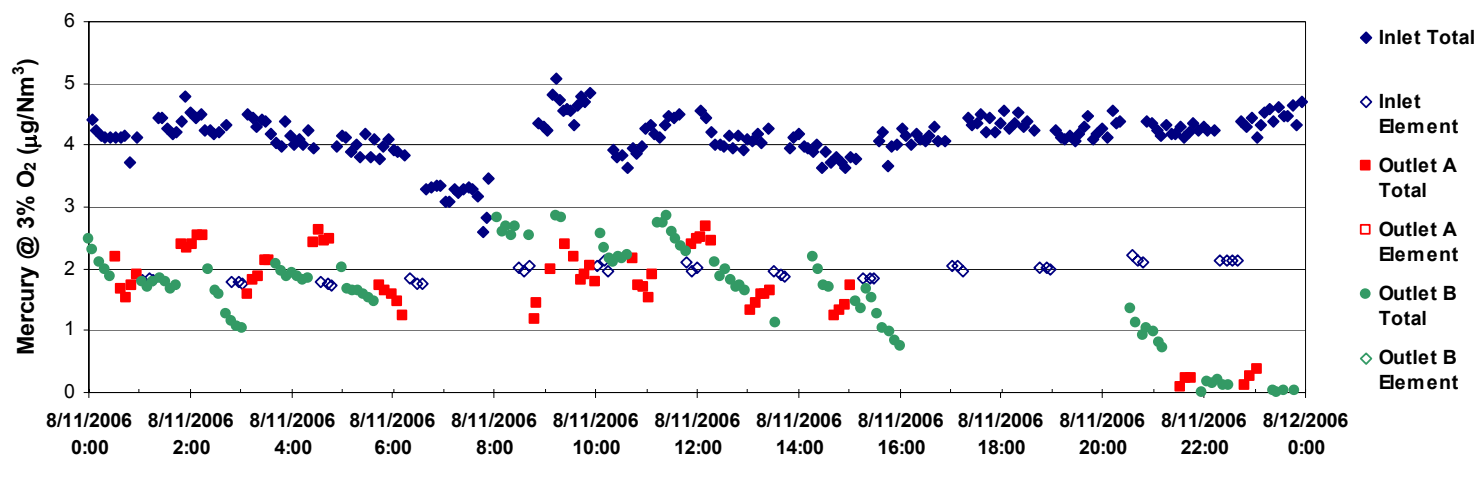

Figure A22. Mercury Concentration Trace for August 112006.

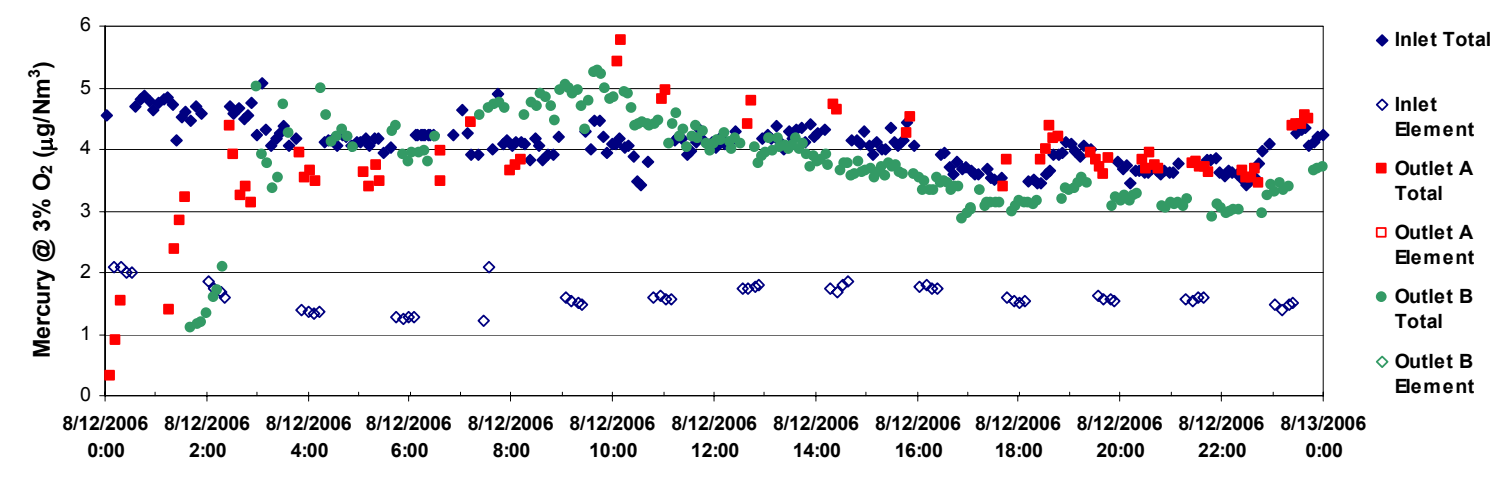

Figure A23. Mercury Concentration Trace for August 122006.

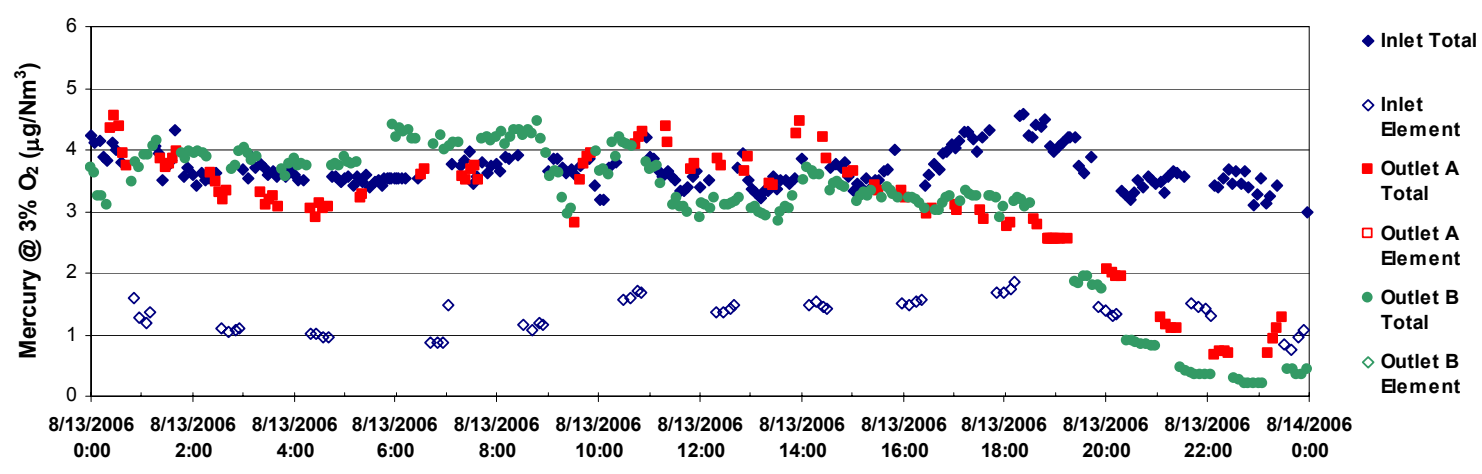

Figure A24. Mercury Concentration Trace for August 132006. 


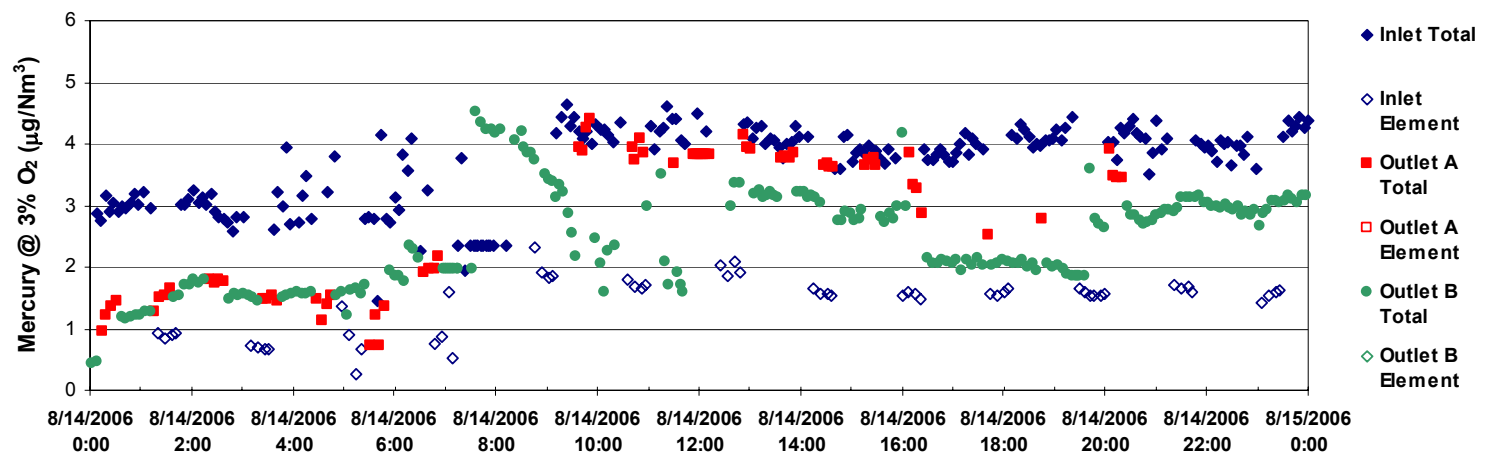

Figure A25. Mercury Concentration Trace for August 142006.

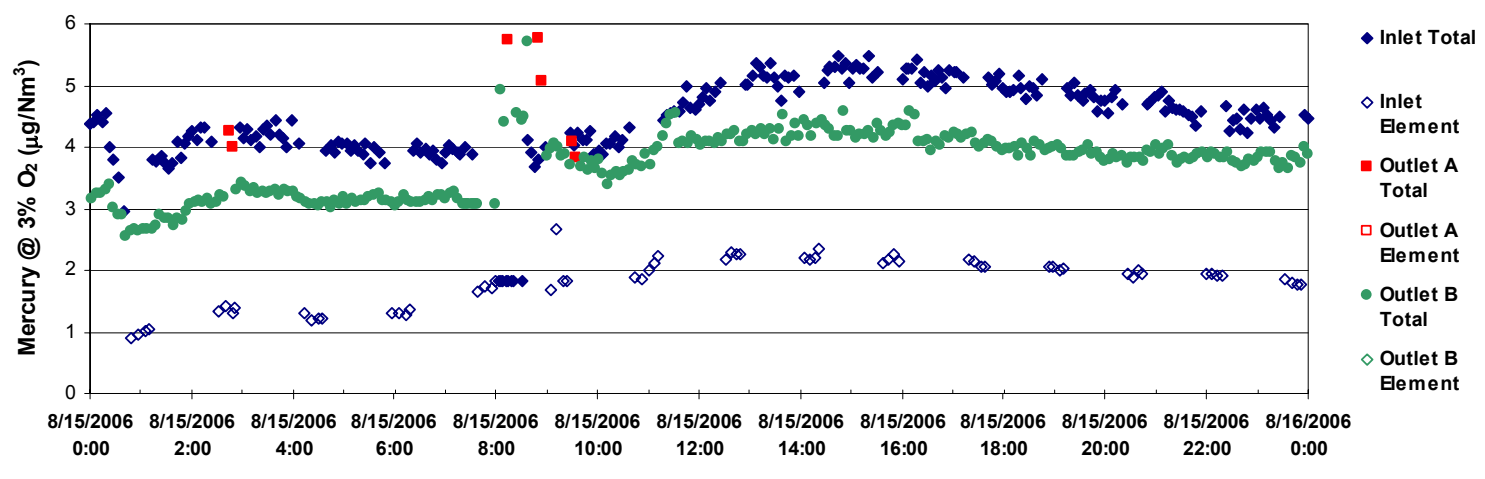

Figure A26. Mercury Concentration Trace for August 152006.

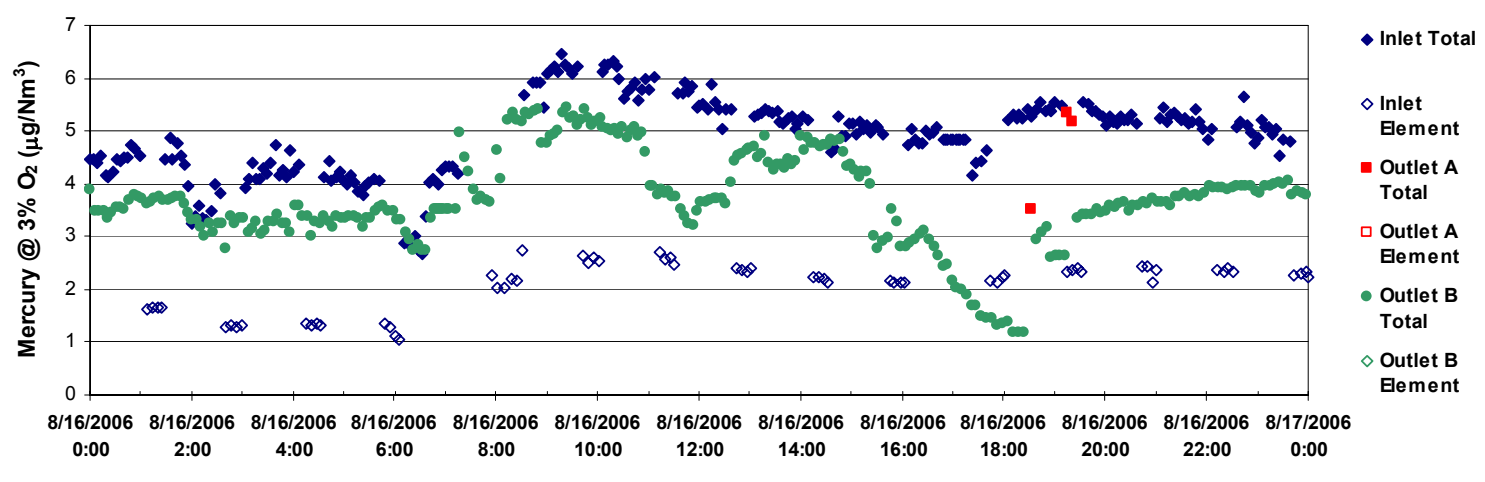

Figure A27. Mercury Concentration Trace for August 162006. 


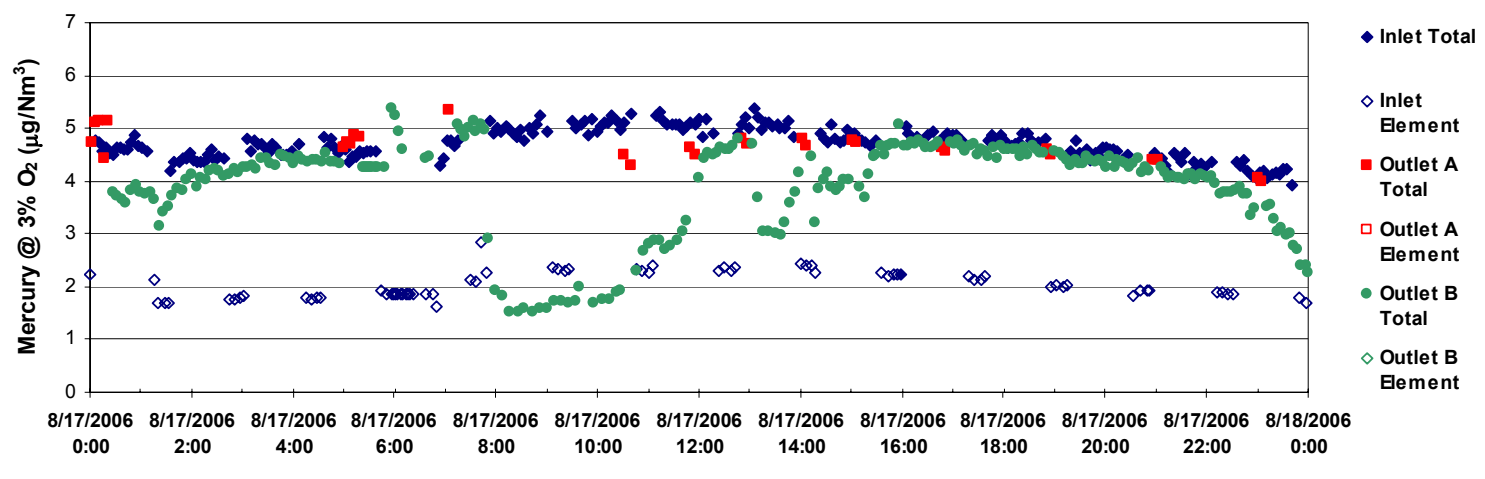

Figure A28. Mercury Concentration Trace for August 172006.

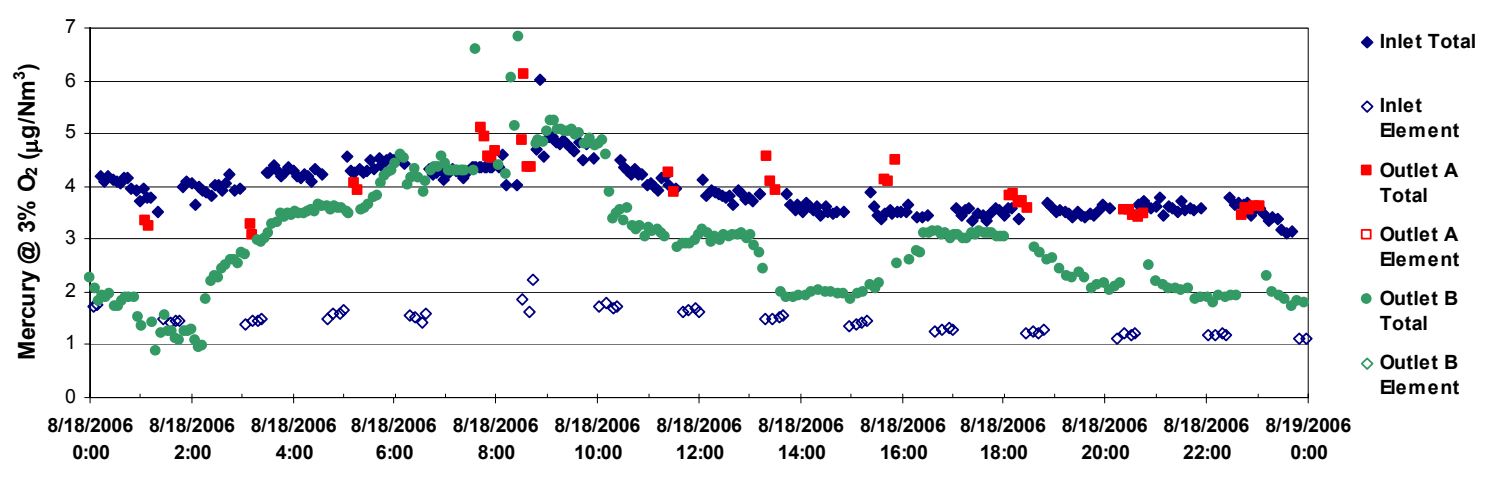

Figure A29. Mercury Concentration Trace for August 182006.

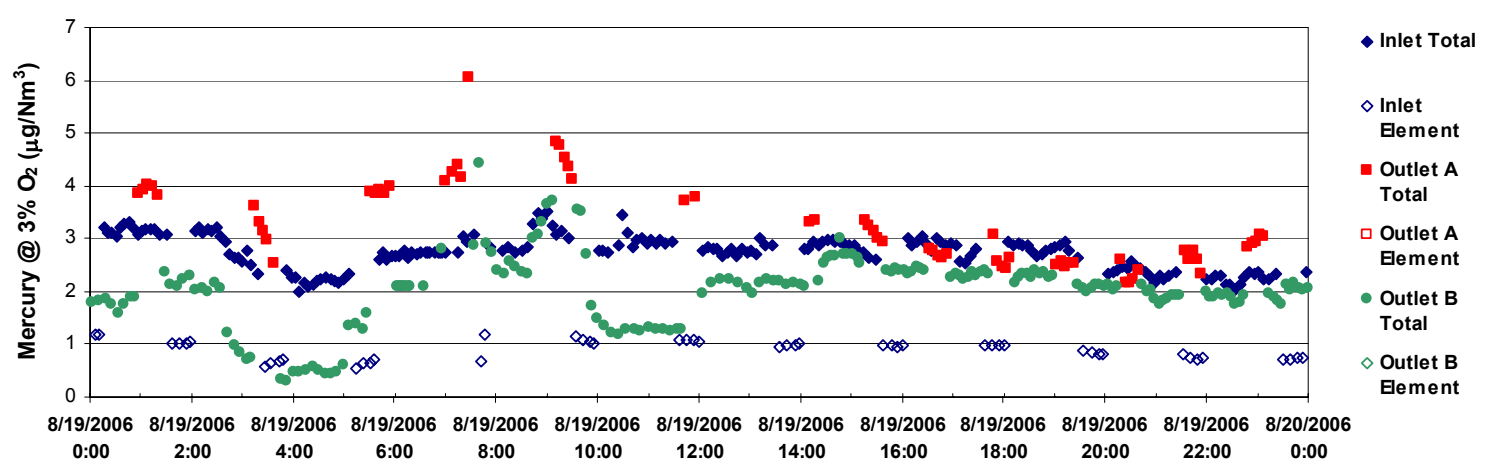

Figure A30. Mercury Concentration Trace for August 192006. 


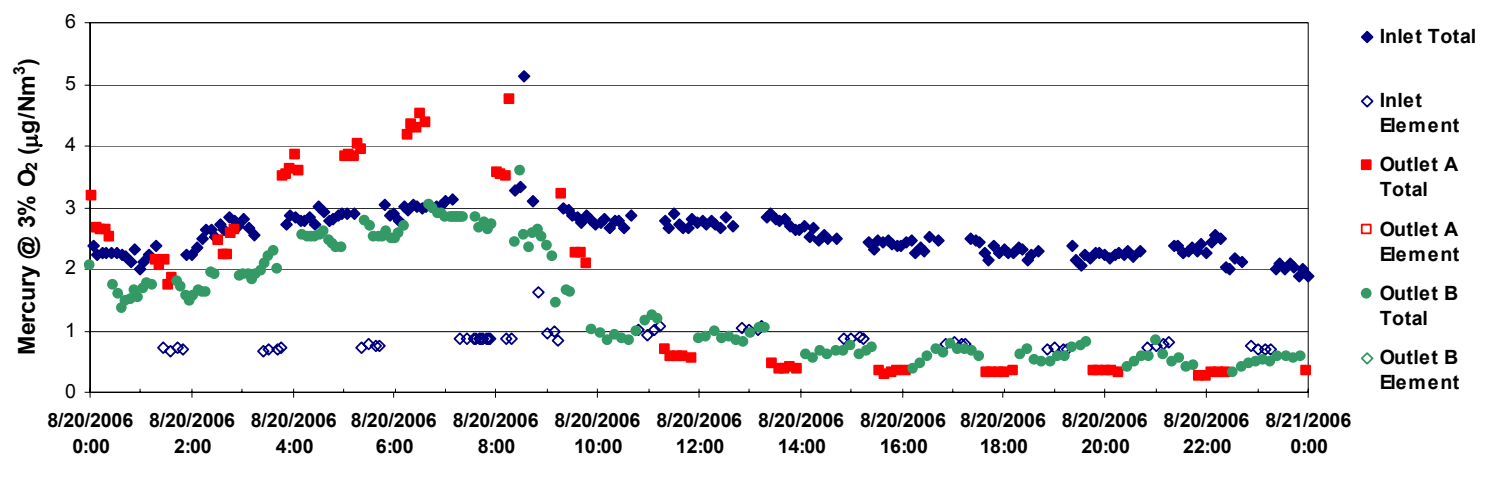

Figure A31. Mercury Concentration Trace for August 202006.

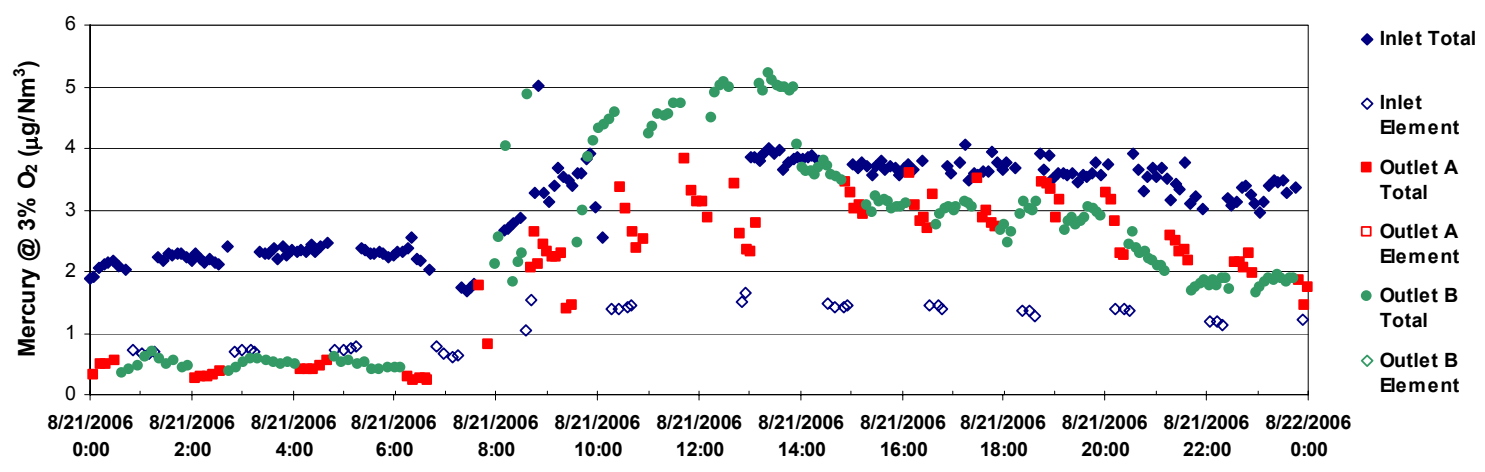

Figure A32. Mercury Concentration Trace for August 212006.

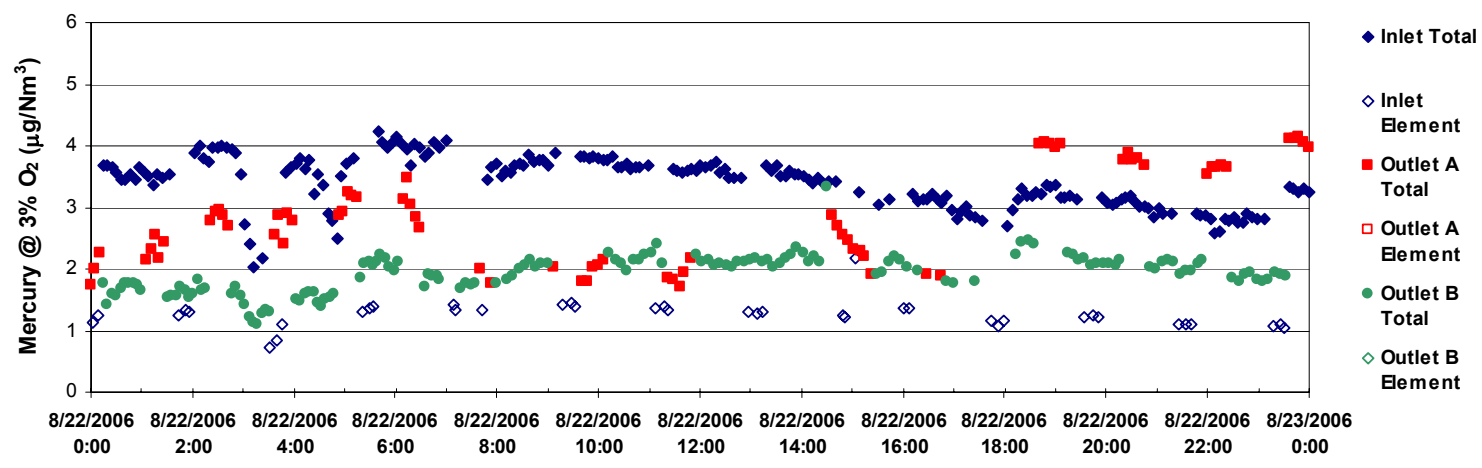

Figure A33. Mercury Concentration Trace for August 222006. 


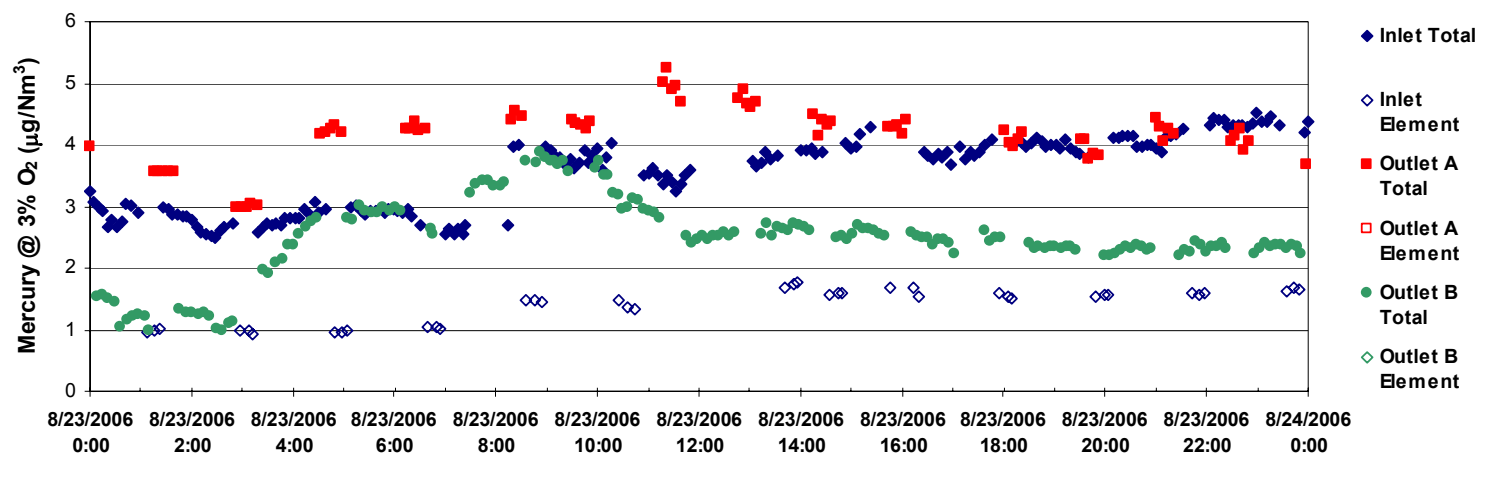

Figure A34. Mercury Concentration Trace for August 232006.

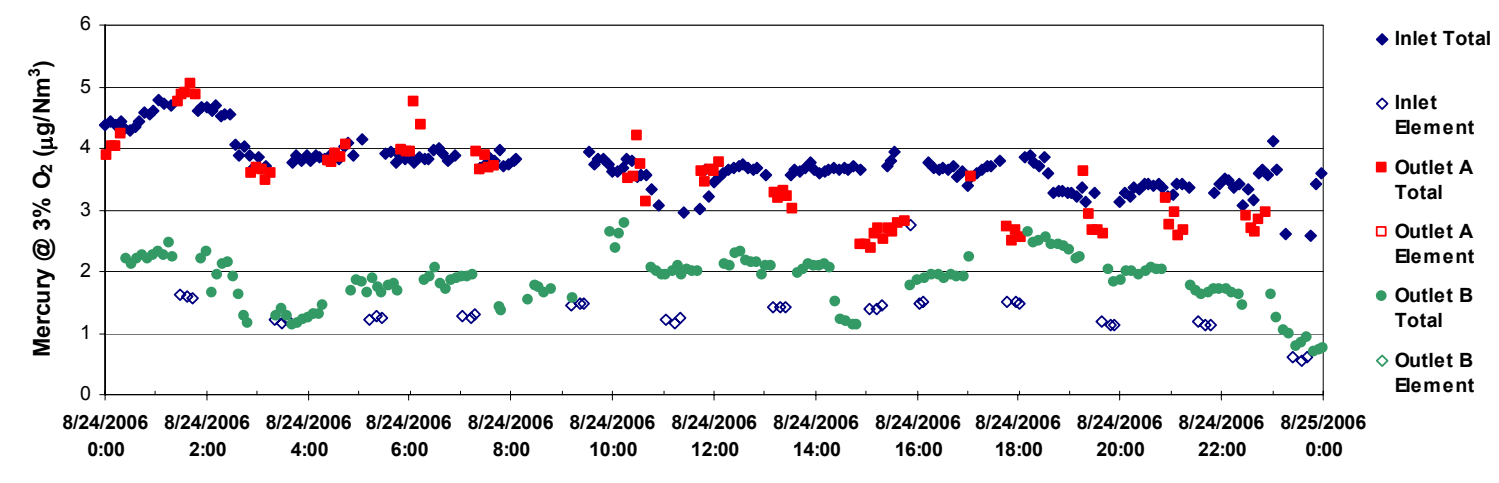

Figure A35. Mercury Concentration Trace for August 242006.

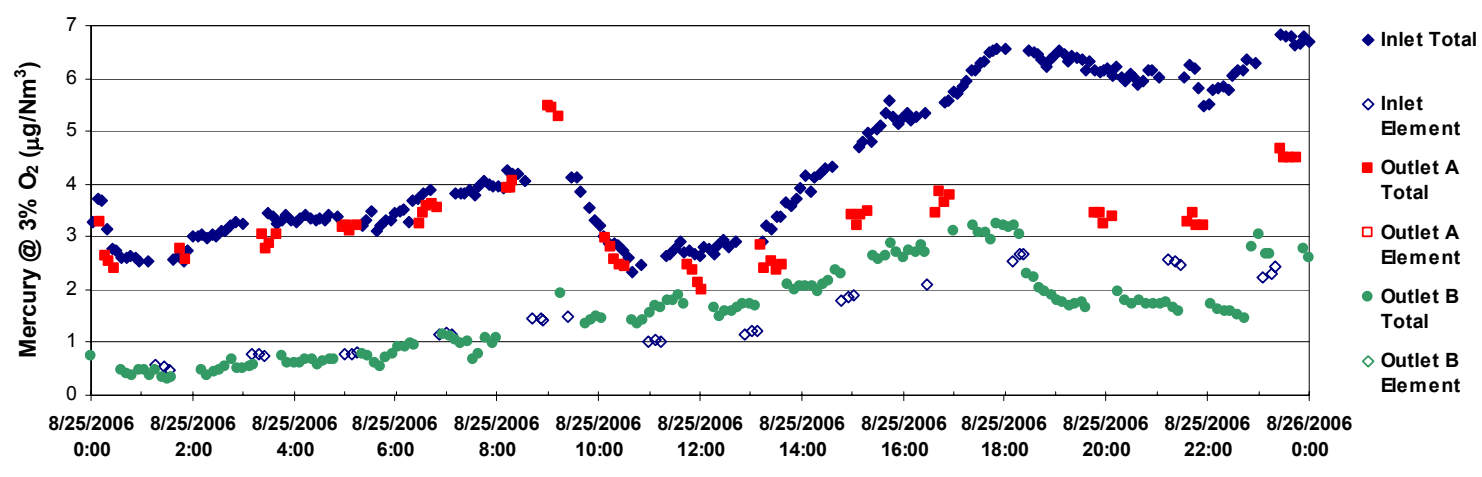

Figure A36. Mercury Concentration Trace for August 252006. 


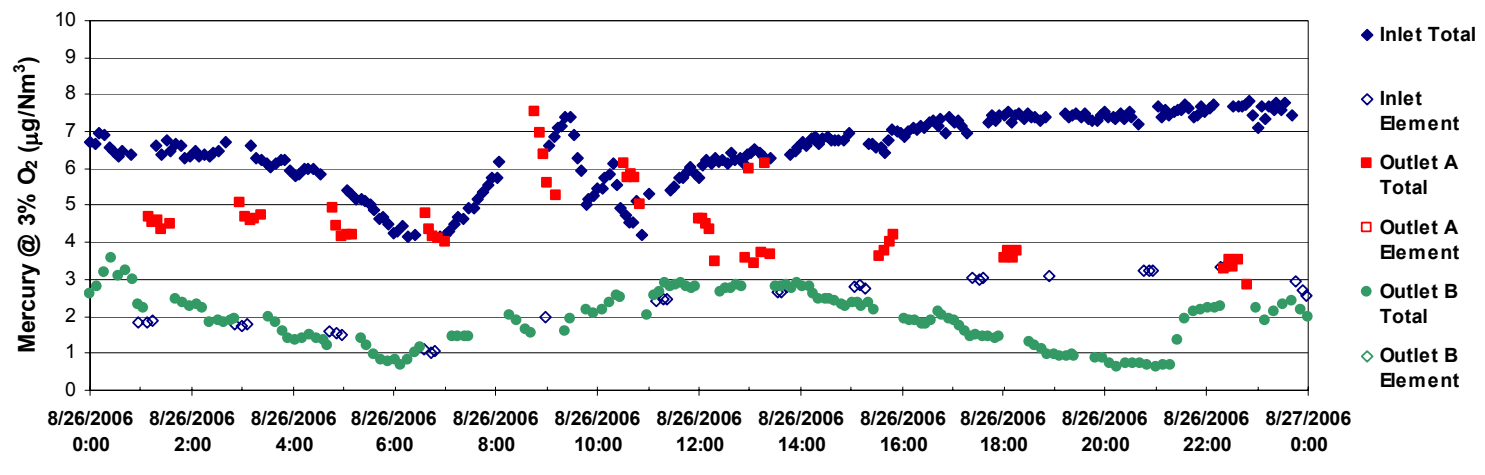

Figure A37. Mercury Concentration Trace for August 262006.

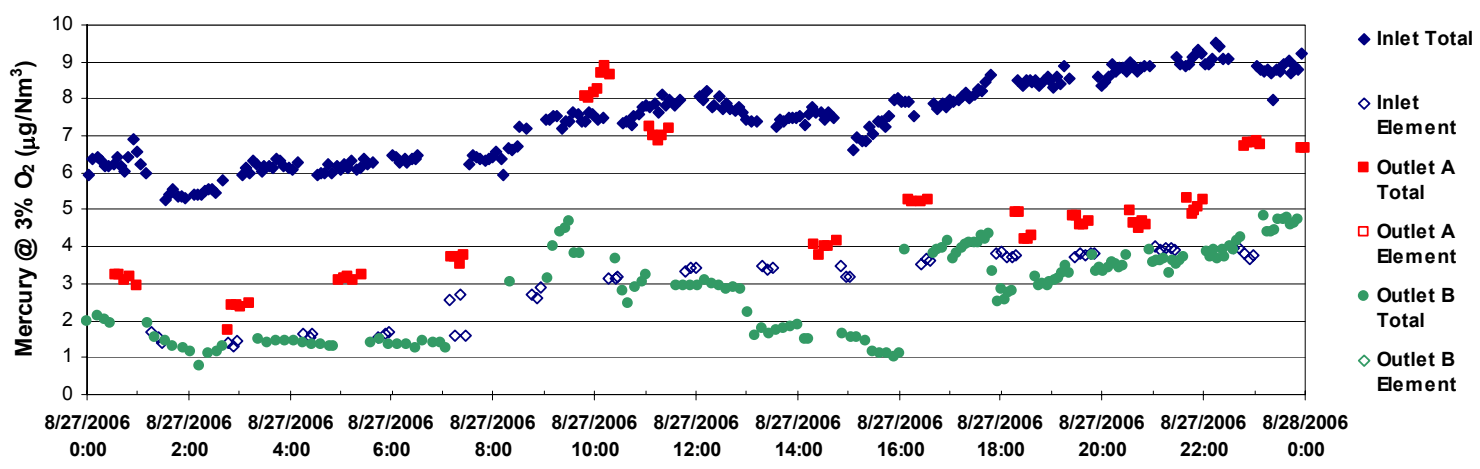

Figure A38. Mercury Concentration Trace for August 272006.

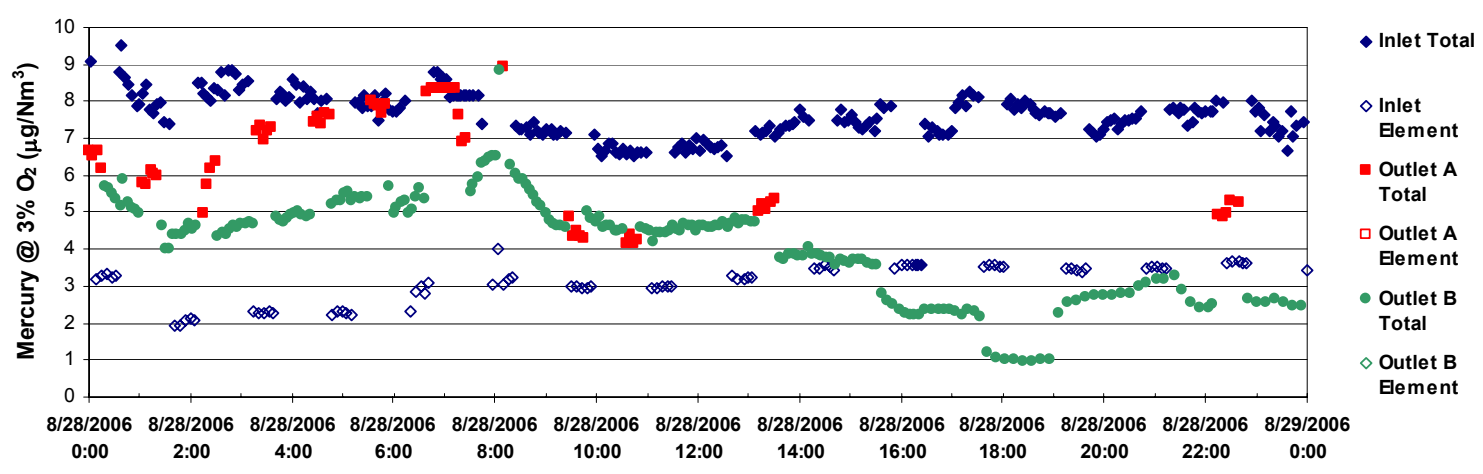

Figure A39. Mercury Concentration Trace for August 282006. 


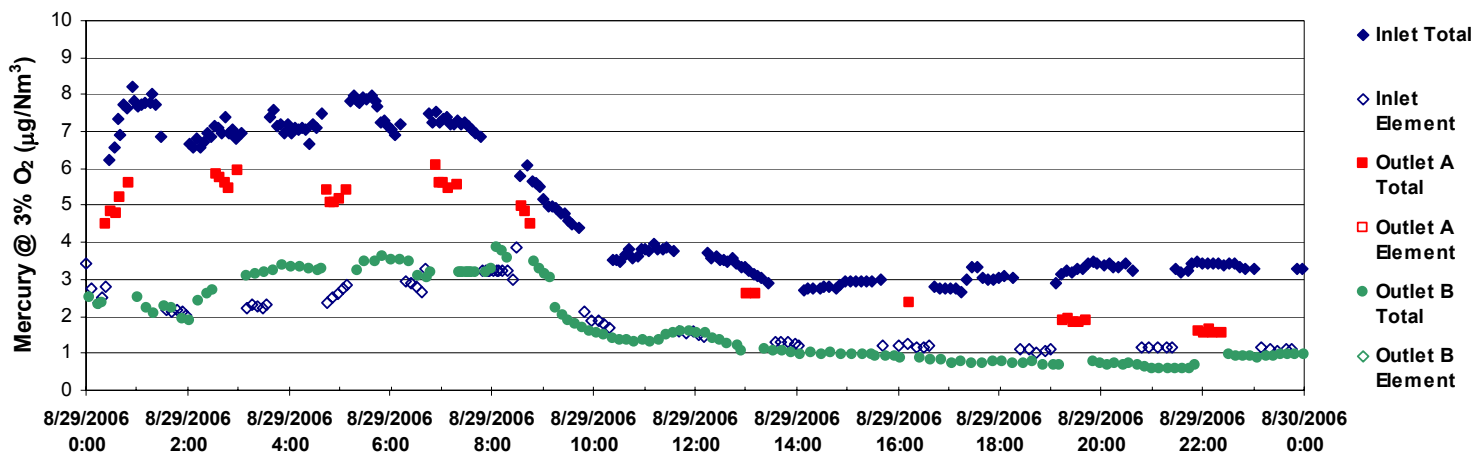

Figure A40. Mercury Concentration Trace for August 292006.

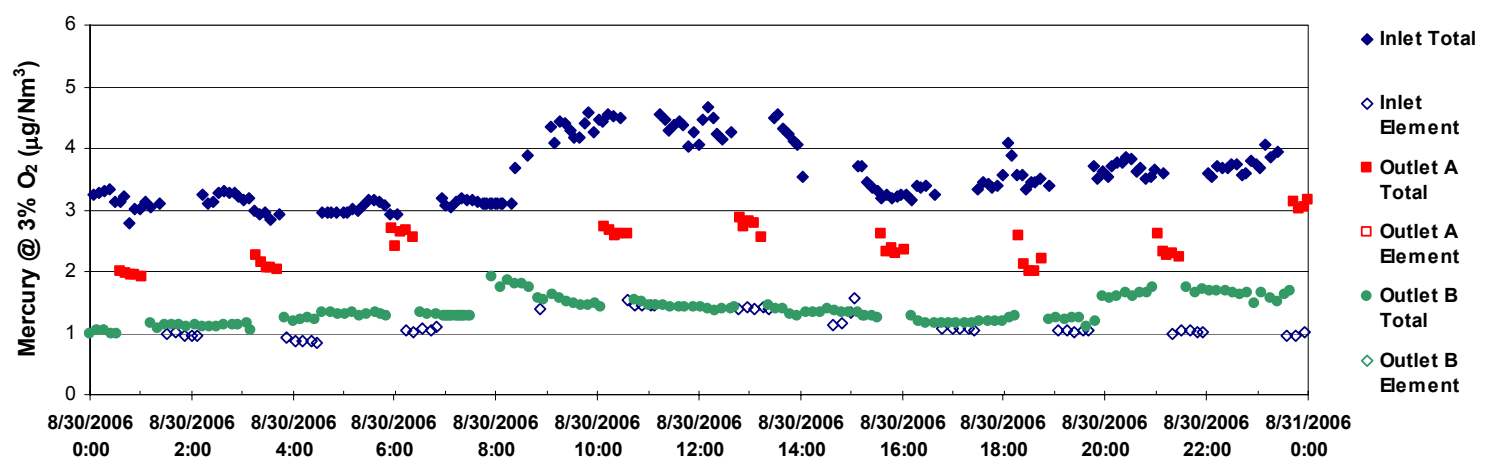

Figure A41. Mercury Concentration Trace for August 302006.

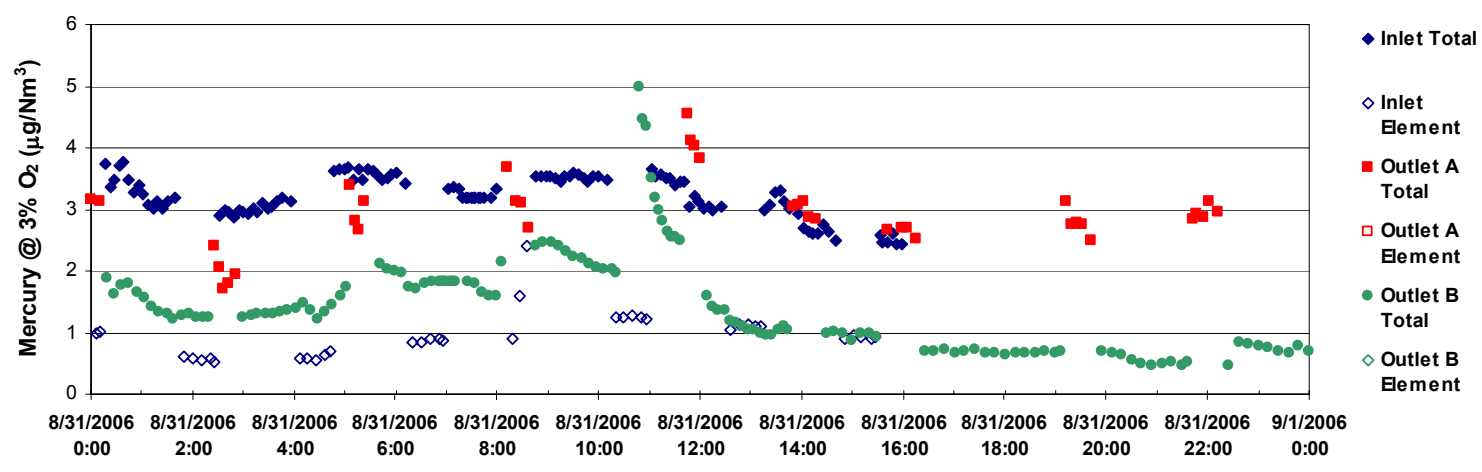

Figure A42. Mercury Concentration Trace for August 312006. 


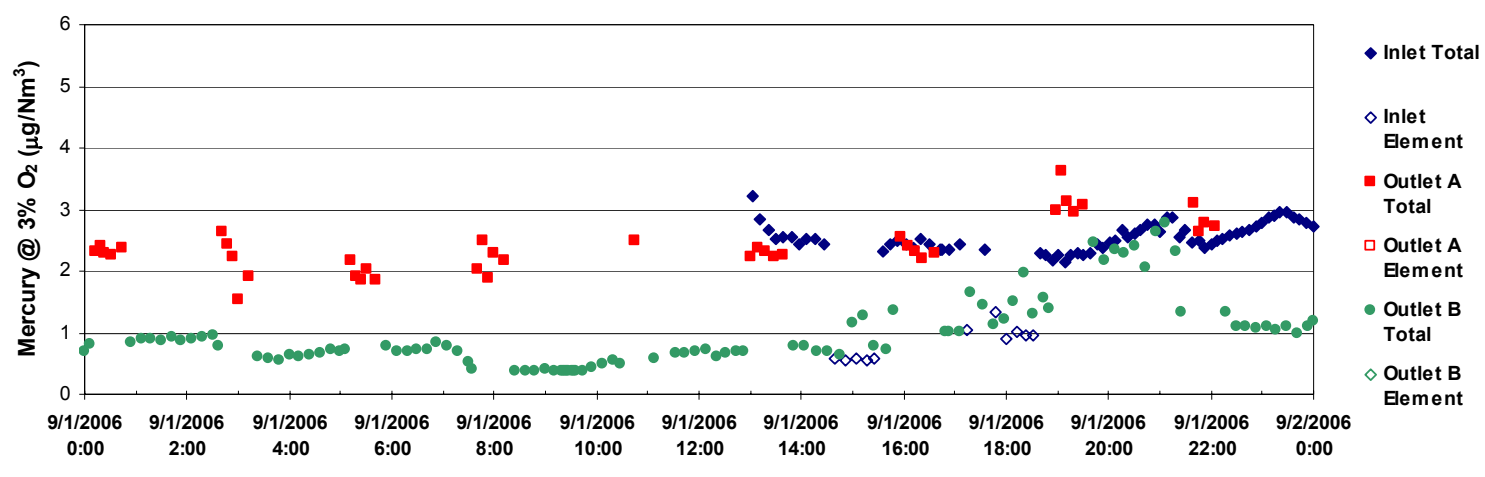

Figure A43. Mercury Concentration Trace for September 12006.

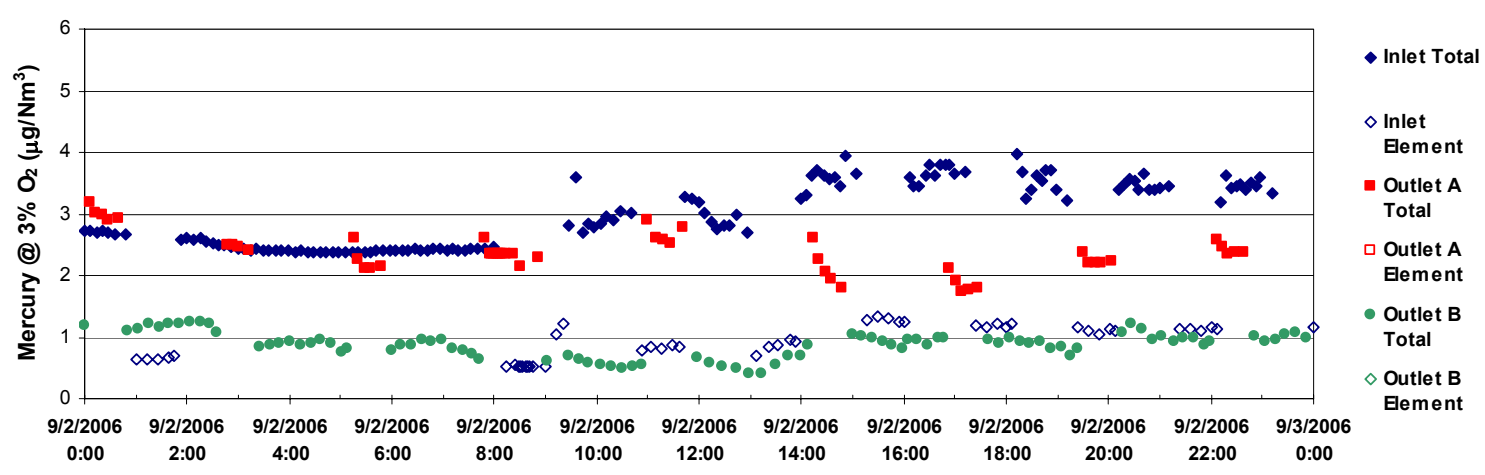

Figure A44. Mercury Concentration Trace for September 22006.

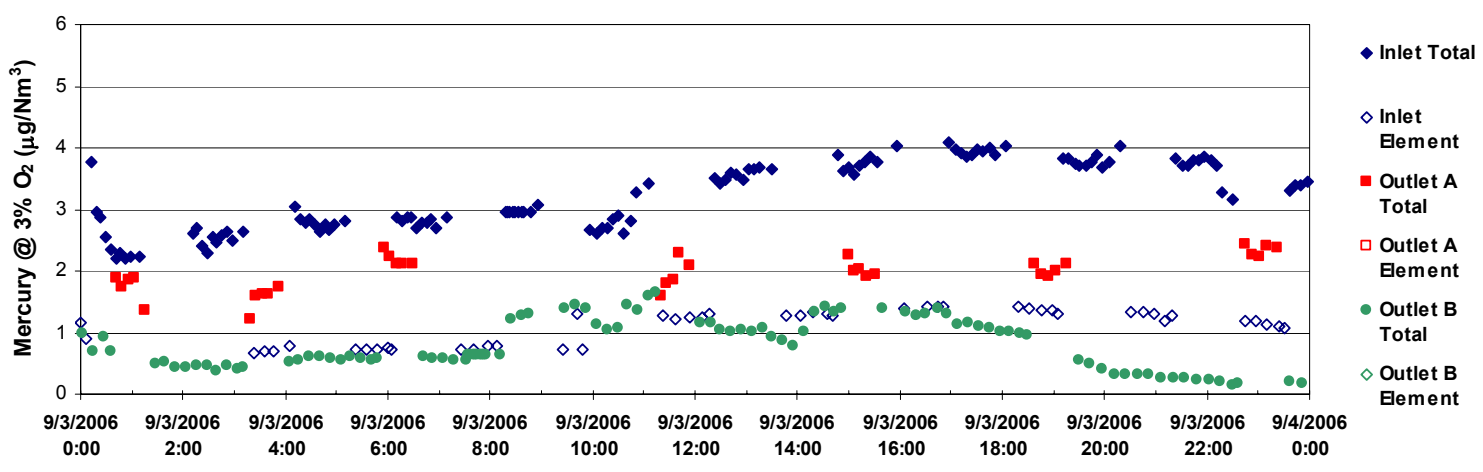

Figure A45. Mercury Concentration Trace for September 32006. 


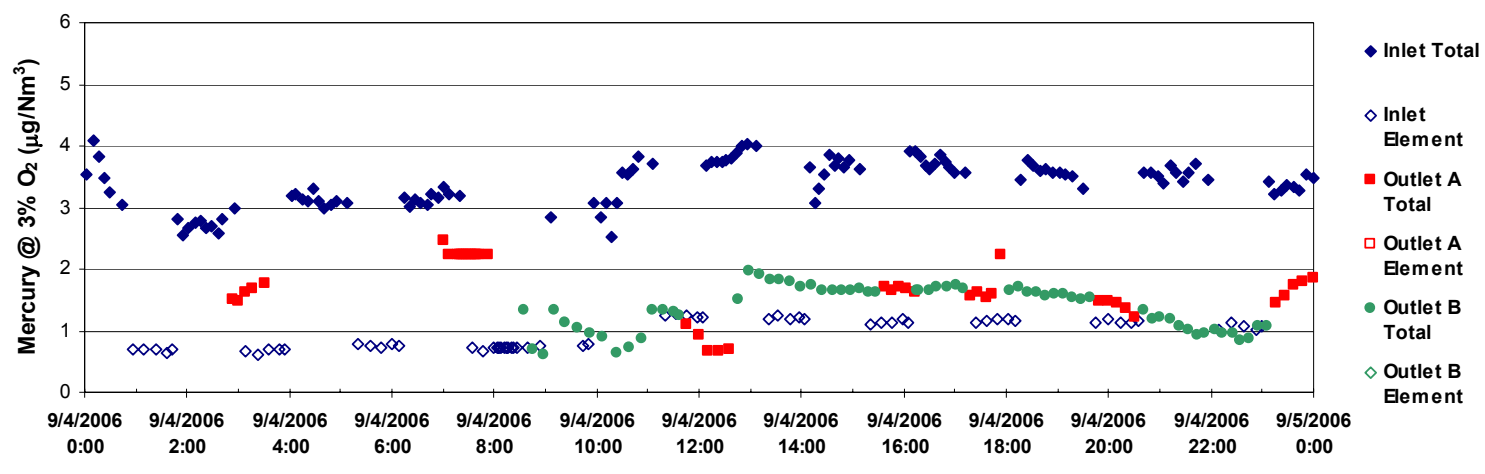

Figure A46. Mercury Concentration Trace for September 42006.

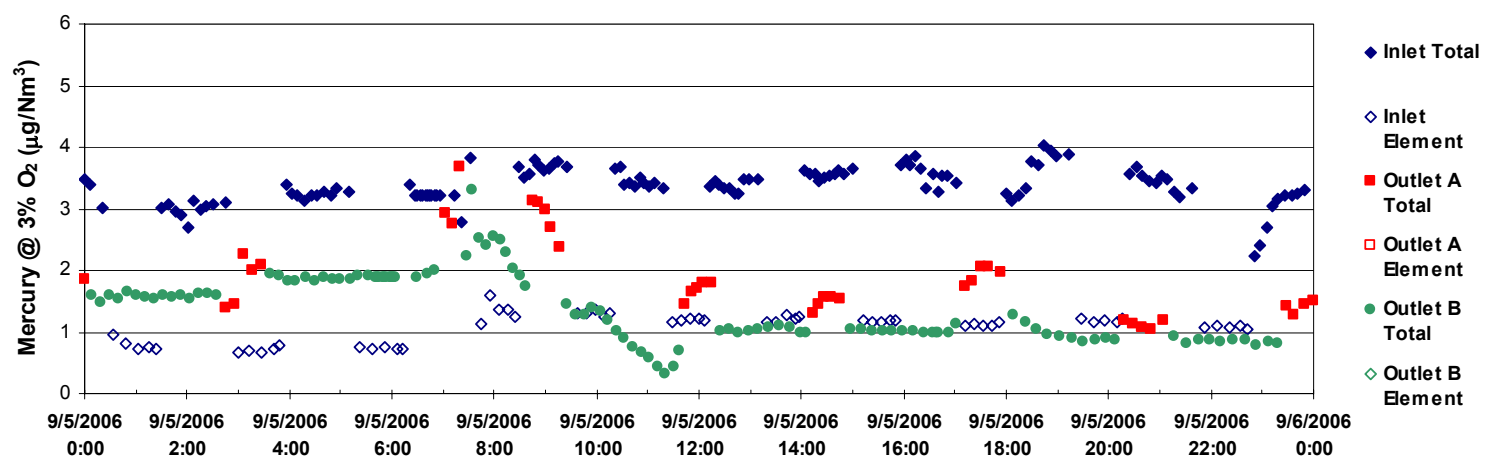

Figure A47. Mercury Concentration Trace for September 52006.

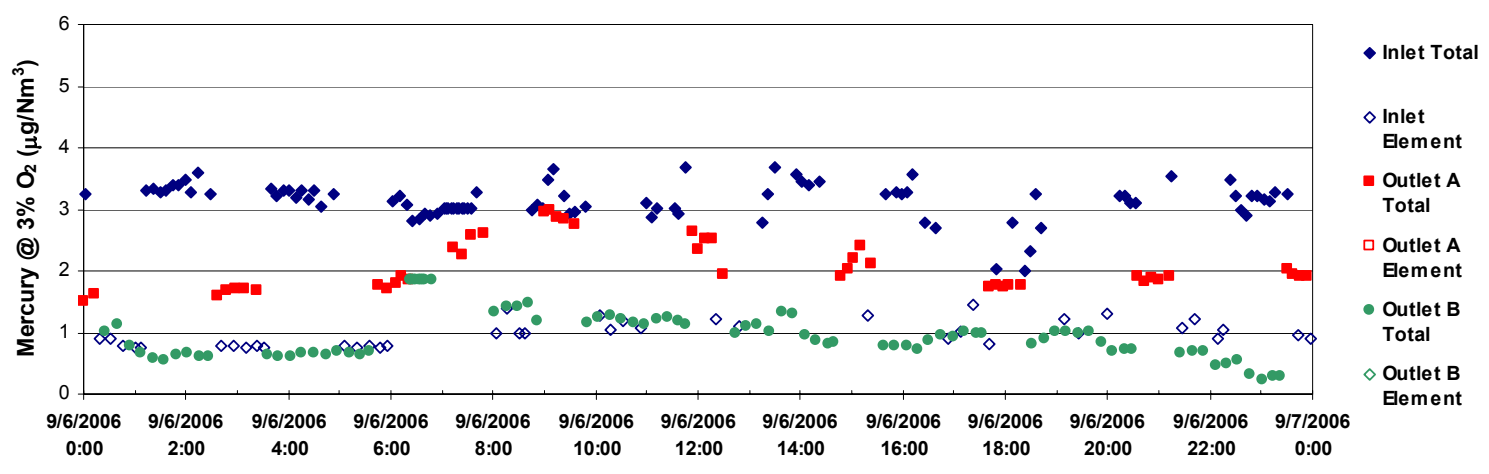

Figure A48. Mercury Concentration Trace for September 62006. 


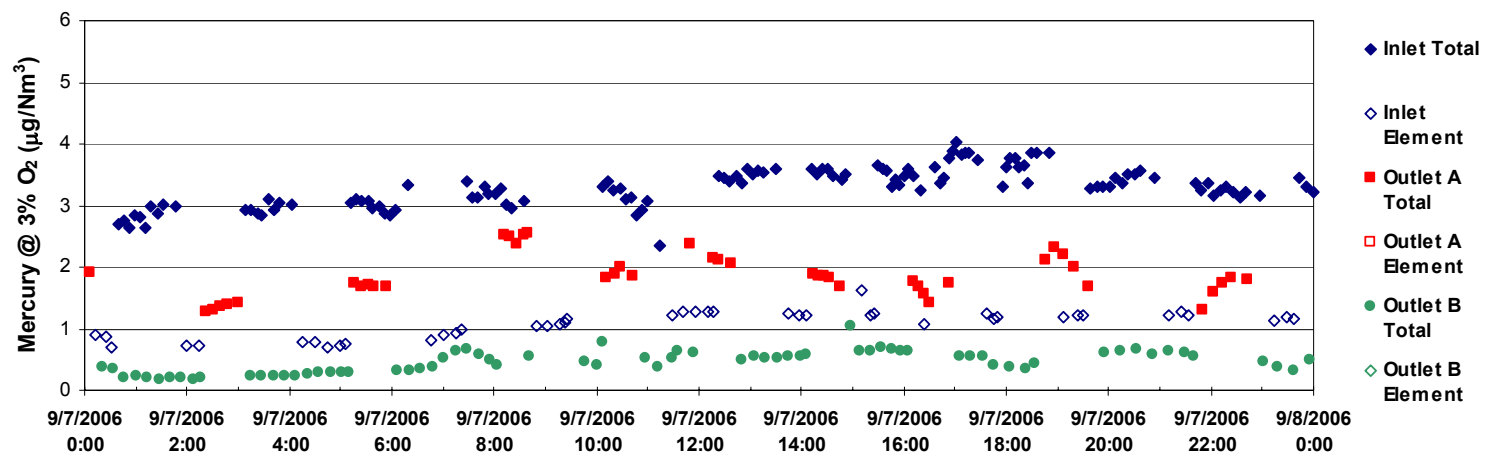

Figure A49. Mercury Concentration Trace for September 72006.

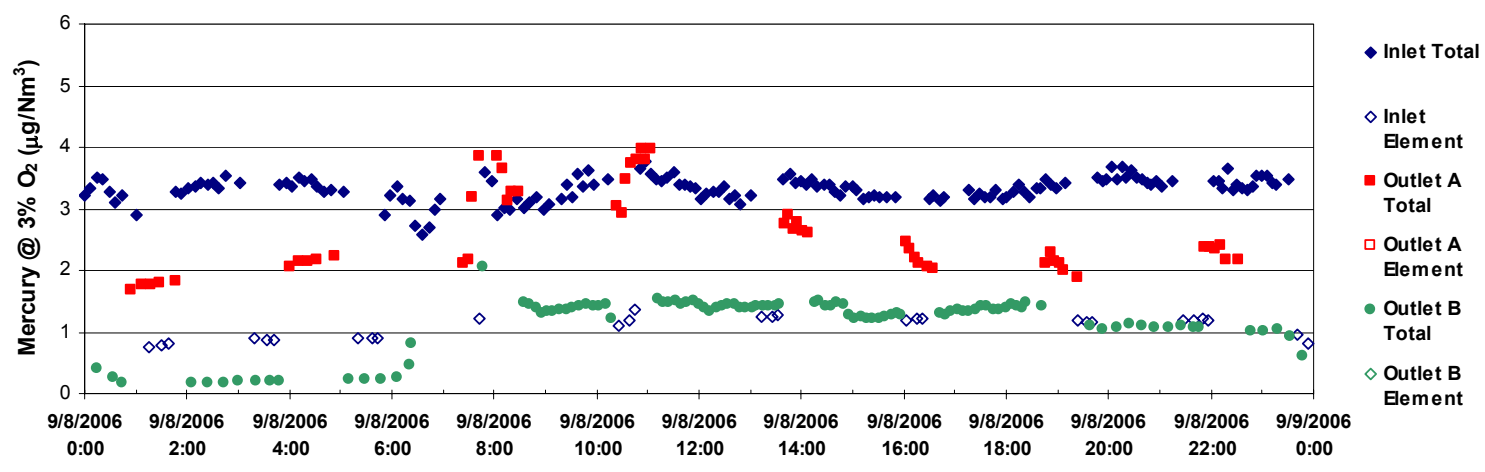

Figure A50. Mercury Concentration Trace for September 82006.

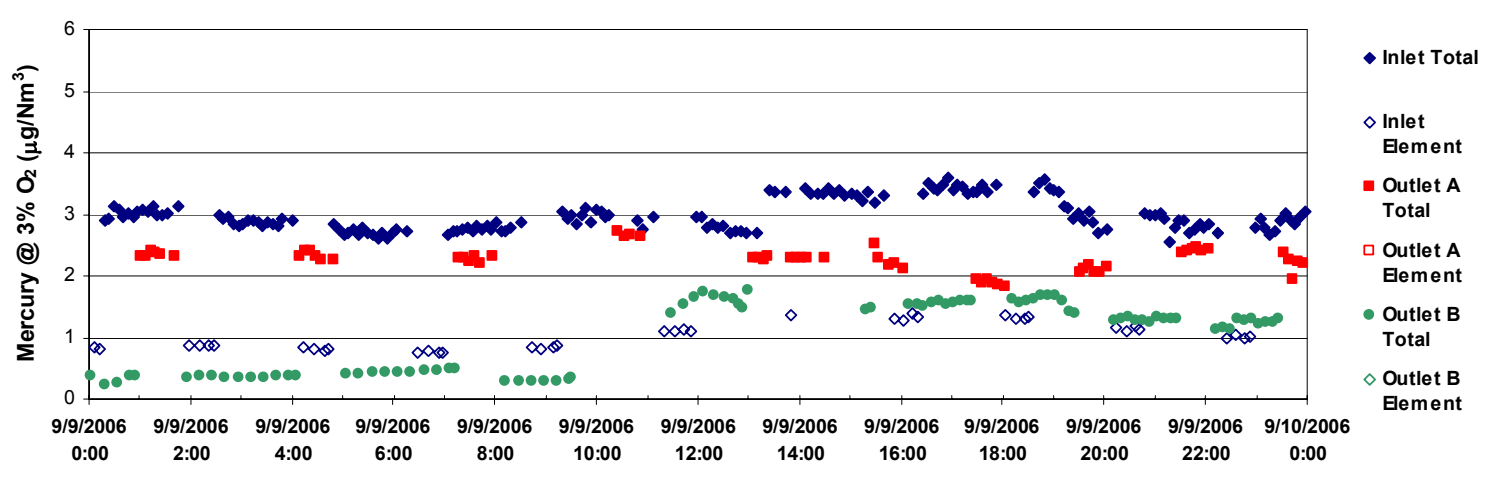

Figure A51. Mercury Concentration Trace for September 92006. 


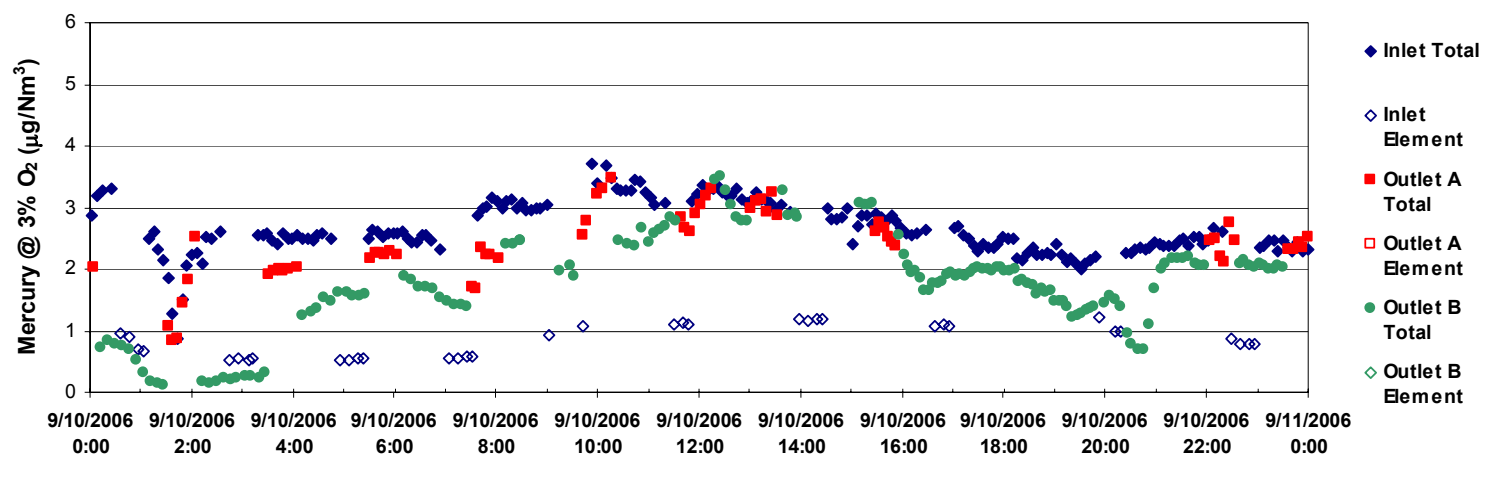

Figure A52. Mercury Concentration Trace for September 102006.

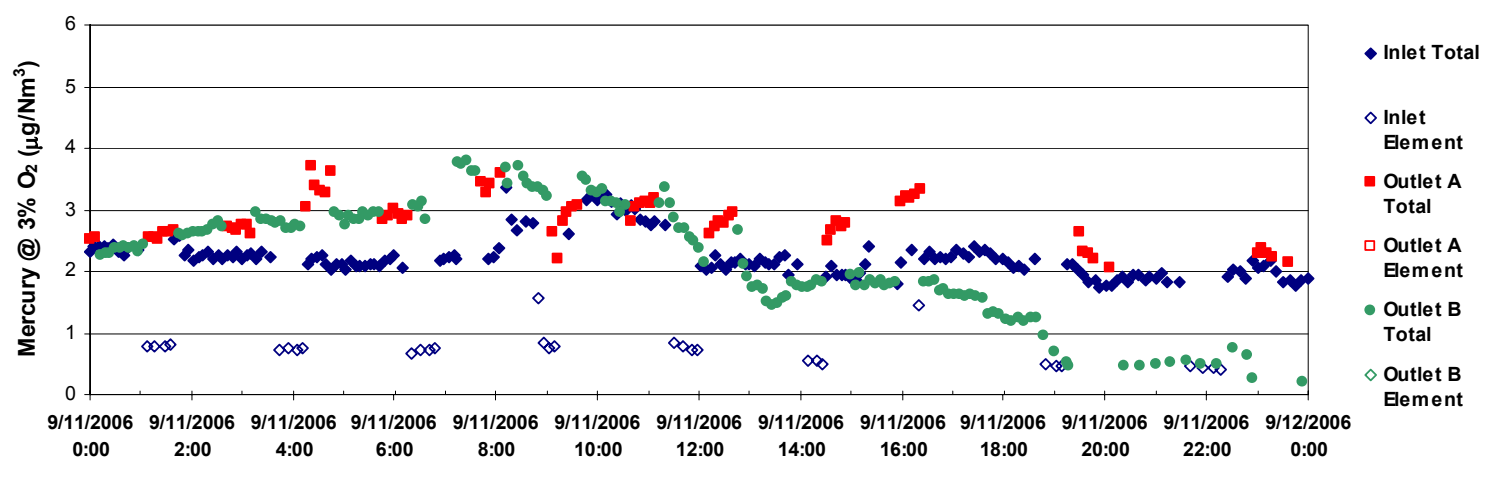

Figure A53. Mercury Concentration Trace for September 112006.

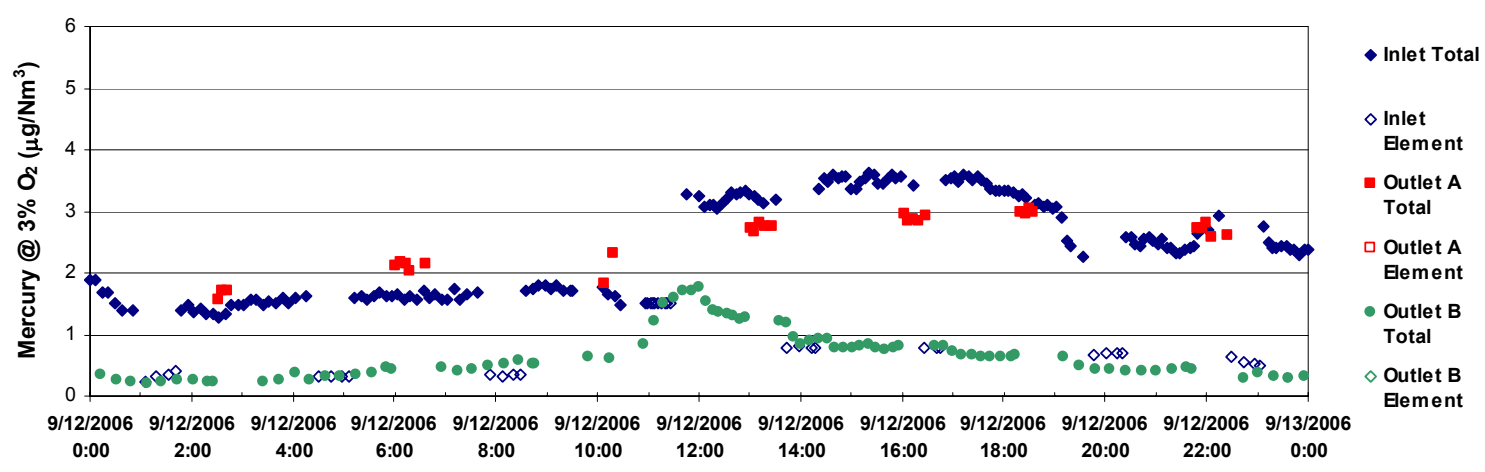

Figure A54. Mercury Concentration Trace for September 122006. 


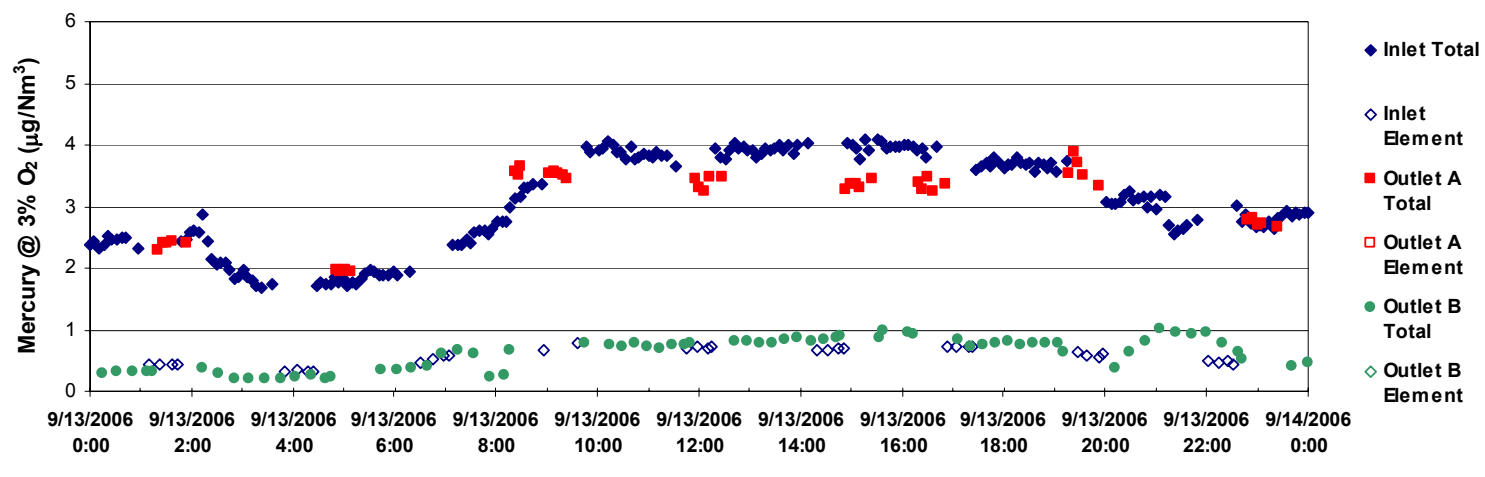

Figure A55. Mercury Concentration Trace for September 132006.

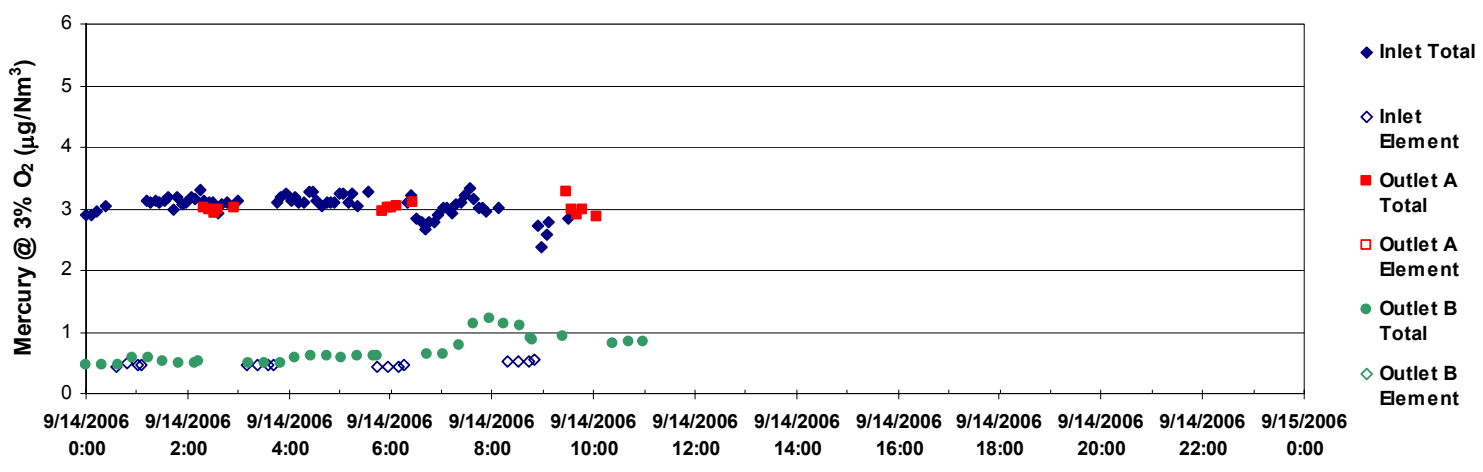

Figure A56. Mercury Concentration Trace for September 142006. 

Appendix B

\begin{tabular}{|c|c|c|c|c|c|c|}
\hline & & & Over-board S & ke Che & & \\
\hline Date & Time & Location & $\begin{array}{l}\text { Over-board } \\
\text { Spike } \\
n g\end{array}$ & $\begin{array}{c}\text { CMM } \\
n g\end{array}$ & $\%$ recovery & Notes \\
\hline $7 / 22 / 2006$ & $8: 25$ & B-el & 28.7 & 28.7 & 100.0 & \\
\hline & $8: 35$ & B-tot & 22.1 & 21.5 & 97.3 & \\
\hline $7 / 23 / 2006$ & $9: 53$ & B-el & 28.2 & 29.1 & 103.2 & \\
\hline & $10: 58$ & B-tot & 22.8 & 22.3 & 97.8 & \\
\hline $7 / 24 / 2006$ & $9: 05$ & B-tot & 21.5 & 18.6 & 86.5 & changed filter-OK \\
\hline & $9: 40$ & B-el & 21.5 & 25.6 & 119.1 & \\
\hline & $16: 35$ & B-tot & 14.8 & 13.6 & 91.9 & \\
\hline $7 / 25 / 2006$ & $9: 37$ & B-el & 20.1 & 22 & 109.5 & \\
\hline & $9: 46$ & B-tot & 22.7 & 21.9 & 96.5 & \\
\hline & $17: 12$ & B-el & 20.9 & 16.9 & 80.9 & changed filter-OK \\
\hline $7 / 26 / 2006$ & $9: 03$ & B-tot & 19.2 & 17.3 & 90.1 & changed filter-OK \\
\hline & $9: 47$ & B-el & 20.3 & 19.1 & 94.1 & \\
\hline $7 / 27 / 2006$ & $9: 40$ & B-tot & 22.1 & 21 & 95.0 & \\
\hline & $9: 45$ & B-el & 17.1 & 14 & 81.9 & changed filter-OK \\
\hline $7 / 28 / 2006$ & 9:19 & B-el & 12.8 & 11.6 & 90.6 & \\
\hline & $9: 23$ & B-tot & 19.6 & 18 & 91.8 & \\
\hline $7 / 29 / 2006$ & 9:00 & B-tot & 19.5 & 18.5 & 94.9 & \\
\hline & $9: 15$ & A-tot & 20.3 & 20.2 & 99.5 & \\
\hline & $9: 25$ & Inlet-tot & 19.6 & 20.9 & 106.6 & \\
\hline & $9: 45$ & Inlet-el & 21.8 & 21.7 & 99.5 & \\
\hline $7 / 30 / 2006$ & $9: 18$ & B-tot & 21.9 & 19.5 & 89.0 & changed filter-OK \\
\hline & 9:36 & A-tot & 21.9 & 20.4 & 93.2 & \\
\hline & $9: 59$ & Inlet-tot & 20.1 & 17.3 & 86.1 & changed filter-OK \\
\hline & $10: 15$ & Inlet-el & 21.2 & 18.9 & 89.2 & \\
\hline $7 / 31 / 2006$ & $9: 22$ & A-tot & 20.6 & 19.3 & 93.7 & \\
\hline & $9: 37$ & B-tot & 20.7 & 19.5 & 94.2 & \\
\hline & $10: 07$ & Inlet-tot & 21.1 & 18.1 & 85.8 & changed filter-OK \\
\hline & $10: 18$ & Inlet-el & 21.6 & 18.9 & 87.5 & changed filter-OK \\
\hline $8 / 1 / 2006$ & $9: 06$ & A-tot & 21.1 & 18.2 & 86.3 & changed filter-OK \\
\hline & $9: 23$ & B-tot & 19.8 & 18.4 & 92.9 & \\
\hline & $9: 53$ & Inlet-el & 22.3 & 18.9 & 84.8 & changed filter-OK \\
\hline & $10: 06$ & Inlet-tot & 20.7 & 19.9 & 96.1 & \\
\hline $8 / 2 / 2006$ & $8: 44$ & Inlet-el & 20.5 & 18.3 & 89.3 & \\
\hline & $9: 13$ & Inlet-tot & 18.6 & 17.5 & 94.1 & \\
\hline & $9: 41$ & B-tot & 19.5 & 20.9 & 107.2 & \\
\hline & $9: 55$ & A-tot & 19.7 & 17.7 & 89.8 & \\
\hline & $15: 37$ & A-tot & 19.8 & 20.5 & 103.5 & \\
\hline & $15: 51$ & B-tot & 21 & 17.3 & 82.4 & \\
\hline & $15: 50$ & Inlet-tot & 19.4 & 17.8 & 91.8 & \\
\hline & $15: 55$ & Inlet-el & 20.1 & 18.2 & 90.5 & \\
\hline $8 / 3 / 2006$ & $8: 43$ & B-tot & 19.1 & 14.4 & 75.4 & changed filter-OK \\
\hline & $8: 58$ & A-tot & 19.4 & 17.4 & 89.7 & \\
\hline & $9: 40$ & Inlet-tot & 20 & 18.3 & 91.5 & \\
\hline & $9: 53$ & Inlet-el & 17.8 & 16.1 & 90.4 & \\
\hline & $16: 54$ & B-out & 22.9 & 22.1 & 96.5 & \\
\hline & $17: 01$ & A-tot & 22.1 & 21.5 & 97.3 & \\
\hline $8 / 4 / 2006$ & $8: 23$ & Inlet-tot & 18.8 & 19.1 & 101.6 & \\
\hline & $8: 45$ & Inlet-el & 20.4 & 15.6 & 76.5 & changed chiller imp. \\
\hline & $9: 15$ & B-tot & 32.9 & 32.1 & 97.6 & \\
\hline & $9: 31$ & A-tot & 22 & 19.4 & 88.2 & \\
\hline & $16: 57$ & B-tot & 23.9 & 23.8 & 99.6 & \\
\hline & $17: 47$ & Inlet-el & 21.2 & 21.1 & 99.5 & \\
\hline $8 / 6 / 2006$ & $14: 24$ & A-tot & 25.8 & 23.9 & 92.6 & \\
\hline & $14: 37$ & B-tot & 24.6 & 19.6 & 79.7 & changed filter-OK \\
\hline & $14: 47$ & Inlet-tot & 21.2 & 20.2 & 95.3 & \\
\hline & $20: 19$ & Inlet-el & 25 & 19.5 & 78.0 & changed filter-OK \\
\hline $8 / 7 / 2006$ & $9: 41$ & B-tot & 22.1 & 22.4 & 101.4 & \\
\hline & $9: 44$ & A-tot & 23.1 & 23.7 & 102.6 & \\
\hline & $12: 04$ & Inlet-tot & 21.7 & 19 & 87.6 & \\
\hline & $12: 27$ & Inlet-el & 21.7 & 15.4 & 71.0 & changed filter-OK \\
\hline $8 / 8 / 2006$ & $9: 22$ & A-tot & 21.6 & 21.5 & 99.5 & \\
\hline & $10: 23$ & B-tot & 24 & 22 & 91.7 & \\
\hline & $10: 39$ & Inlet-el & 23.2 & 17.8 & 76.7 & changed filter-OK \\
\hline & $10: 47$ & Inlet-tot & 23.6 & 22.6 & 95.8 & \\
\hline $8 / 9 / 2006$ & $9: 11$ & A-tot & 24.7 & 24 & 97.2 & \\
\hline & $9: 18$ & B-tot & 22.6 & 22.4 & 99.1 & \\
\hline & $9: 45$ & Inlet-el & 19.6 & 15.4 & 78.6 & changed filter-OK \\
\hline & $9: 48$ & Inlet-tot & 22.6 & 19.6 & 86.7 & \\
\hline
\end{tabular}




\begin{tabular}{|c|c|c|c|c|c|c|}
\hline \multicolumn{7}{|c|}{ Over-board Spike Checks } \\
\hline \multicolumn{7}{|c|}{ Over-board } \\
\hline \multirow[t]{4}{*}{$8 / 10 / 2006$} & $7: 58$ & B-tot & 24.6 & 16.9 & 68.7 & changed filter-OK \\
\hline & $8: 08$ & A-tot & 23.3 & 22.5 & 96.6 & \\
\hline & $8: 23$ & Inlet-tot & 24.4 & 19.2 & 78.7 & changed filter-OK \\
\hline & $16: 27$ & Inlet-el & 23.5 & 19.6 & 83.4 & changed filter-OK \\
\hline \multirow[t]{4}{*}{$8 / 11 / 2006$} & $8: 18$ & B-tot & 24.5 & 19.1 & 78.0 & changed filter-OK \\
\hline & $8: 22$ & A-tot & 24.5 & 19 & 77.6 & changed filter-OK \\
\hline & $8: 35$ & Inlet-el & 19.5 & 15 & 76.9 & changed filter-OK \\
\hline & $8: 56$ & Inlet-tot & 22.5 & 20.1 & 89.3 & \\
\hline \multirow[t]{4}{*}{$8 / 12 / 2006$} & $7: 05$ & B-tot & 23.2 & 23.4 & 100.9 & \\
\hline & $7: 16$ & A-tot & 22.6 & 20 & 88.5 & \\
\hline & $7: 28$ & Inlet-el & 16.1 & 13 & 80.7 & changed filter-OK \\
\hline & $7: 39$ & Inlet-tot & 18.9 & 17.3 & 91.5 & \\
\hline \multirow[t]{4}{*}{ 8/13/2006 } & $6: 35$ & B-tot & 25.3 & 23.5 & 92.9 & \\
\hline & $6: 45$ & A-tot & 24.3 & 22.1 & 90.9 & \\
\hline & $6: 56$ & Inlet-el & 12.7 & 9.9 & 78.0 & changed filter-OK \\
\hline & 7:06 & Inlet-tot & 19 & 17.1 & 90.0 & \\
\hline \multirow[t]{6}{*}{ 8/14/2006 } & $8: 28$ & Inlet-tot & 28.3 & 25 & 88.3 & \\
\hline & $8: 36$ & Inlet-el & 24.4 & 24.1 & 98.8 & \\
\hline & $8: 16$ & A-tot & 31.9 & 30.2 & 94.7 & \\
\hline & $8: 22$ & B-tot & 21.2 & 18.3 & 86.3 & changed filter-OK \\
\hline & $12: 17$ & A-tot & 25.1 & 22.2 & 88.4 & \\
\hline & $12: 23$ & B-tot & 25.1 & 22.9 & 91.2 & \\
\hline \multirow[t]{4}{*}{$8 / 15 / 2006$} & $8: 34$ & B-tot & 24.9 & 24.1 & 96.8 & \\
\hline & $8: 42$ & A-tot & 29.3 & 26.9 & 91.8 & \\
\hline & $8: 50$ & Inlet-tot & 20.8 & 17.5 & 84.1 & changed filter-OK \\
\hline & 9:00 & Inlet-el & 22.8 & 21.2 & 93.0 & \\
\hline \multirow[t]{4}{*}{ 8/16/2006 } & $7: 53$ & B-tot & 27.9 & 23.8 & 85.3 & \\
\hline & 8:05 & B-tot & 26 & 27.3 & 105.0 & \\
\hline & $8: 25$ & Inlet-el & 24.4 & 21.6 & 88.5 & \\
\hline & $8: 33$ & Inlet-tot & 22.3 & 21.4 & 96.0 & \\
\hline $8 / 17 / 2006$ & $6: 41$ & B-tot & 25.4 & 23.2 & 91.3 & \\
\hline & $7: 15$ & Inlet-tot & 24.6 & 23.7 & 96.3 & \\
\hline & $7: 35$ & Inlet-el & 23.6 & 23 & 97.5 & \\
\hline & $7: 55$ & A-tot & 24.9 & 22.5 & 90.4 & \\
\hline $8 / 18 / 2006$ & $8: 22$ & B-tot & 27 & 23.7 & 87.8 & \\
\hline & $8: 30$ & A-tot & 25.9 & 21.1 & 81.5 & changed filter-OK \\
\hline & $8: 39$ & Inlet-el & 22.5 & 21 & 93.3 & \\
\hline & $8: 48$ & Inlet-tot & 24.2 & 22.4 & 92.6 & \\
\hline $8 / 19 / 2006$ & $7: 20$ & A-tot & 26.9 & 25.2 & 93.7 & \\
\hline & $7: 34$ & B-tot & 22.4 & 20.1 & 89.7 & \\
\hline & $7: 42$ & Inlet-el & 10.6 & 7.1 & 67.0 & changed filter-OK \\
\hline & $7: 52$ & Inlet-tot & 33 & 25.8 & 78.2 & changed filter-OK \\
\hline $8 / 20 / 2006$ & $8: 11$ & A-tot & 24.9 & 20.5 & 82.3 & changed filter-OK \\
\hline & $8: 22$ & B-tot & 22.5 & 18.6 & 82.7 & changed filter-OK \\
\hline & $8: 28$ & Inlet-tot & 28.22 & 26.6 & 94.3 & \\
\hline & $8: 42$ & Inlet-el & 20.5 & 16.8 & 82.0 & changed filter-OK \\
\hline $8 / 21 / 2006$ & $8: 24$ & B-tot & 21.8 & 18.1 & 83.0 & \\
\hline & $8: 30$ & Inlet-el & 16.8 & 11.7 & 69.6 & changed filter-OK \\
\hline & $8: 34$ & A-tot & 24.3 & 14.2 & 58.4 & changed filter-OK \\
\hline & $8: 40$ & Inlet-tot & 21.6 & 19.4 & 89.8 & \\
\hline $8 / 22 / 2006$ & $7: 39$ & A-tot & 25.2 & 18.7 & 74.2 & changed filter-OK \\
\hline & $7: 58$ & B-tot & 21.4 & 15.8 & 73.8 & changed filter-OK \\
\hline & $14: 53$ & Inlet-el & 21.2 & 13.8 & 65.1 & changed filter-OK \\
\hline & $15: 02$ & Inlet-tot & 24.2 & 18.4 & 76.0 & changed filter-OK \\
\hline $8 / 23 / 2006$ & $8: 02$ & B-tot & 22.5 & 17.1 & 76.0 & changed filter-OK \\
\hline & $8: 16$ & A-tot & 24.1 & 20.6 & 85.5 & \\
\hline & $11: 57$ & Inlet & 18.2 & 10.8 & 59.3 & changed gold-OK \\
\hline & $15: 22$ & Inlet & 24.5 & 20.7 & 84.5 & \\
\hline & $16: 50$ & Inlet & 17.5 & 18.3 & 104.6 & \\
\hline $8 / 24 / 2006$ & $15: 32$ & Inlet-tot & 23.6 & 19.5 & 82.6 & changed filter-OK \\
\hline & $15: 39$ & Inlet-el & 20.1 & 16.3 & 81.1 & changed filter-OK \\
\hline & $17: 21$ & B-tot & 17.4 & 16.9 & 97.1 & \\
\hline & $17: 25$ & A-tot & 18.2 & 14.8 & 81.3 & changed filter-OK \\
\hline $8 / 25 / 2006$ & $16: 28$ & Inlet-el & 23.2 & 18.4 & 79.3 & changed filter-OK \\
\hline & $16: 33$ & Inlet-tot & 25.6 & 21.9 & 85.5 & \\
\hline & $16: 58$ & B-tot & 26.5 & 21.4 & 80.8 & \\
\hline & $17: 01$ & A-tot & 25.2 & 22.6 & 89.7 & \\
\hline $8 / 26 / 2006$ & $9: 21$ & B-tot & 23.7 & 20.1 & 84.8 & \\
\hline & $12: 52$ & A-tot & 20.2 & 13.5 & 66.8 & changed filter-OK \\
\hline & $18: 54$ & Inlet-el & 18.6 & 16.1 & 86.6 & \\
\hline & $18: 59$ & Inlet-tot & 27.9 & 23.5 & 84.2 & \\
\hline
\end{tabular}




\begin{tabular}{|c|c|c|c|c|c|c|}
\hline \multicolumn{7}{|c|}{ Over-board Spike Checks } \\
\hline Date & Time & Location & $\begin{array}{l}\text { Over-board } \\
\text { Spike }\end{array}$ & CMM & $\%$ recovery & Notes \\
\hline \multirow[t]{4}{*}{ 8/27/2006 } & $6: 50$ & Inlet-tot & 25.5 & 20.7 & 81.2 & \\
\hline & $7: 11$ & Inlet-el & 16.1 & 12.2 & 75.8 & changed filter-OK \\
\hline & $16: 00$ & B-tot & 28.5 & 27.4 & 96.1 & \\
\hline & $16: 15$ & A-tot & 32.7 & 31.4 & 96.0 & \\
\hline \multirow[t]{4}{*}{$8 / 28 / 2006$} & $7: 44$ & Inlet-tot & 30.4 & 26.2 & 86.2 & \\
\hline & $7: 56$ & Inlet-el & 30.6 & 25.5 & 83.3 & \\
\hline & $8: 02$ & B-tot & 31.2 & 27.9 & 89.4 & \\
\hline & $8: 10$ & A-tot & 32.4 & 29.1 & 89.8 & \\
\hline \multirow[t]{4}{*}{$8 / 29 / 2006$} & $8: 19$ & B-tot & 30.8 & 25.7 & 83.4 & \\
\hline & $8: 27$ & A-tot & 29.3 & 24.2 & 82.6 & \\
\hline & $8: 24$ & Inlet-el & 31.7 & 25.5 & 80.4 & changed filter-OK \\
\hline & $8: 33$ & Inlet-tot & 27.9 & 22.3 & 79.9 & changed filter-OK \\
\hline \multirow[t]{4}{*}{$9 / 6 / 2006$} & $6: 48$ & B-tot & 17.6 & 15 & 85.2 & \\
\hline & $6: 51$ & A-tot & 17.6 & 15 & 85.2 & \\
\hline & $7: 41$ & Inlet-tot & 27.5 & 25.5 & 92.7 & \\
\hline & $8: 03$ & Inlet-el & 22.2 & 19.6 & 88.3 & \\
\hline \multirow[t]{4}{*}{ 9/7/2006 } & $11: 56$ & B-tot & 20.7 & 19.7 & 95.2 & \\
\hline & $14: 38$ & A-tot & 17.8 & 17.5 & 98.3 & \\
\hline & $14: 47$ & Inlet-tot & 21.4 & 19.9 & 93.0 & \\
\hline & $14: 56$ & Inlet-el & 23.5 & 19.7 & 83.8 & \\
\hline \multirow[t]{4}{*}{$9 / 8 / 2006$} & $7: 38$ & B-tot & 17.2 & 14.5 & 84.3 & \\
\hline & $7: 43$ & A-tot & 25.2 & 23.6 & 93.7 & \\
\hline & $16: 47$ & Inlet-el & 20.4 & 12.4 & 60.8 & \\
\hline & $16: 54$ & Inlet-tot & 27.6 & 24.8 & 89.9 & \\
\hline \multirow[t]{4}{*}{$9 / 9 / 2006$} & $12: 40$ & B-tot & 26.9 & 22.3 & 82.9 & \\
\hline & $13: 20$ & A-tot & 25.3 & 17.2 & 68.0 & changed filter-OK \\
\hline & $13: 44$ & Inlet-el & 27.1 & 21.6 & 79.7 & changed filter-OK \\
\hline & $13: 49$ & Inlet-tot & 33.5 & 26.8 & 80.0 & \\
\hline \multirow[t]{4}{*}{$9 / 10 / 2006$} & $9: 24$ & B-tot & 21.8 & 19.9 & 91.3 & changed gold \\
\hline & $9: 36$ & Inlet-el & 19.2 & 11.2 & 58.3 & \\
\hline & $9: 40$ & A-tot & 25.5 & 20 & 78.4 & \\
\hline & $9: 53$ & Inlet-tot & 27.4 & 24.2 & 88.3 & \\
\hline \multirow[t]{4}{*}{$9 / 11 / 2006$} & $7: 46$ & A-tot & 26.9 & 24.1 & 89.6 & \\
\hline & $8: 08$ & B-tot & 25.1 & 21.4 & 85.3 & \\
\hline & 8:18 & Inlet-tot & 24.2 & 19.7 & 81.4 & changed filter-OK \\
\hline & $8: 36$ & Inlet-el & 20.2 & 9.4 & 46.5 & changed filter-OK \\
\hline \multirow[t]{3}{*}{$9 / 12 / 2006$} & $9: 44$ & B-tot & 17.7 & 14.4 & 81.4 & \\
\hline & $10: 12$ & A-tot & 20.8 & 20.1 & 96.6 & \\
\hline & $11: 39$ & Inlet-tot & 22.1 & 22.5 & 101.8 & changed filter-OK \\
\hline \multirow[t]{4}{*}{$9 / 13 / 2006$} & $9: 16$ & B-tot & 23.7 & 18.9 & 79.7 & \\
\hline & $9: 30$ & Inlet-el & 18.3 & 17.3 & 94.5 & \\
\hline & $9: 36$ & A-tot & 17.6 & 15.6 & 88.6 & \\
\hline & $9: 45$ & Inlet-tot & 25.3 & 24.9 & 98.4 & \\
\hline
\end{tabular}

